UNIVERSIDADE DE SÃO PAULO

\title{
ESCOLA DE ENFERMAGEM
}

RENATA LUANA DA SILVA

FATORES ASSOCIADOS À INTENSIDADE DE DOR PERINEAL APÓS O PARTO NORMAL:

ESTUDO TRANSVERSAL

São Paulo

2014 


\section{FATORES ASSOCIADOS À INTENSIDADE DE DOR PERINEAL APÓS O PARTO NORMAL: ESTUDO TRANSVERSAL}

Dissertação apresentada ao Programa de Pós-Graduação em Enfermagem da Escola de Enfermagem da Universidade de São Paulo para obtenção do título de Mestra em Ciências.

Trata-se da versão corrigida e a versão original encontra-se na Biblioteca da Escola de Enfermagem da USP.

Área de concentração: Cuidado em Saúde.

Orientadora: Prof ${ }^{\underline{a}} \operatorname{Dr}^{\mathrm{a}}$ Sonia M. Junqueira Vasconcellos de Oliveira

São Paulo 
AUTORIZO A REPRODUÇÃO E DIVULGAÇÃO TOTAL OU PARCIAL DESTE TRABALHO, POR QUALQUER MEIO CONVENCIONAL OU ELETRÔNICO, PARA FINS DE ESTUDO E PESQUISA, DESDE QUE CITADA A FONTE.

Assinatura:

Data:

\section{Catalogação na Publicação (CIP)}

Biblioteca "Wanda de Aguiar Horta"

Escola de Enfermagem da Universidade de São Paulo

Silva, Renata Luana da

Fatores associados à intensidade de dor perineal após o parto normal: estudo transversal / Renata Luana da Silva. São Paulo, 2014.

$106 \mathrm{p}$.

Dissertação (Mestrado) - Escola de Enfermagem da Universidade de São Paulo.

Orientadora: Prof.. ${ }^{\text {a }}$ Dr. ${ }^{a}$ Sonia Maria Junqueira Vasconcellos de Oliveira

Área de concentração: Cuidado em Saúde

1. Dor. 2. Períneo. 3. Período pós-parto. I. Título. 
Nome: Renata Luana da Silva

Título: Fatores associados à intensidade de dor perineal após o parto normal: Estudo transversal

Dissertação apresentada ao Programa de Pós-Graduação em Enfermagem da Escola de Enfermagem da Universidade de São Paulo para obtenção do título de Mestra em Ciências.

Aprovada em:

Banca examinadora

$\operatorname{Prof}^{\underline{a}} \operatorname{Dr}^{\mathrm{a}}$

Instituição:

Julgamento: Assinatura:

$\operatorname{Prof}^{\mathrm{a}} \mathrm{Dr}^{\mathrm{a}}$

Instituição:

Julgamento: Assinatura:

$\operatorname{Prof}^{\mathrm{a}} \mathrm{Dr}^{\mathrm{a}}$

Instituição:

Julgamento: Assinatura: 


\section{DEDICATÓRIA}

A meus pais, Izabel e Pedro, e a minha tia Neuza, que me ensinaram a importância da integridade e resiliência e que me apoiam incondicionalmente.

A Roberta, cuja amizade e confiança motivaram-me 0 caminhar na pósgraduação. 


\section{AGRADECIMENTOS}

À professora Doutora Sonia Maria Junqueira Vasconcellos de Oliveira, pela orientação, confiança e ensinamentos na condução deste estudo.

Às professoras Doutoras do curso de Obstetrícia, em especial, Elizabete Franco Cruz, Jacqueline Isaac Machado Brigagão, Nadia Zanon Narch e Roselane Gonçalves, pelos ensinamentos e por serem meus exemplos de resiliência.

Às professoras Doutoras Flora Maria Barbosa da Silva e Maria Luiza Gonzalez Riesco e às colegas Adriana Amorim Francisco e Caroline Bosco Paiva, pelas recomendações importantes na condução deste estudo.

À professora Doutora Adriana Caroci e Ana Paula Sayuri Sato, pelas indicações preciosas na elaboração deste trabalho.

À professora Doutora Angela Ochiai, pela confiança e apoio de sempre.

Ao mestre em ciências Bernardo dos Santos e ao professor Luis Carlos Ferreira de Almeida pelo suporte em estatística.

À professora Ivone Borelli, pela correção do português.

À equipe profissional da Biblioteca Wanda de Aguiar Horta/ EEUSP, pelo suporte na busca de literatura científica.

À enfermeira Mirian Hiromi Kinjo e toda a Equipe de Enfermagem do Amparo Maternal, pela ajuda e acolhimento durante a coleta dos dados.

À minha amada irmã Ana Livia Silva, pela maturidade em compreender minhas ausências e pelo sorriso que clareia até os dias mais cinzas.

Às amigas: Claudia de Azevedo Aguiar, pela companhia e disponibilidade inabaláveis, além dos pães de mel nos dias amargos; Edilaine Batista Mendes, pela uma grande parceria e amizade neste desafio; Daniella Miguel Benittez e Thatiane Bortolozo Menendez, pelo carinho e apoio sempre que precisei.

À CAPES, pela bolsa de mestrado.

E um agradecimento especial a cada mulher que participou deste estudo. 


\section{EPÍGRAFE}

Que nada nos limite, que nada nos defina, que nada nos sujeite. Que a liberdade seja nossa própria substância, já que viver é ser livre. Porque alguém disse e eu concordo que o tempo cura, que a mágoa passa, que decepção não mata. E que a vida sempre, sempre continua. 
SILVA, R. L. Fatores associados à intensidade de dor perineal após o parto normal: estudo transversal. [Dissertação]. São Paulo: Escola de Enfermagem, Universidade de São Paulo; 2014.

\section{RESUMO}

Introdução: A dor perineal é frequente no período de pós-parto, entretanto, não há um consenso entre a associação da intensidade de dor com os fatores maternos, neonatais e a assistência obstétrica recebida no trabalho de parto e parto. Objetivos: Identificar a prevalência e a intensidade de dor perineal no primeiro dia de pósparto normal; analisar a associação entre intensidade de dor perineal e características sociodemográficas maternas, histórico obstétrico, assistência ao trabalho de parto, parto e pós-parto e características do $\mathrm{RN}$ e analisar a associação entre a intensidade de dor perineal e o escore de interferência na execução das atividades maternas. Método: Estudo transversal com coleta de dados realizada no Alojamento Conjunto. A amostra foi composta por 596 puérperas no primeiro dia de pós-parto. Os dados foram obtidos por entrevista e análise de prontuário, e a intensidade de dor foi mensurada pela Escala Numérica Visual (0 a 10). Foram utilizados os testes Quiquadrado com simulação de Monte Carlo e ANOVA. As variáveis que apresentaram $p \leq 0,20$ foram relacionadas por meio de regressão logística ordinal. A significância utilizada foi de $5 \%$ para todos os testes estatísticos. Resultados: A prevalência de dor perineal encontrada foi $38,3 \%$ e a intensidade média de 4,6 ( $\mathrm{dp}=1,9$ ), considerada como moderada. A ausência de dor no períneo esteve associada à ausência de trauma $(p<0,001)$ e à multiparidade $(p=0,012)$. A dor leve esteve associada à primiparidade $(p=0,012)$, à ter estudado mais de 12 anos $(p=0,001)$ e à episiotomia $(p<0,001)$. $A$ dor moderada esteve associada a ter estudado mais de 12 anos $(p=0,001)$ e a presença de um trauma perineal $(p<0,001)$. A dor intensa associou-se à episiotomia $(p<0,001)$. Puérperas que estudaram até 8 anos tiveram proteção contra o aumento em uma 
categoria de intensidade de dor no períneo (OR 0,5; IC 95\% 0,3 $0,9)$ e ter tido laceração de $2^{\circ}$ grau no parto aumentou em 3,4 vezes a chance de ter aumento em uma categoria de intensidade de dor (OR 3,4; IC 95\% 1,7 - 6,9). A dor perineal interferiu significativamente na realização de todas as atividades investigadas, com exceção de evacuar. CONCLUSÃO: Maiores intensidades de dor perineal estão associadas a ter estudado por 12 anos ou mais, à presença de mais de um trauma perineal e à episiotomia. A dor perineal interfere nas atividades maternas durante o pós-parto.

Palavras-chave: Dor. Períneo. Período pós-parto. Saúde materna. 
SILVA, R. L. Associated factors with the intensity of perineal pain after vaginal delivery: cross-sectional study. [Dissertation]. São Paulo: Escola de Enfermagem, Universidade de São Paulo; 2014.

\section{ABSTRACT}

Introduction: Perineal pain is a frequent event in the postpartum period. However, there is no agreement between pain intensity association with maternal factors, neonatal factors and obstetric care received during labor and delivery. Objectives: To identify the prevalence and intensity of perineal pain in the first day of postpartum after vaginal delivery; to analyze the association between intensity of perineal pain and maternal sociodemographic characteristics, obstetric history, obstetric care during labor, delivery and postpartum period and newborn's characteristics, and to analyze the association between intensity of perineal pain and the interference score in the implementation of maternal activities. Methods: Cross-sectional study, a data collection undertaken in the postnatal ward. The sample consisted of 596 mothers interviewed in their first postpartum day after. Data were collected trough interview and review of medical records. The intensity of pain was measured with the Numeric Visual Scale $(0-10)$. The chi-square tests were used with Monte Carlo simulation and ANOVA and variables with $p \leq 0.20$ were related by ordinal logistic regression. The significance adopted was $5 \%$ for all statistical tests. Results: The prevalence of perineal mean pain was $38.3 \%$ and the pain intensity $4.6(S D=1.9)$, classified as moderate. The absence of perineal pain was associated with the absence of trauma $(p<0.001)$ and multiparity $(p=0.012)$. Mild pain was associated with primiparity $(p=0.012)$, education more than 12 years $(p=0.001)$ and episiotomy $(p<0.001)$. The moderate pain was associated with studying 12 years or more $(p=0.001)$ and any of a perineal trauma $(p<0.001)$. Severe pain was associated with an 
episiotomy $(p<0.001)$. Studying up to 8 years was a protective factor against the increase in one perineal pain intensity category (OR 0.5; $95 \% \mathrm{Cl} 0.3$ to 0.9 ) and 2nd degree tear in childbirth increased by 3.4 times the chance of a higher in a category of pain intensity (OR 3.4; $95 \% \mathrm{Cl} 1.7$ to 6.9 ). The perineal pain interfered significantly in carrying out all activities surveyed, except for the fecal evacuation. CONCLUSION: Greater perineal pain intensities are associated with having studied for 12 years or more, of study more than one perineal trauma and an episiotomy. The perineal pain interferes in the activities of the women during the postpartum period.

Keywords: Pain. Perineum. Postpartum period. Maternal health 


\section{LISTA DE ILUSTRAÇÕES}

Figura 1. Escala Numérica Visual $(0$ a 10)................................ 48

Figura 2. Escala de interferência da dor nas atividades.................. 49

Figura 3. Diagrama de recrutamento das participantes do estudo.

São Paulo, 2013. 


\section{LISTA DE TABELAS}

Tabela 1. Distribuição das puérperas, conforme as características sociodemográficas. São Paulo, 2013 58

Tabela 2. Distribuição das puérperas, conforme o histórico obstétrico. São Paulo, 2013.

Tabela 3. Distribuição das puérperas, conforme as características da assistência obstétrica prestada no CPN. São Paulo, 2013.

Tabela 4. Média, desvio-padrão (dp), mediana e valores máximo e mínimo do peso (gramas) e perímetros cefálico e torácico $(\mathrm{cm})$ dos recém-nascidos $(\mathrm{RN})$. São Paulo, 2013 62

Figura 4. Frequências da intensidade de dor perineal. São Paulo, 2013. 63

Tabela 5. Frequências da realização de atividades entre as puérperas com dor perineal no primeiro dia de pós-parto. São Paulo, 2013

Tabela 6. Frequências da interferência da dor perineal na realização de atividades no primeiro dia de pós-parto. São Paulo, 2013. 63

Tabela 7. Média, desvio-padrão, mediana e valores máximo e mínimo da interferência da dor perineal ao executar atividades. São Paulo, 2013

Tabela 8. Frequências do escore (1 a 10) de interferência da dor perineal na realização das atividades das puérperas. São Paulo, 2013.

Tabela 9. Distribuição das puérperas, conforme os métodos de alívio da dor utilizados durante a internação pós-parto. São Paulo, 2013... 65 Tabela 10. Média, desvio-padrão (dp), mediana e valores máximo e mínimo do intervalo de tempo entre consumo de fármacos e pósparto e inclusão no estudo. São Paulo, 2013.

Tabela 11. Análise estatística bivariada das variáveis categóricas em relação à ocorrência de dor perineal. São Paulo, 2013.

Tabela 12. Análise estatística bivariada das médias das variáveis numéricas em relação à presença de dor perineal. São Paulo, 2013.68 
Tabela 13. Análise estatística bivariada das variáveis categóricas em relação à intensidade de dor perineal. São Paulo, 2013....................70 Tabela 14. Análise estatística bivariada das médias das variáveis numéricas em relação à intensidade de dor perineal. São Paulo,

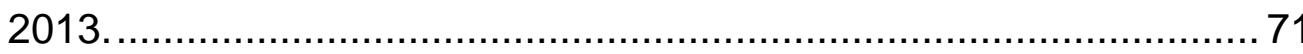

Tabela 15. Análise estatística bivariada das médias da interferência da dor perineal na realização das atividades em relação à intensidade de dor perineal. São Paulo, 2013. .............................. 72

Tabela 16. Análise estatística multivariada em relação à intensidade de dor perineal. São Paulo, 2013................................................ 73 


\section{LISTA DE QUADROS}

Quadro 1. Classificações fisiopatológicas da dor.............................. 20

Quadro 2. Comparação entre as escalas de dor.............................. 25

Quadro 3. Estudos sobre ocorrência e intensidade de dor perineal.. 33 


\section{SUMÁRIO}

RESUMO

ABSTRACT

LISTA DE ILUSTRAÇÕES

LISTA DE TABELAS

LISTA DE QUADROS

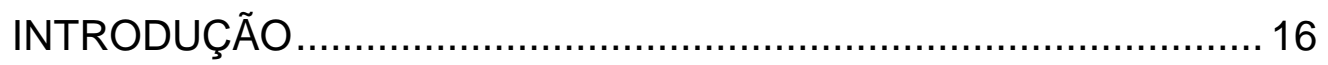

1.1 DOR

1.2 DOR PERINEAL NO PÓS-PARTO NORMAL............................... 27

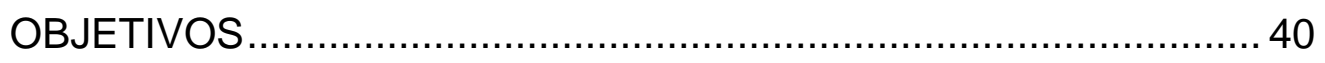

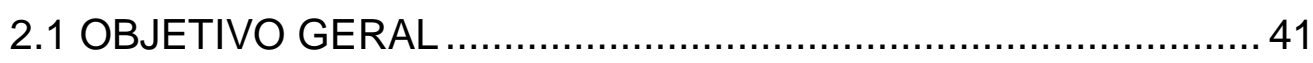

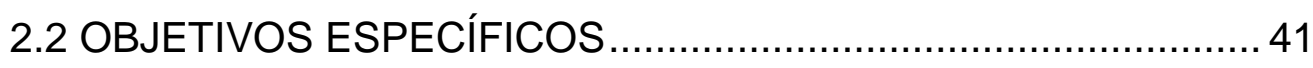

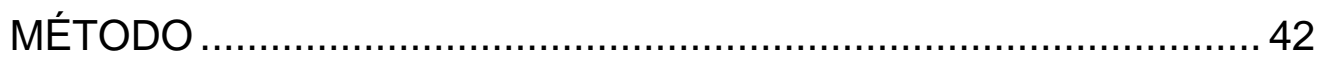

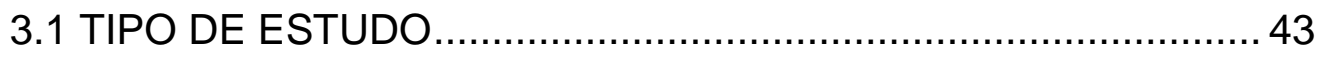

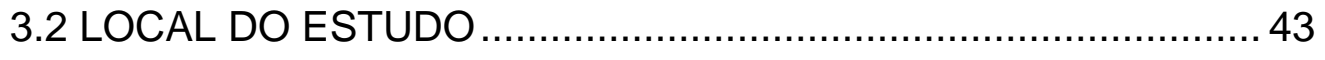

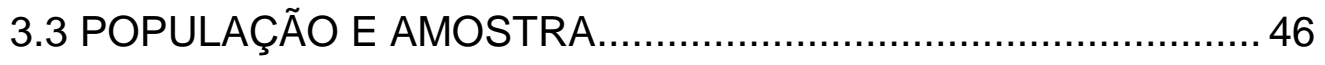

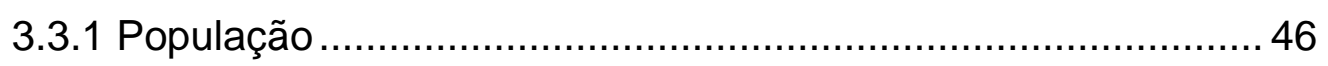

3.3.2 Critérios de Elegibilidade .................................................. 46

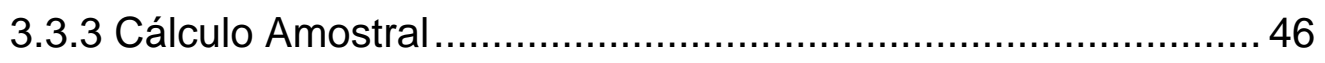

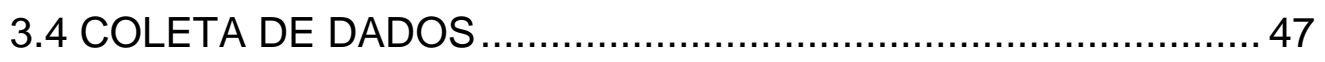

3.4.1 Instrumento de Coleta de Dados .......................................... 48

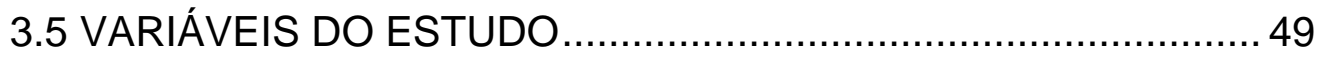

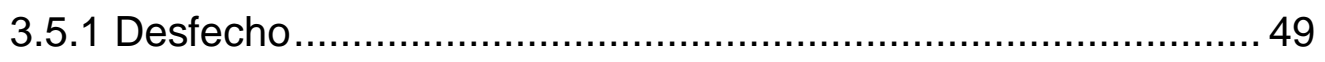

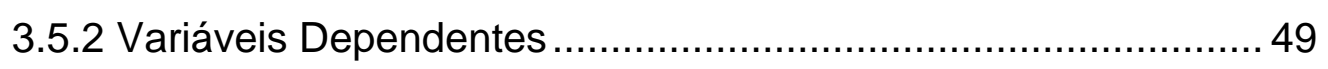

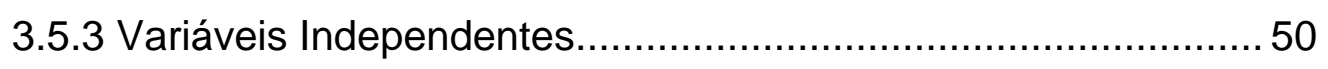

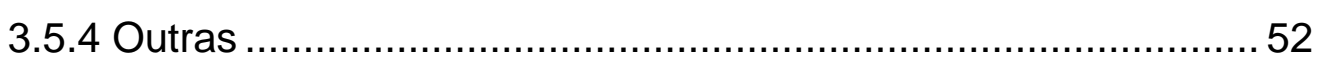

3.8 TRATAMENTO E ANÁLISE DOS DADOS .................................. 52

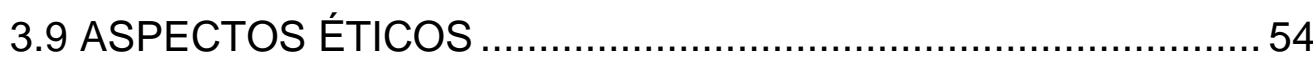

RESULTADOS

4.1 CARACTERIZAÇÃO DAS MULHERES .................................... 56

4.2 CARACTERIZAÇÃO DO PARTO E DO RECÉM-NASCIDO ........59 
4.3 CARACTERIZAÇÃO DA DOR PERINEAL .......................... 62

4.4 ANÁLISE BIVARIADA .................................................... 65

4.5 ANÁLISE MULTIVARIADA ............................................... 72

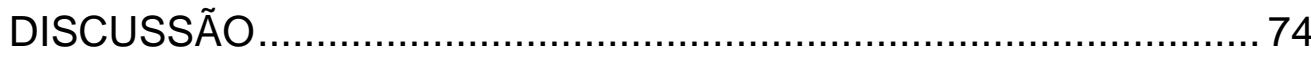

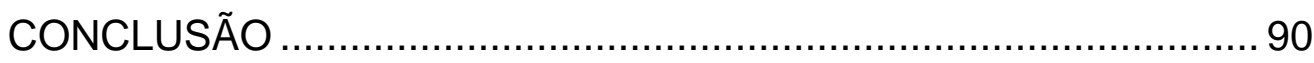

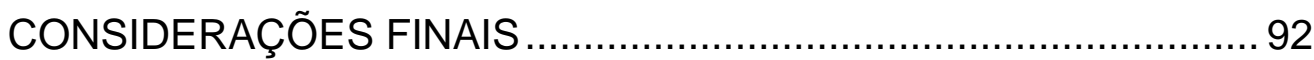

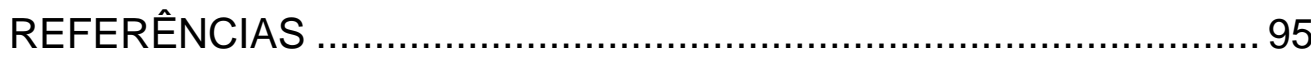

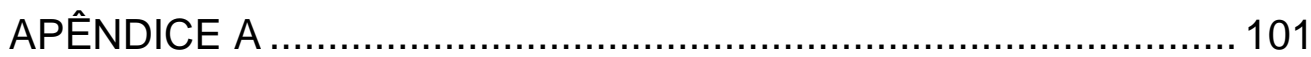

APÊNDICE B .............................................................. 103

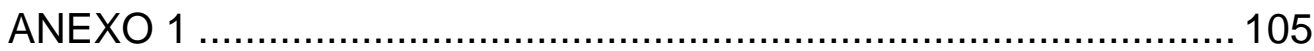

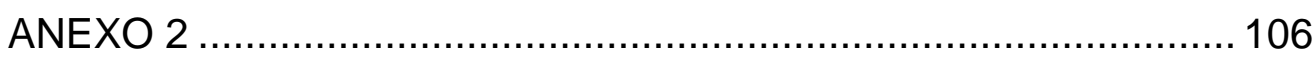


INTRODUÇÃO 
Durante minha formação profissional como obstetriz, observei que muitos profissionais de saúde empenhavam-se para que as gestantes vivenciassem a gravidez e o parto de maneira saudável. Após o parto, no entanto, os cuidados a estas mulheres eram, frequentemente, negligenciados, limitando-se às orientações sobre amamentação, pois a assistência ao recém-nascido (RN) era prioridade.

Neste contexto, quando uma puérpera procurou-me queixando-se de dor perineal intensa decorrente de uma episiotomia extensa realizada no parto, fui motivada a investigar a repercussão da dor perineal na vida dessas mulheres-mãe. Durante uma visita domiciliar, percebi que a dor no períneo impunha a esta mulher limitações na mobilidade, no autocuidado e nos cuidados aos filhos. Além disso, observei que a cicatrização da episiotomia gerava sentimentos de angústia quanto às repercussões dessa mutilação genital em seu relacionamento conjugal e em sua autoestima.

Assim, surgiu o estímulo para pesquisar quais os aspectos que podem causar a dor no períneo após o parto e seus impactos nas atividades de vida diária da puérpera.

\subsection{DOR}

A concepção do que é a dor, bem como os conhecimentos relacionados a ela vêm mudando e ampliando-se nas últimas décadas. Até 1970, a dor era vista como resultado de morbidades e não recebia tratamento eficaz. Foi por meio do pesquisador John J. Bonica que a dor recebeu atenção, reconhecimento e investimentos para a pesquisa. Na década de 1980, houve grande avanço no tratamento da dor em decorrência do aumento no fomento para estudos, da difusão das pesquisas e reconhecimento de sua importância pelas revistas, que resultaram em expansão do número de programas de treinamento de profissionais para o manejo da dor. 
As divisões nacionais da International Association for the Study of Pain (IASP), rapidamente, espalharam-se pelos Estados Unidos da América e fortaleceram os debates sobre a dor (LOESER, 2009).

Melzack e Katz (2013) citam que as primeiras hipóteses sobre dor foram decorrentes de experimentos sobre a anatomia e fisiologia da dor que buscavam encontrar fibras e caminhos para o cérebro que fossem de finalidade única da dor. Desta forma, a dor era tida como específica e captada por receptores e fibras próprios de dor que projetavam o impulso doloroso pela medula espinhal até um centro de dor situado no cérebro. Não eram, ainda, considerados os aspectos psicológicos da dor, bem como a presença de ansiedade, depressão e influências de experiências anteriores de dor.

As teorias que se desenvolveram em oposição àquela da especificidade ainda mantinham o cérebro como receptor passivo de mensagens dolorosas. Entretanto, contribuíram no direcionamento correto dos estudos: a resposta exclusiva da dor está na medula espinhal e longe da periferia do corpo. A mudança de paradigma ocorreu com a hipótese das comportas de Melzack e Wall, em 1965, na qual a modulação da informação aferente foi evidenciada, além de reconhecer que o sistema nervoso era capaz de controlar o fluxo ascendente da medula espinhal para o cérebro, usando os circuitos descendentes do corno dorsal da medula, conhecidos como mecanismos de comporta. Esta teoria enfatiza o papel dinâmico do cérebro e leva em consideração os fatores fisiológicos da dor. A partir de então, vários especialistas de saúde passaram a integrar a equipe de tratamento da dor e iniciaram-se os estudos relacionados aos estímulos aferentes inócuos para o tratamento da dor crônica e aguda, como a estimulação nervosa elétrica transcutânea (LOESER, 2009; MELZACK; KATZ; 2013).

A teoria das comportas de Melzack e Wall inspirou estudos sobre mecanismos nociceptivos periféricos, fármacos que interferem na modulação da dor e a influência dos aspectos emocionais, 
afetivos e ambientais nos comportamentos dolorosos. Tem-se, então, um novo paradigma de tratamento da dor:

Esta teoria fundamental mostrou que uma abordagem biopsicossocial da dor era muito mais eficaz do que o conceito biomédico tradicional da dor como uma resposta geneticamente determinada do encéfalo a um evento nóxico (LOESER, 2009, p.1).

Mais adiante, foi reconhecida que a ocorrência de lesão tissular não prevê obrigatoriedade de presença de dor e que esta pode ocorrer, inclusive, na ausência de lesão. Houve também dissociação entre a dor, o sofrimento e os comportamentos dolorosos quando se reconheceu, há cerca de 20 anos, que os comportamentos dolorosos crônicos podem se prolongar a despeito da cura da lesão e relacionam-se a fatores emocionais, ambientais e comportamentais (LOESER, 2009).

Desta forma, conforme a IASP, a definição de dor mantevese como "uma experiência sensorial e emocional desagradável, associada a dano tecidual real ou potencial, ou descrita em termos de tal dano" e envolve os aspectos emocionais, culturais e sensitivos do indivíduo, embora mantendo a subjetividade (IASP, 2011).

A dor é um fenômeno complexo que pode ser compreendido por quatro componentes: fisiopatologia (nocicepção, inflamação e neuropatia), dor, sofrimento e comportamento doloroso. A nocicepção ocorre quando os neurotransmissores detectam a lesão tissular, além de alterações inflamatórias e neurais. Compreende dores somáticas e viscerais. A dor somática é bem localizada na superfície corporal e a dor visceral é difusa. A dor inflamatória ocorre tal como a dor nociceptiva, tem sua intensidade agravada em razão da reação neurológica perante a inflamação. Compreende condições inflamatórias crônicas, como artrite e queimaduras. A dor neuropática tem resposta exagerada e/ou distorcida a qualquer estímulo somático e decorre de lesão no sistema nervoso central ou periférico, além de estar associada à parestesia ou alteração da temperatura. É o caso da dor torácica pós-toracotomia, dor do 
membro fantasma e neuropatia diabética. Os mecanismos de transdução, transmissão, atividade elétrica e resposta dolorosa estão sumariamente apresentados nos dados do Quadro 1. Os neurônios receptores de dor podem ser acionados por alterações de diversas magnitudes nas energias mecânica, térmica ou químicas e são bloqueados por anestesia local ou regional, em geral, bloqueadores de canal de sódio ou por hipnose ou distração, que promovem o bloqueio da modulação descendente (LOESER, 2009; TWADDLE; COOKE; 2009).

A resposta à nocicepção é a dor, que é gerada por impulsos aferentes na medula espinhal e no encéfalo e pode ocorrer mesmo sem estímulo nóxico (como nos casos da dor em membro fantasma, em razão de lesões no sistema nervoso periférico, na medula espinhal ou no encéfalo). A dor pode ser transitória, aguda e crônica em razão do câncer ou crônica por causa de outras patologias.

Quadro 1. Classificações fisiopatológicas de dor.

\begin{tabular}{|c|c|c|c|}
\hline \multirow{2}{*}{ Mecanismo } & \multicolumn{3}{|c|}{ Classificação } \\
\hline & Nociceptiva & Inflamatória & Neuropática \\
\hline Transdução & $\begin{array}{l}\text { Receptores } \\
\text { periféricos } \\
\text { fazem a } \\
\text { transdução de } \\
\text { estímulos } \\
\text { mecânicos, } \\
\text { térmicos e } \\
\text { químicos em } \\
\text { potenciais de } \\
\text { ação. }\end{array}$ & $\begin{array}{l}\text { Lesão tissular } \\
\text { significativa resulta } \\
\text { em alterações } \\
\text { fisiológicas no } \\
\text { sistema nervoso } \\
\text { que potencializam a } \\
\text { dor. } \\
\text { Mediadores pró- } \\
\text { inflamatórios } \\
\text { diminuem o limiar } \\
\text { para a transdução. }\end{array}$ & $\begin{array}{l}\text { Resulta de } \\
\text { uma lesão no } \\
\text { sistema } \\
\text { nervoso } \\
\text { periférico } \\
\text { central. }\end{array}$ \\
\hline Transmissão & $\begin{array}{l}\text { Para a medula } \\
\text { espinhal por } \\
\text { meio de nervos } \\
\text { intactos. }\end{array}$ & $\begin{array}{l}\text { Altera as } \\
\text { propriedades e a } \\
\text { função dos } \\
\text { neurônios centrais } \\
\text { e periféricos. }\end{array}$ & $\begin{array}{l}\text { Anormal, uma } \\
\text { vez que os } \\
\text { próprios nervos } \\
\text { estão } \\
\text { alterados. } \\
\text { As alterações } \\
\text { das } \\
\text { propriedades e } \\
\text { da função dos } \\
\text { (Continua) }\end{array}$ \\
\hline
\end{tabular}


(Continuação)

\begin{tabular}{|l|l|l|l|} 
& & & $\begin{array}{l}\text { neurônios } \\
\text { centrais e } \\
\text { periféricos } \\
\text { perpetuam-se. } \\
\text { Processada e } \\
\text { interpretada } \\
\text { como dor. }\end{array}$ \\
$\begin{array}{l}\text { Atividade } \\
\text { elétrica }\end{array}$ & $\begin{array}{l}\text { Processada e } \\
\text { interpretada } \\
\text { como dor. } \\
\text { Adaptativa, os } \\
\text { Resposta } \\
\text { dolorosa } \\
\text { fonômenos } \\
\text { dolorosos são } \\
\text { protetores. } \\
\text { Pequenas } \\
\text { Exargias, }\end{array}$ & $\begin{array}{l}\text { Processada e } \\
\text { interpretada como } \\
\text { dor. }\end{array}$ & $\begin{array}{l}\text { Exagerada } \\
\text { anormal. }\end{array}$ \\
Eacinação. & Pós-operatório, \\
artrite reumatoide. & $\begin{array}{l}\text { Neuralgia pós- } \\
\text { herpética, } \\
\text { radiculopatia } \\
\text { lombar. }\end{array}$ \\
\hline
\end{tabular}

Fonte: Loeser (2009, p.12). Retirado na íntegra.

A dor transitória ocorre na ativação de nociceptores na ausência de lesão tissular e representa as dores do dia a dia, quando não há relação entre a dor e a presença de alguma patologia, como a dor decorrente de uma picada de agulha. Sua única relevância ocorre quando ela decorre de procedimentos em saúde (como uma punção lombar que necessita de prevenção medicamentosa da dor que ocorrerá, como consequência do procedimento). A dor aguda decorre de lesão corporal e ativação de transdutores nociceptivos no local da lesão, que acaba por alterar o sistema nervoso autônomo da região lesionada. A restauração da normalidade da função dos nociceptores costuma ser rápida e até antes da restauração do tecido lesionado. A dor aguda relaciona - se com a lesão tissular imediata e cirurgias, é de duração limitada e pode requerer analgesia em conjunto com tranquilização e apoio até que a pessoa afetada possa retomar suas atividades normais. Também pode servir de sinalização, para que a pessoa não se machuque ainda mais. Na dor aguda intensa, como a do trabalho de parto, a mulher pode mostrar-se dissociada e com menor resposta ao ambiente (LOESER, 2009; TWADDLE; COOKE; 2009).

A dor crônica em razão do câncer ocorre muito mais em decorrência da lesão contínua provocada pelo tumor e/ou pelo 
tratamento do que influenciada por fatores ambientais ou antecedentes pessoais. Pode demandar cuidados paliativos ou, ao menos, analgesia com opioides e outros medicamentos. Por outro lado, a dor crônica causada por outras patologias ou dor persistente ocorre em decorrência de lesão ou doença ocorrida no passado e que a cura já deve ter acontecido, entretanto, outros fatores perpetuam a dor. Pode ter havido uma reorganização dos sistemas moduladores espinhal no local da lesão/doença que impede que o corpo recupere - se totalmente, como também pode ter ocorrido lesão direta no sistema nervoso ou mecanismos compensatórios que perpetuam a dor. Em razão de sua longa permanência, a pessoa com dor crônica está mais susceptível a sofrer influências ambientais, psicológicas e comportamentais, o que acaba por interferir em seu dia a dia. O sistema nervoso reajustado pode não responder como o esperado aos tratamentos disponíveis e, desta forma, o restabelecimento da pessoa afetada requer um modelo biopsicossocial de atenção em saúde, incluindo, também, estratégias psicológicas construídas sobre princípios cognitivos e comportamentais, uma vez que a dor crônica está mesclada à fisiologia e psicologia de quem a sente. A pessoa com dor crônica pode apresentar sintomas depressivos, retraimento, irritabilidade, labilidade emocional, fadiga, hiper ou hipossonolência e inatividade (LOESER, 2009; TWADDLE; COOKE; 2009).

A resposta afetiva negativa gerada pela dor é o sofrimento. Não se sabe ao certo se o sofrimento é acrescentado à dor no encéfalo ou se tem sua origem em outras áreas do cérebro, uma vez que também acontece em resposta a estados psicológicos, como luto, ansiedade e depressão. Por sua vez, o comportamento doloroso é a resposta ao sofrimento, sendo expresso por alterações na face e na movimentação, gemidos, prostração e busca por atendimento em saúde. Apesar de ser influenciado por antecedentes pessoais e fatores ambientais/sociais, o comportamento doloroso é o único que pode ser medido, pois somente ele constitui-se de eventos 
registráveis, a saber: início, duração, intensidade, incapacidade, frequência, tipo e periodicidade. Conforme Loeser (2009, p.2) "o modo como as pessoas pensam e aquilo que elas temem e preveem são também fortes determinantes do sofrimento e do comportamento doloroso". O autor afirma que o tratamento da dor deve abranger todos os aspectos a ela relacionados e recomenda que se considerem também estratégias terapêuticas com abordagem cognitivo-comportamental, físicas e farmacológicas.

Há necessidade de quantificar a intensidade de dor a fim de que se avalie a eficácia das medidas disponíveis para seu alívio. Para tanto, a equipe profissional pode lançar mão de instrumentos ou escalas de avaliação da dor, disponíveis em três categorias de medida: fisiológica, observacional e autorreferida. O instrumento de avaliação da dor só é válido se permitir mensurar a dor em si e não outra condição estressante qualquer. Vale destacar que nenhuma medida de avaliação da dor apresenta $100 \%$ de assertividade (STRONG et al., 2002; IASP, 2011). A avaliação fisiológica da dor refere-se às alterações biológicas, como por exemplo, frequência cardíaca e respiratória, tensão muscular, transpiração e outras alterações associadas à resposta ao estresse. Entretanto, nem sempre é possível identificar se as alterações ocorrem pela presença da dor ou em razão de outro fator estressante. Esta avaliação é empregada quando não é possível utilizar a avaliação observacional da dor, sobretudo, em neonatos (STRONG et al., 2002).

A avaliação observacional da dor é feita por uma profissional de saúde ou por alguém que conheça bem a pessoa com dor e compreenda a análise de alguns aspectos da dor, em geral, relacionados às alterações no comportamento ou ao desempenho de atividades. Contudo, é uma medida de custo elevado, visto que requer disponibilidade integral de um profissional para cada indivíduo e é de menor sensibilidade sobre os aspectos subjetivos da dor. Convenientemente empregada para avaliar a dor de 
crianças, também é uma boa medida complementar da dor autorreferida (STRONG et al., 2002).

Considerada padrão ouro entre as medidas de avaliação da dor, a avaliação autorreferida possibilita acessar a percepção de dor da pessoa que a sente. Todavia, não é possível ser administrada em pessoas impossibilitadas de responder. A avaliação autorreferida é feita com o auxílio de escalas ou questionários, como a Escala Visual Analógica (VAS), Escala Numérica Visual (0 a 10), questionário de McGill e mapa da dor (STRONG et al., 2002). Nos dados do Quadro 2 encontra-se uma síntese das escalas de dor mais empregadas em nosso meio.

Strong et al. (2002) recomendam que a dor seja avaliada antes, durante e depois de uma intervenção em saúde ou tratamento. A descrição da dor refere-se à sua localização, intensidade e/ou sensação.

Para identificar a localização da dor, é empregado o desenho da dor de Margoli, que consiste em uma representação do corpo humano dividido em 45 áreas no qual o indivíduo assinala o local da dor e atribui um escore de 0 a 10 para a sua intensidade. 0 Questionário de McGill (MPQ) inclui uma escala numérica de intensidade de dor e uma série de palavras que a descreve, dividida em três categorias: sensorial, afetiva e avaliativa. Embora seja multidimensional, o foco do MPQ é na descrição da dor e não em sua intensidade (STRONG et al., 2002).

É, particularmente, interessante ter acesso à descrição da dor fornecida por quem a sente, pois pode ajudar a indicar sua origem, em especial, em uma Unidade de Pronto-Atendimento. As descrições da dor podem variar entre aguda e crônica, difusa e localizada, constante e intermitente, pulsátil (sugerindo doença óssea ou metástase), surda ou em cólicas (associadas à dor visceral ou síndromes intestinais), dor em queimação ou formigamento e em punhalada ou lancinante (referindo-se a lesões nervosas), cortante (dor súbita ou aguda relacionada com os nervos), dolorida (de menor 
intensidade), emergente (aumento inesperado da dor que supera a analgesia já em uso) e incidente (decorrente de uma atividade específica, como caminhar) (TWADDLE; COOKE; 2009).

Quadro 2. Comparação entre as escalas da dor.

\begin{tabular}{|c|c|c|c|c|}
\hline População & $\begin{array}{c}\text { Escala } \\
\text { Numérica } \\
\text { Visual (0 a } \\
10)\end{array}$ & $\begin{array}{c}\text { Escala } \\
\text { Analógica } \\
\text { Visual (VAS) }\end{array}$ & $\begin{array}{c}\text { Escala de } \\
\text { faces de } \\
\text { Wong Baker }\end{array}$ & $\begin{array}{c}\text { Questionário } \\
\text { de McGill }\end{array}$ \\
\hline $\begin{array}{l}\text { Compreensão } \\
\text { e aplicabilidade }\end{array}$ & $\begin{array}{c}\text { Geralmente, } \\
\text { bem } \\
\text { compreendida } \\
\text { e bem aceita. } \\
\text { Pode ser } \\
\text { escrita ou } \\
\text { oral. }\end{array}$ & $\begin{array}{c}\text { Em geral, } \\
\text { facilmente } \\
\text { compreendida. } \\
\text { Requer um } \\
\text { instrumento } \\
\text { que a } \\
\text { profissional } \\
\text { deve } \\
\text { disponibilizar. } \\
\text { Uma } \\
\text { graduação } \\
\text { numérica e, } \\
\text { opcionalmente, } \\
\text { graduação do } \\
\text { nível da cor. }\end{array}$ & $\begin{array}{l}\text { Facilmente } \\
\text { compreendida, } \\
\text { embora possa } \\
\text { refletir uma } \\
\text { resposta } \\
\text { emocional à } \\
\text { dor, em lugar } \\
\text { de intensidade } \\
\text { do sintoma. }\end{array}$ & $\begin{array}{c}\text { É o mais } \\
\text { extenso } \\
\text { inventário de } \\
\text { dor } \\
\text { disponível. } \\
\text { Maior demora } \\
\text { para a } \\
\text { profissional e } \\
\text { à pessoa. } \\
\text { Requer mais } \\
\text { interpretação. }\end{array}$ \\
\hline Crianças & $\begin{array}{l}\text { As crianças } \\
\text { menores } \\
\text { podem ser } \\
\text { incapazes de } \\
\text { usá-la. }\end{array}$ & $\begin{array}{l}\text { A intensidade } \\
\text { no código de } \\
\text { cores é um } \\
\text { meio eficaz de } \\
\text { mensuração. }\end{array}$ & $\begin{array}{l}\text { Desenvolvida } \\
\text { para crianças. }\end{array}$ & $\begin{array}{l}\text { Crianças } \\
\text { mais novas } \\
\text { podem não } \\
\text { completar. }\end{array}$ \\
\hline Adultos & Eficaz. & $\begin{array}{l}\text { Vantajosa nas } \\
\text { barreiras de } \\
\text { linguagem } \\
\text { Cerca de } 10 \% \\
\text { dos adultos } \\
\text { ficam confusos } \\
\text { com o teste. }\end{array}$ & $\begin{array}{c}\text { Útil para } \\
\text { pessoas } \\
\text { desacostuma- } \\
\text { das a graduar } \\
\text { suas } \\
\text { experiências. }\end{array}$ & $\begin{array}{l}\text { Eficaz e } \\
\text { reprodutível. }\end{array}$ \\
\hline $\begin{array}{l}\text { Com } \\
\text { comprometi- } \\
\text { mento da } \\
\text { cognição }\end{array}$ & $\begin{array}{l}\text { A eficácia } \\
\text { varia com o } \\
\text { grau de } \\
\text { disfunção } \\
\text { cognitiva. }\end{array}$ & $\begin{array}{l}\text { A eficácia varia } \\
\text { com o grau de } \\
\text { disfunção } \\
\text { cognitiva. }\end{array}$ & $\begin{array}{l}\text { A eficácia } \\
\text { varia com o } \\
\text { grau de } \\
\text { disfunção } \\
\text { cognitiva. }\end{array}$ & $\begin{array}{l}\text { A eficácia } \\
\text { varia com o } \\
\text { grau de } \\
\text { disfunção } \\
\text { cognitiva, }\end{array}$ \\
\hline
\end{tabular}

Fonte: Loeser (2009, p.19). Adaptado.

Para quantificar a intensidade de dor, as escalas utilizadas com mais frequência são a VAS e a numérica de 11 pontos. A VAS consiste em uma linha, que pode ser vertical ou horizontal, com um 
ponto inicial equivalente à ausência de dor e um ponto final equivalente à dor insuportável. Ela tem $10 \mathrm{~cm}$ de comprimento e o indivíduo assinala a intensidade de dor, de acordo com os pontos inicial e final. É uma escala simples, de fácil aplicação, universal e confiável quanto à comparação da dor do indivíduo consigo mesmo, todavia, é menos confiável na comparação da dor entre pessoas distintas. A Escala Numérica Visual ( 0 a 10) é semelhante à VAS, contudo, apresenta marcações com os números de 0 a 10 e, assim, permite comparar a dor entre indivíduos. É também a escala mais empregada nas pesquisas, além de ter fácil compreensão (STRONG et al., 2002).

Algumas escalas são empregadas para mensurar a interferência da dor nas atividades diárias, denominadas de "autoeficácia". As escalas mais aplicadas são: predição de dor e movimentação (MAPPS), questionário de dor e autoeficácia (PSEQ) e autoeficácia de Gauge. Usando a MAPPS, a pessoa com dor é estimulada a dizer o quanto acha que pode executar determinado movimento, a intensidade de dor enquanto o executa e a razão pela qual imagina que não conseguirá fazer 0 movimento avaliado. A escala PSEQ é semelhante à Likert e é específica para dor crônica, na qual $o$ indivíduo indica um valor entre 0 e 6 que representa 0 quanto acredita que conseguirá realizar as atividades apesar da dor. Já na escala de Gauge, a pessoa com dor estima, entre 1 e 10, o quanto conseguirá realizar a atividade sem receber ajuda de terceiros (STRONG et al., 2002).

Fauconnier et al. (2009) compararam cinco instrumentos para avaliação da intensidade de dor pélvica aguda, sendo três escalas autorreferidas (VAS, Escala Numérica Visual e Escala Verbal) e dois instrumentos comportamentais não verbais desenvolvidos para o estudo. Os autores identificaram que todos os instrumentos avaliados mensuravam adequadamente a dor, contudo, as escalas comportamentais tiveram tendência a subestimar sua intensidade, apresentaram aplicabilidade mais complexa e suas vantagens 
permaneceram desconhecidas quando comparadas às demais. As escalas autorreferidas identificaram melhor a dor leve e moderada e foram mais fáceis de serem aplicadas e entendidas.

\subsection{DOR PERINEAL NO PÓS-PARTO NORMAL}

No Brasil, dados do Ministério da Saúde revelaram que, em 2011, ocorreram cerca de três milhões de partos dos quais, aproximadamente, a metade foi vaginal (BRASIL, 2012). Após o parto vaginal, muitas mulheres queixam-se de dor perineal $e$, embora não haja dados oficiais sobre a prevalência de dor perineal em nível nacional, estudos locais estimam que ela ocorra entre $18,5 \%$ e $92,3 \%$ das mulheres nos primeiros dias de pós-parto (BELEZA et al., 2012; FRANCISCO et al., 2011a, 2011b, 2012; LEITE, 2012).

Pesquisas internacionais também registraram que a dor perineal é um problema que atinge grande número de puérperas que tiveram parto vaginal. Na Austrália, os resultados de uma entrevista estruturada com 215 mulheres revelaram que $90,0 \%$ delas relataram dor perineal após 72 horas do parto vaginal. A maioria $(53,0 \%)$ classificou a dor como leve, 33,0\% descreveram-na como moderada e 3,7\%, intensa (EAST et al., 2012).

Uma coorte conduzida no Reino Unido e composta por 241 mulheres identificou a dor perineal em $92,0 \%$ das puérperas no primeiro dia de pós-parto e em $22,0 \%$, na sétima semana pós-parto (ANDREWS et al., 2008).

No Reino Unido, das 200 primíparas analisadas, a dor perineal esteve presente em $96,7 \%$ no puerpério imediato, 43,9\% delas com seis semanas após o parto e persistiu por um ano em 17,8\% (MACLEOD et al., 2013).

Um estudo de coorte sobre os efeitos da episiotomia entre 396 primíparas assistidas em uma maternidade na Turquia apontou 
$38,7 \%$ e $16,8 \%$ de dor entre mulheres com e sem episiotomia, respectivamente, na terceira semana de pós-parto (KARAÇAM et al., 2013).

Nos Estados Unidos da América, um survey realizado com 2.400 mulheres constatou que, entre as 1.656 puérperas que tiveram parto vaginal, $41,0 \%$ queixaram-se de dor perineal nos primeiros 2 meses depois do parto (DECLERCQ et al., 2014).

Um ano após o parto, 32,6\% das mulheres que tiveram trauma perineal relataram dor em um survey realizado no Reino Unido com 482 mulheres de diversas paridades. As frequências de dor foram maiores entre mulheres com parto instrumentalizado (36,4\% versus $30,0 \%)$, entretanto, sem diferença estatística significante (WILLIAMS; HERRON-MARX; KNIBB; 2007).

Uma coorte comparou as desordens ocorridas no assoalho pélvico de 627 primíparas submetidas à episiotomia seletiva e de rotina. Após quatro anos da realização do parto, relataram dor no períneo cerca de $6,0 \%$ das que tiveram episiotomia seletiva e $8,0 \%$ daquelas com episiotomia rotineira (FRITEL et al., 2008).

Neste cenário, a dor perineal pode apresentar-se como uma queixa a curto ou longo prazo, uma vez que pode se manifestar desde as primeiras horas após o parto (ALMEIDA; RIESCO; 2008) e persistir para além do período puerperal (DECLERCQ et al., 2014; FRITEL et al., 2008; MACLEOD et al., 2013; SAYINER et al., 2010).

No entanto, nos primeiros dias após o nascimento, a dor perineal tende a ser mais intensa (MACLEOD et al., 2013), ocorrendo redução da frequência e da magnitude com o decorrer do tempo (CHANG et al., 2011; KARAÇAM et al., 2013; MACLEOD et al., 2013; SOUZA e SILVA et al., 2013).

Durante a primeira semana de pós-parto, a diminuição da intensidade de dor perineal foi mais lenta às mulheres taiwanesas submetidas à episiotomia e, na segunda semana, a intensidade de dor delas foi ainda maior do que daquelas sem episiotomia (CHANG et al., 2011). 
As mulheres que foram randomizadas na Turquia para receberem ou não massagem perineal durante o período expulsivo reportaram dor perineal durante todo o seguimento. As proporções de períneos dolorosos entre o grupo experimental e controle foram, respectivamente, $69,7 \%$ e $72,7 \%$ no puerpério imediato, $28,1 \%$ e $31,1 \%$ na terceira semana e $8,9 \%$ e $13,9 \%$ um ano após o parto. A intensidade média de dor no puerpério imediato foi 1,2 pontos para ambos os grupos (KARAÇAM; EKMEN; ÇALIZIR; 2012).

Um estudo longitudinal foi conduzido com 119 mulheres brasileiras para avaliar os efeitos do laser na cicatrização da episiotomia. Houve perda de seguimento aos dois e seis meses após o parto, mantendo-se na investigação 85 e 79 mulheres, respectivamente. Constatou-se $16,5 \%$ e $6,3 \%$ de dor perineal, respectivamente, e para $15,3 \%$ das puérperas, a intensidade de dor foi de leve a moderada aos dois meses (SOUZA e SILVA et al., 2013).

$\mathrm{Na}$ Noruega, das 300 mulheres que tiveram partos espontâneos ou instrumentalizados, 208 mensuraram sua dor no períneo e 37,0\% relataram dor de intensidade leve; 43,0\%, moderada e 20,0\%, intensa, no primeiro dia de pós-parto, sem diferença significativa entre a intensidade de dor e o tipo de parto (FODSTAD; LAINE; STAFF; 2013).

Diante disto, diversas investigações vêm sendo conduzidas com o objetivo de identificar quais são os fatores associados a dor perineal no pós-parto. Entre os aspectos estudados, incluem-se as características maternas e neonatais e os fatores relacionados à assistência obstétrica. Entretanto, observa-se que, entre os estudos, não há consenso quanto aos fatores que se associam à dor, exceto em relação ao trauma perineal.

Alguns trabalhos identificaram que a etnia, a idade e a paridade materna, o peso do $\mathrm{RN}$, a episiotomia, o tipo de sutura e o fio utilizado no reparo perineal parecem estar relacionados à dor nessa região. 
Com relação à cor da pele, uma coorte conduzida no Novo México, com 576 puérperas, as mulheres brancas de etnia não hispânica estiveram associadas a dor no períneo $(p=0,05)$ na alta hospitalar (LEEMAN et al., 2009). Por outro lado, não houve diferença estatisticamente significativa entre a cor da pele autorreferida das puérperas e a ocorrência de dor perineal em um estudo brasileiro (FRANCISCO et al., 2011a).

Existe discordância entre os estudos com relação à interferência da idade materna. Um estudo brasileiro com 303 puérperas foi conduzido com o objetivo de identificar a intensidade e a prevalência da dor perineal e associá-las às características obstétricas, maternas e do RN. Entre as variáveis estudadas, somente a idade materna $(\mathrm{ORa}=1,08)$ e a episiotomia $(\mathrm{ORa}=3,80)$ foram associadas à dor perineal (FRANCISCO et al., 2011a). Por outro lado, o estudo turco citado anteriormente não encontrou associação estatística entre idade materna e dor (FODSTAD; LAINE; STAFF; 2013).

No estudo já citado anteriormente (LEEMAN et al. 2009), foi observada maior proporção e intensidade de dor perineal em primíparas. Resultados divergentes foram encontrados em dois estudos anteriormente citados (EAST et al., 2012; FRANCISCO et al., 2011a), que não identificaram associação entre paridade e dor perineal.

Quanto aos fatores neonatais, peso e perímetros -cefálico e torácico- não estiveram associados à ocorrência de dor no estudo supracitado (FRANCISCO et al., 2011a).

A pesquisa citada anteriormente apontou que a presença de episiotomia aumentou a chance de dor perineal em cerca de cinco vezes no primeiro dia e de três vezes na terceira semana após o parto. A intensidade dolorosa foi duas vezes maior entre aquelas com episiotomia, tanto no primeiro dia como na terceira semana depois do parto (KARAÇAM et al., 2013). 
Uma revisão sistemática da Biblioteca Cochrane incluiu 16 estudos envolvendo 8.184 mulheres e comparou dois métodos de sutura empregados no reparo da episiotomia e de lacerações de segundo grau. Verificou que a técnica de sutura contínua esteve associada com menos dor, menor necessidade de analgesia e de remoção da sutura comparada à técnica tradicional interrompida (KETTLE; DOWSWELL; ISMAIL; 2012).

Em relação ao material de sutura, outra revisão sistemática mostrou que o categute, fio absorvível natural, comparado ao fio absorvível sintético (ácido poliglicólico e poliglactina), aumentou a queixa de dor perineal durante o puerpério imediato (KETTLE; DOWSWELL; ISMAIL; 2010).

Após o parto vaginal, é comum que ocorram traumas perineais que consistem em lacerações espontâneas, episiotomia ou ambos. Estas lesões variam quanto à gravidade e estão associadas às complicações no pós-parto, incluem maior risco de trauma perineal posterior, necessidade de sutura, complicações na cicatrização (CARROLI; MIGNINI; 2009), risco de infecção, incontinência anal (LAINE et al., 2011) e urinária, dispareunia (CHANG et al., 2011; KARAÇAM et al., 2013; SAYINER et al., 2010; YENIEL; PETRI; 2014) e dor perineal (SAYINER et al., 2010; SHAHRAKI et al., 2011).

No Brasil, dados oficiais disponíveis sobre a ocorrência dos traumas perineais estão relacionados à episiotomia. Eles são oriundos de um inquérito nacional realizado com 4.122 mulheres entre 15 e 49 anos de idade e indicaram que este procedimento cirúrgico foi realizado em cerca de $70,0 \%$ de todos os partos vaginais ocorridos nos 5 anos anteriores à pesquisa. A prática de episiotomia esteve significativamente associada à região do País onde o parto ocorreu. A região Sudeste apresentou a maior prevalência de episiotomia (80,3\%) (LAGO; LIMA; 2009). Dados mais atuais da Pesquisa Nascer no Brasil apontam redução desse procedimento, mostrando que das 23.940 mulheres entrevistadas, 
$53,5 \%$ tiveram episiotomia no parto, sendo realizada em $56,7 \%$ dos partos da região Sudeste. Esta intervenção foi feita com maior frequência nos partos de mulheres de risco obstétrico habitual (56,1\%; $p<0,001)$ (LEAL et al., 2014).

Os resultados da coorte taiwanesa anteriormente citada indicam que puérperas sem episiotomia relataram significativamente menor intensidade de dor nas primeira, segunda e sexta semanas de pós-parto comparadas às mulheres que realizaram o procedimento (CHANG et al., 2011).

Evidências apontam que a ocorrência e a intensidade de dor perineal após o parto vaginal vêm sendo relacionadas à presença $e$ à gravidade do trauma nessa região (BELEZA et al., 2012; CHANG et al., 2011; EAST et al., 2012; KARAÇAM et al., 2013; LEEMAN et al., 2009; MACARTHUR; MACARTHUR; 2004; SOUZA e SILVA et al., 2013; STEEN, 2010), embora a dor possa estar presente mesmo entre mulheres com integridade perineal (EAST et al., 2012).

Uma revisão sistemática que teve como objetivo avaliar a literatura sobre o papel da gravidez e a via de parto sobre a saúde sexual e as disfunções sexuais na mulher identificou que a dor perineal e a dispareunia correlacionam-se com a extensão do trauma perineal. Em alguns dos estudos avaliados, a episiotomia e a lesão do esfíncter anal estiveram relacionadas com a maior frequência de dor (YENIEL; PETRI; 2014).

A seguir, os dados do Quadro 3 sintetizam as informações dos trabalhos supracitados. 
Quadro 3. Estudos sobre ocorrência e intensidade de dor perineal.

\begin{tabular}{|c|c|c|c|c|}
\hline $\begin{array}{l}\text { Autor (ano) } \\
\text { e local do } \\
\text { estudo }\end{array}$ & $\begin{array}{l}\text { Objetivo do } \\
\text { estudo }\end{array}$ & $\begin{array}{l}\text { Tipo de estudo, } \\
\text { amostra e } \\
\text { tempo de pós- } \\
\text { parto }\end{array}$ & $\begin{array}{c}\text { Escala de dor } \\
\text { utilizada e variáveis } \\
\text { estudadas }\end{array}$ & $\begin{array}{c}\text { Resultados relacionados à dor } \\
\text { perineal }\end{array}$ \\
\hline $\begin{array}{l}\text { MACARTHUR; } \\
\text { MACARTHUR } \\
\text { (2004) } \\
\text {-Hospital } \\
\text { universitário / } \\
\text { Canadá }\end{array}$ & $\begin{array}{l}\text { Estimar a } \\
\text { frequência de dor } \\
\text { e investigar a } \\
\text { associação entre } \\
\text { trauma perineal e } \\
\text { dor }\end{array}$ & $\begin{array}{l}\text { - Coorte } \\
\text { - } 447 \text { puérperas } \\
-1^{\circ} \text { e } 7^{0} \text { dias e } 6^{a} \\
\text { semana }\end{array}$ & $\begin{array}{l}\text { - McGill } \\
\text { - Escala numérica (0 a 10) } \\
\text { - Variáveis maternas } \\
\text { - Tipo de trauma e tipo de } \\
\text { parto } \\
\text { - Tempo de pós-parto } \\
\text { - Atividades no pós-parto }\end{array}$ & $\begin{array}{l}\text { - Dor no } 1^{0} \text { dia pós-parto: } 92,0 \% \\
\text { - Redução da mediana da dor, de acordo com } \\
\text { os traumas no } 7^{\circ} \text { dia e } 6^{a} \text { semana de pós- } \\
\text { parto } \\
\text { - Redução da interferência da dor ao realizar } \\
\text { atividades no } 7^{\circ} \text { dia e } 6^{a} \text { semana de pós- } \\
\text { parto. }\end{array}$ \\
\hline $\begin{array}{l}\text { WILLIAMS; } \\
\text { HERRON- } \\
\text { MARX; KNIBBS } \\
\text { (2007) } \\
\text { - Local do } \\
\text { estudo não } \\
\text { mencionado/ } \\
\text { Reino Unido }\end{array}$ & $\begin{array}{l}\text { Investigar a } \\
\text { duração de } \\
\text { morbidades } \\
\text { perineais entre } \\
\text { mulheres que } \\
\text { estiveram } \\
\text { expostas a } \\
\text { diferentes tipos de } \\
\text { parto }\end{array}$ & $\begin{array}{l}\text { - Transversal } \\
-482 \text { mulheres } \\
-11^{\circ} \text { ano }\end{array}$ & $\begin{array}{l}\text { - Escala de dor não } \\
\text { informada no artigo } \\
\text { - Características maternas } \\
\text { - Tipo de parto }\end{array}$ & $\begin{array}{l}\text { - } 32,6 \% \text { de dor no períneo em mulheres com } \\
\text { trauma perineal } \\
\text { - Ocorrência de dor de acordo com o tipo de } \\
\text { parto: normal }(30,0 \%) \text {, fórceps }(23,1 \%), \\
\text { ventosa ( } 25,0 \%) \\
\text { - Mulheres asiáticas tiveram } \\
\text { significativamente maior ocorrência de dor }\end{array}$ \\
\hline $\begin{array}{l}\text { ANDREWS et } \\
\text { al. (2008) } \\
\text {-Hospital } \\
\text { universitário / } \\
\text { Reino Unido }\end{array}$ & $\begin{array}{l}\text { Determinar a } \\
\text { intensidade de } \\
\text { dor, usando duas } \\
\text { escalas diferentes }\end{array}$ & $\begin{array}{l}\text { - Transversal } \\
-241 \text { puérperas } \\
-1^{\circ} \text { e } 5^{\circ} \text { dias e } 2^{\circ} \\
\text { mês }\end{array}$ & $\begin{array}{l}\text { - Escala verbal }(0 \text { a } 3) \\
\text { - Escala numérica }(0 \text { a } 10) \\
\text { - Tipo de trauma perineal } \\
\text { - Atividades executadas } \\
\text { (repousar, sentar e } \\
\text { movimentar-se) }\end{array}$ & $\begin{array}{l}\text { No } 10 \text { dia: } \\
\text { - } 92,0 \% \text { de dor perineal } \\
\text { - Escala verbal: maior mediana da dor ao } \\
\text { sentar e ao movimento entre mulheres com } \\
\text { episiotomia ou laceração de } 2^{\circ} \text { grau } \\
\text { - Escala numérica: maior mediana de dor ao } \\
\text { repouso, ao sentar e ao movimento entre } \\
\text { mulheres com episiotomia ou laceração de } 2^{\circ} \\
\text { grau }\end{array}$ \\
\hline
\end{tabular}

(Continua) 


\begin{tabular}{|c|c|c|c|}
\hline $\begin{array}{l}\text { FRITEL et al } \\
(2008) \\
\text { - } 2 \text { Hospitais } \\
\text { Universitários / } \\
\text { França }\end{array}$ & $\begin{array}{l}\text { Comparar } \\
\text { desfechos entre } \\
\text { mulheres com } \\
\text { episiotomia } \\
\text { seletiva e rotineira }\end{array}$ & $\begin{array}{l}\text { - Descritivo } \\
\text { - } 627 \text { puérperas } \\
\text { - 4ํano }\end{array}$ & $\begin{array}{l}\text { - Escala de dor não } \\
\text { informada no artigo } \\
\text { - Presença de dor perineal, } \\
\text { dispareunia, incontinência } \\
\text { urinária }\end{array}$ \\
\hline $\begin{array}{l}\text { LEEMAN et al. } \\
\text { (2009) } \\
\text { - Hospital } \\
\text { Universitário / } \\
\text { Estados Unidos } \\
\text { da América }\end{array}$ & $\begin{array}{l}\text { Estudar os efeitos } \\
\text { do trauma } \\
\text { perineal, trabalho } \\
\text { de parto e parto } \\
\text { na incidência de } \\
\text { dor }\end{array}$ & $\begin{array}{l}\text { - Coorte } \\
\text { - } 576 \text { puérperas } \\
\text { - Alta hospitalar, 6ํㅗ } \\
\text { semana e } 3^{\circ} \text { mês }\end{array}$ & $\begin{array}{l}\text { - VAS } \\
\text { - Questionário de McGill } \\
\text { - Variáveis maternais e de } \\
\text { assistência ao parto }\end{array}$ \\
\hline $\begin{array}{l}\text { CHANG et al. } \\
\text { (2011) } \\
\text {-Centro médico/ } \\
\text { Taiwan }\end{array}$ & $\begin{array}{l}\text { Comparar efeitos } \\
\text { da episiotomia na } \\
\text { dor perineal, } \\
\text { incontinência } \\
\text { urinária e } \\
\text { atividade sexual }\end{array}$ & $\begin{array}{l}\text { - Coorte } \\
\text { - } 243 \text { puérperas } \\
\text { - 1e e } 3^{\circ} \text { dia, } 1^{a}, 2^{a} \text { e } \\
6^{a} \text { semana e } 3^{\circ} \text { mês } \\
\text { de pós-parto }\end{array}$ & $\begin{array}{l}\text { - VAS } \\
\text { - Questionário de McGill } \\
\text { - Tempo de pós-parto } \\
\text { - Condição perineal }\end{array}$ \\
\hline $\begin{array}{l}\text { FRANCISCO et } \\
\text { al. (2011a) } \\
\text { - Hospital } \\
\text { Universitário / } \\
\text { Brasil }\end{array}$ & $\begin{array}{l}\text { Prevalência e } \\
\text { intensidade da dor } \\
\text { perineal }\end{array}$ & $\begin{array}{l}\text { - Transversal } \\
\text { - } 303 \text { puérperas de } \\
\text { gestação de risco } \\
\text { habitual e parto } \\
\text { normal } \\
\text {-Até } 2^{\circ} \text { dia }\end{array}$ & $\begin{array}{l}\text { - Escala numérica (0 a 10) } \\
\text { - Régua peri-rule } \\
\text { - REEDA } \\
\text { - Características maternas } \\
\text { e do RN } \\
\text { - Tipo de parto } \\
\text { - Condição perineal }\end{array}$ \\
\hline $\begin{array}{l}\text { BELEZA et al } \\
\text { (2012) } \\
\text { - Centro de } \\
\text { Referência da } \\
\text { Mulher / Brasil }\end{array}$ & $\begin{array}{l}\text { Mensurar e } \\
\text { caracterizar a dor } \\
\text { perineal }\end{array}$ & $\begin{array}{l}\text { - Descritivo/ } \\
\text { transversal } \\
\text { - } 50 \text { primíparas com } \\
\text { episiotomia, } \\
\text { gestação de baixo e } \\
\text { médio risco, sem } \\
\text { uso de analgésico e } \\
\text { anti-inflamatório } \\
\text { - } 6 \text { a } 16 \mathrm{~h}\end{array}$ & $\begin{array}{l}\text { - Escala numérica (0 a 10) } \\
\text { - Questionário McGill } \\
\text { - Idade, escolaridade } \\
\text { - Pré-natal, idade } \\
\text { gestacional } \\
\text { - Característica e } \\
\text { intensidade de dor } \\
\text { - Dor ao movimento e } \\
\text { repouso }\end{array}$ \\
\hline
\end{tabular}

Prevalência de dor perineal:

- Episiotomia seletiva: 6,0\%

- Episiotomia rotineira: 8,0\%

- $80,6 \%$ de dor na alta hospitalar

- Descrição da dor: 35,8\% desconfortável,

$3,5 \%$ aflitiva e $0,9 \%$ horrível ou excruciante

- Menor média de dor perineal em mulheres sem episiotomia estatisticamente significante com 1, 2 e 6 semanas de pós-parto

- Redução mais rápida do escore de dor de mulheres sem episiotomia

- Prevalência de dor perineal 18,5\%

- Dor média 4,8 de intensidade

- Associação da dor perineal com: episiotomia

$(p=0,001)$ e maior idade materna $(p=0,025)$

- Dor média 5

- Sentar, deitar e deambular limitadas pela dor

- $52,0 \%$ tiveram dor ao repouso e $100 \%$ no movimento

(Continua) 


\begin{tabular}{|c|c|c|c|}
\hline $\begin{array}{l}\text { EAST et al. } \\
\text { (2012) } \\
\text {-Hospital } \\
\text { terciário/ } \\
\text { Austrália }\end{array}$ & $\begin{array}{l}\text { Estabelecer a } \\
\text { prevalência de dor } \\
\text { perineal, seus } \\
\text { efeitos no pós- } \\
\text { parto e uso de } \\
\text { analgesia }\end{array}$ & $\begin{array}{l}\text { - Transversal } \\
\text { - } 215 \text { puérperas } \\
\text { - } 72 \mathrm{~h} \text { de pós-parto }\end{array}$ & $\begin{array}{l}\text { - VAS } \\
\text { - Atividades no pós-parto } \\
\text { - Condição perineal } \\
\text { - Características maternas } \\
\text { e do parto }\end{array}$ \\
\hline $\begin{array}{l}\text { KARAÇAM, } \\
\text { EKMEN; } \\
\text { ÇALIZIR (2012) } \\
\text { - Hospital/ } \\
\text { Turquia }\end{array}$ & $\begin{array}{l}\text { Investigar se a } \\
\text { massagem } \\
\text { perineal no parto } \\
\text { diminui trauma } \\
\text { perineal e } \\
\text { problemas } \\
\text { relacionados ao } \\
\text { trauma }\end{array}$ & $\begin{array}{l}\text { - Ensaio clínico } \\
\text { - } 404 \text { puérperas (202 } \\
\text { grupo experimental } \\
\text { e } 202 \text { grupo } \\
\text { controle) } \\
-1^{\circ} \text { dia, } 3^{\text {a }} \text { semana e } \\
1^{\circ} \text { ano }\end{array}$ & $\begin{array}{l}\text { - VAS } \\
\text { - Características maternas } \\
\text { - Frequência de dor }\end{array}$ \\
\hline $\begin{array}{l}\text { LEITE (2012) } \\
\text {-CPN / Brasil }\end{array}$ & $\begin{array}{l}\text { Avaliar } \\
\text { morbidades } \\
\text { perineais até } 48 \mathrm{~h} \\
\text { pós-parto }\end{array}$ & $\begin{array}{l}\text { - Transversal } \\
\text { - } 100 \text { puérperas de } \\
\text { risco habitual } \\
\text { - } 24 \mathrm{~h} \text { e } 48 \mathrm{~h}\end{array}$ & $\begin{array}{l}\text { - Escala numérica (0 a 10) } \\
\text { - Condição perineal } \\
\text { - Tempo de pós-parto }\end{array}$ \\
\hline $\begin{array}{l}\text { SOUZA E } \\
\text { SILVA et al. } \\
(2013) \\
\text {-CPN/ Brasil }\end{array}$ & $\begin{array}{l}\text { Verificar a } \\
\text { dispareunia, a dor } \\
\text { perineal e as } \\
\text { alterações na } \\
\text { cicatrização } \\
\text { perineal em } \\
\text { mulheres } \\
\text { submetidas à } \\
\text { episiotomia }\end{array}$ & $\begin{array}{l}\text { - Longitudinal } \\
\text { - } 119 \text { puérperas com } \\
\text { episiotomia } \\
\text { - } 2^{\circ} \text { e } 6^{\circ} \text { mês }\end{array}$ & $\begin{array}{l}\text { - Escala numérica ( } 0 \text { a 10) } \\
\text { - Intensidade da dor } \\
\text { perineal }\end{array}$ \\
\hline
\end{tabular}

- Média de dor 4,2 e frequência de $90,0 \%$ -Dor leve $(53,0 \%)$, moderada $(33,0 \%)$ e forte $(3,7 \%)$

- Associação entre a intensidade de dor e 0 tipo de trauma $(p=0,003)$

- Sem associação com a intensidade de dor: paridade, parto anterior, tipo de parto atual, uso de compressa quente no períneo no expulsivo, tempo, uso de epidural e pós-parto

Frequências de dor perineal no grupo experimental e controle:

$-1^{\circ}$ dia: $69,7 \%$ e $72,7 \%$

- $3^{\mathrm{a}}$ semana: $28,1 \%$ e $31,1 \%$

- 1으. ano: $8,9 \%$ e $13,9 \%$.

Intensidade média de dor perineal: 1,2 pontos em ambos os grupos no $1^{\circ} \mathrm{dia}$

- 36,0\% (24h) e 13,0\% (48h) de prevalência de dor

- Intensidade de dor no puerpério imediato: leve $(8,0 \%)$, moderada $(22,0 \%)$ e forte $(6,0 \%)$ - Intensidade de dor entre $24 \mathrm{~h}$ e $48 \mathrm{~h}$ : leve $(20,0 \%)$, moderada $(11,0 \%)$ e forte $(2,0 \%)$

- Intensidade de dor perineal no $2^{\circ}$ mês: leve $(9,4 \%)$, moderada $(5,9 \%)$ e forte $(1,2 \%)$

- Intensidade de dor perineal no 60 mês: leve $(1,3 \%)$, moderada $(2,4 \%)$, forte $(1,3 \%)$ e insuportável $(1,3 \%)$

(Continua) 


\begin{tabular}{|c|c|c|c|c|}
\hline $\begin{array}{l}\text { DECLERCQ et } \\
\text { al. (2014) } \\
\text { - EUA }\end{array}$ & $\begin{array}{l}\text { Conhecer as } \\
\text { experiências de } \\
\text { maternidades nos } \\
\text { EUA e identificar } \\
\text { lacunas na } \\
\text { assistência }\end{array}$ & $\begin{array}{l}\text { - Survey } \\
\text { - } 1.656 \text { puérperas de } \\
\text { partos vaginais } \\
\text { - 2ำ mês }\end{array}$ & $\begin{array}{l}\text { - Escala de dor não } \\
\text { informada no artigo } \\
\text { - Dor perineal } \\
\text { - Tempo de pós-parto } \\
\text { - Condição perineal } \\
\text { - Paridade } \\
\text { - Tipo de parto }\end{array}$ & $\begin{array}{l}\text { - Frequência de dor: } 77,0 \% \text { em primíparas e } \\
52,0 \% \text { em multíparas } \\
\text { - Episiotomia: } 31,1 \% \text { em primíparas e } 19,2 \% \\
\text { em multíparas } \\
\text { - Primíparas e dor: } 82,0 \% \text { entre as que } \\
\text { tiveram episiotomia e } 67,0 \% \text { sem episiotomia } \\
\text { ( } p=0,027 \text { ) } \\
\text { - Multípara e dor: } 18,0 \% \text { entre as que tiveram } \\
\text { episiotomia e } 5,0 \% \text { sem episiotomia ( } p=0,000 \text { ) }\end{array}$ \\
\hline $\begin{array}{l}\text { YENIEL; PETRI } \\
(2014) \\
\text { - Alemanha }\end{array}$ & $\begin{array}{l}\text { Examinar a } \\
\text { literatura } \\
\text { sobre o impacto } \\
\text { da gravidez e da } \\
\text { via de parto em } \\
\text { disfunções sexual } \\
\text { e no pós-parto }\end{array}$ & $\begin{array}{l}\text { - Revisão } \\
\text { Sistemática } \\
\text { - } 20 \text { estudos com } \\
\text { amostra maior que } \\
100 \text { puérperas }\end{array}$ & $\begin{array}{l}\text { - Tipo de parto } \\
\text { - Tipo de trauma perineal } \\
\text { - Disfunções sexuais } \\
\text { - Desconfortos no } \\
\text { puerpério }\end{array}$ & $\begin{array}{l}\text { - Dor perineal afetou até } 92,0 \% \text { das } \\
\text { puérperas e persistiu por até } 2 \text { meses } \\
\text { - Episiotomia, lesão de esfíncter anal e parto } \\
\text { instrumentalizado estiveram associados à } \\
\text { maior dor no períneo }\end{array}$ \\
\hline
\end{tabular}


Outro aspecto que merece ainda comentar relacionado à dor perineal é o local de ocorrência do parto, considerando as diferenças observadas no traumatismo do períneo e as práticas de atenção adotadas na assistência à mulher.

De acordo com Schneck et al. (2012), em nosso País, após os anos de 1990, intensificou-se o questionamento ao modelo obstétrico hospitalar, em razão das elevadas taxas de cesarianas e da ausência de melhora nos índices de mortalidade materna e perinatal. Para as autoras, mesmo com os avanços do conhecimento científico e do emprego progressivo da tecnologia na assistência ao parto não ocorreu, na mesma dimensão, o impacto esperado na melhora dos indicadores de saúde.

Em decorrência desse processo de mudança no atendimento ao parto e nascimento, a década de 1990 foi marcada pela proposição de políticas públicas com a finalidade de garantir boas práticas obstétricas e melhoria da assistência à mulher no período gravídico-puerperal nos serviços de saúde do Sistema Único de Saúde (SUS). Entre as políticas do Ministério da Saúde, o atendimento ao parto em ambiente fora do hospital foi recomendado mediante a criação do Centro de Parto Normal (CPN), instituído pela Portaria no 985/1999 (BRASIL, 1999).

O cenário atual da assistência obstétrica continua em transformação. Neste sentido, há pouco mais de 3 anos foi implementado o programa de assistência à gestação e parto, denominado Rede Cegonha (Portaria no 1.459/2011), que visa a assegurar à mulher $\mathrm{o}$ direito à atenção humanizada à gravidez, ao parto e ao puerpério, bem como à criança o direito ao nascimento seguro, crescimento e desenvolvimento saudáveis. Este Programa oferece subsídios para abertura e manutenção de CPN no País, em claro movimento de migração dos partos de risco habitual ocorridos nos Centros Obstétricos (CO) dos hospitais para os CPNs. Apesar de todo o empenho do Ministério da Saúde, constata-se ainda que, nos últimos 20 anos, poucos CPNs foram implementados em nosso 
meio. Neste modelo de atenção ao parto, o cuidado está centrado na figura da obstetriz e da enfermeira obstetra, como as profissionais melhores qualificadas para conduzir o parto como evento fisiológico, além de preconizar menos intervenções e proporcionar maiores benefícios à puérpera e seu bebê (BRASIL, 2011; 2013).

Neste sentido, estudo transversal brasileiro, que comparou os resultados maternos em mulheres de baixo risco atendidas em CPN peri-hospitalar e hospital, encontrou diferença estatística nas condições perineais e a maior frequência de mulheres com episiotomia ocorreu no hospital (32,9\% versus $25,7 \%$ ) (SCHNECK et al., 2012). Assim, a dor é um problema debilitante que afeta a mulher física e emocionalmente, independente do local da assistência prestada no parto. Ela limita a realização de atividades de autocuidado e de cuidados com a família. Nos primeiros dias de pósparto, muitas puérperas relatam que a dor dificulta para sentar, amamentar, urinar, dormir e cuidar do RN (ANDREWS et al., 2008; BELEZA et al., 2012; DECLERCQ et al., 2014; EAST et al., 2012; FRANCISCO et al., 2012; STEEN, 2010). Como refere Steen em seu artigo "I can't sit down" é frequente ouvirmos a puérpera queixar-se "eu não consigo sentar" (STEEN, 2005).

Além disso, a dor perineal pode influenciar o retorno da vida sexual semanas após o parto (KETTLE; DOWSWELL; ISMAIL; 2012) e na experiência da maternidade (DECLERCQ et al., 2014), provocar irritabilidade, depressão e até exaustão materna (STEEN, 2010).

Embora a dor perineal possa apresentar-se de modo distinto às mulheres, a maioria delas descreve-a como uma sensação em pressão (PITANGUI et al., 2009) latejante, dolorida, incômoda, ardida e chata (BELEZA et al., 2012; PITANGUI et al., 2009), que repuxa, que esquenta, que prende, que deixa tenso (BELEZA et al., 2012). Isto demonstra o quanto ela causa desconforto, desprazer e restringe os movimentos da mulher. 
Em razão do elevado número de mulheres acometidas pela dor no períneo após o parto vaginal, bem como suas consequências, este estudo faz-se necessário, pois abordará os fatores maternos, neonatais e assistenciais que se relacionam com a ocorrência e a intensidade de dor e que ainda não estão claramente descritos na literatura. Deste modo, questiona-se qual a prevalência da dor perineal e quais fatores maternos e neonatais estão associados à sua intensidade, no primeiro dia após o parto normal, em mulheres que pariram em um Centro de Parto Normal? Há algum cuidado comumente oferecido à mulher em trabalho de parto que está associado a dor perineal no pós-parto? Quais as atividades realizadas pela puérpera no Alojamento Conjunto (AC) têm maior interferência da dor perineal no primeiro dia de pós-parto?

Espera-se que este estudo permita enriquecer a qualidade da assistência obstétrica à medida que apontará variáveis que se relacionam com a dor perineal após o parto normal e, assim, subsidiar direcionamentos para novos estudos que proponham mudanças na prática obstétrica de assistência ao parto. 


\subsection{OBJETIVO GERAL}

- Identificar a prevalência e a intensidade de dor perineal no primeiro dia de pós-parto normal.

\subsection{OBJETIVOS ESPECÍFICOS}

- Analisar a associação entre intensidade de dor perineal e as características sociodemográficas maternas, histórico obstétrico, assistência ao trabalho de parto, parto e pós-parto e características do RN.

- Analisar a associação entre intensidade de dor perineal e o escore de interferência na execução das atividades maternas. 


\subsection{TIPO DE ESTUDO}

Trata-se de um estudo transversal sobre a dor perineal após o parto normal, aninhado ao projeto de pesquisa "Tempo de duração do efeito analgésico da crioterapia na dor perineal no pós-parto: ensaio clínico", que teve coleta de dados simultânea com o presente estudo.

\subsection{LOCAL DO ESTUDO}

O estudo ocorreu no AC do Amparo Maternal (AM), que conta com um CPN intra-hospitalar e equipe em regime de colaboração no que tange divisão de responsabilidades na assistência ao parto entre profissionais da medicina e da enfermagem. Localizada na região sul da cidade de São Paulo, esta instituição tem caráter filantrópico, é administrada pela Associação Congregação de Santa Catarina e está vinculada ao Sistema Único de Saúde (SUS). Possui 14 leitos de pré-parto no CPN, quatro salas de parto, seis leitos de pós-parto imediato, 84 leitos de alojamento conjunto e oito de terapia intensiva neonatal. A instituição não possui Unidade de Terapia Intensiva para adulto.

Destinada à assistência de parturientes de risco habitual e moderado, neste CPN, a equipe de médicos obstetras é responsável pela internação da gestante, por assistir partos operatórios e distócicos e fornecer retaguarda nas intercorrências detectadas pelas enfermeiras obstétricas durante o trabalho de parto e parto. A assistência à mulher em trabalho de parto e parto de evolução fisiológica é prestada por enfermeiras obstétricas e obstetrizes.

A presença de um acompanhante de livre escolha da parturiente é estimulada durante o trabalho de parto e parto. Além disso, o AM conta com doulas voluntárias, que são treinadas pela própria instituição para prestar suporte emocional à mulher. 
Durante o trabalho de parto, são adotados métodos não medicamentosos para alívio da dor no trabalho de parto, tais como, deambulação, banho de aspersão, massagem na região lombar realizada pelo acompanhante ou doula, bola suíça, banqueta de parto e balanço pélvico. Ademais, às parturientes é ofertada uma dieta leve e não há restrição quanto à ingesta hídrica.

O uso de ocitocina sintética intravenosa para indução ou condução do trabalho de parto é comum, entretanto, esta não inviabiliza a deambulação da parturiente. O partograma é adotado como rotina de cuidado durante o trabalho de parto e nele constam informações sobre a dinâmica do trabalho de parto, sinais vitais, movimentação da mulher, infusão de ocitocina e demais intervenções.

O trabalho de parto e o parto ocorrem em ambientes separados. Assim, no período expulsivo, a parturiente é encaminhada à sala de parto onde ocorre a expulsão fetal, em geral, com a mulher na posição semissentada. A realização de episiotomia é seletiva e a prática de algum tipo de proteção perineal é adotada pela profissional que assiste a parturiente. A episiotomia ou sutura da laceração é realizada sob anestesia local, em geral, a lidocaína $2,0 \%$ sem vasoconstrictor. Os fios utilizados para sutura são: categute 2-0 nas lacerações de primeiro grau, 0 agulhado nas de segundo e o poliglactina ou categute cromado naquelas de terceiro grau. No período de coleta dos dados, a sutura do trauma era realizada sob técnica contínua na mucosa vaginal e separada nos demais tecidos. Não há registro no prontuário quanto à manobra de proteção perineal, indicação da episiotomia, tipo de fio e técnica empregados na sutura. Após o parto, as mulheres que apresentam edema ou hematoma vulvar e/ou perineal podem receber aplicação de gelo local, três vezes ao dia, sendo a mesma prática mantida no AC, embora a instituição não tenha um protocolo para utilização desta terapia. 
Faz parte do protocolo institucional a administração de analgésico (Dipirona sódica $500 \mathrm{mg}, 6 / 6$ horas) e anti-inflamatório (Diclofenaco de Sódio 50mg, 8/8 horas), ambos por via oral e independente da presença ou não de dor. Esta prescrição inicia-se imediatamente após o parto e é mantida durante todo o período de internação no AC. Durante a coleta de dados houve um acordo com a chefia da maternidade para modificar o protocolo para que a administração de anti-inflamatório fosse suspensa nas primeiras 24 horas de pós-parto, uma vez que o consumo deste fármaco prejudicaria a avaliação do efeito anti-inflamatório proporcionado pela crioterapia. No entanto, até que todos os profissionais fossem avisados quanto à suspensão do medicamento, algumas mulheres consumiram 0 anti-inflamatório. Após 0 parto, mãe e bebê permanecem sob observação por algumas horas e, durante esse período, o aleitamento materno e o contato entre ambos são possibilitados.

No $A C$, não é permitida a presença de acompanhante e a visita de familiares e amigos acontece entre 11 e 18 horas. As mulheres e bebês ocupam enfermarias que dispõem, em cada uma, de dois a cinco pares de leitos adulto e neonatal e, em algumas, banheiro anexo à enfermaria. Os recém-nascidos em boas condições clínicas permanecem com a mãe em AC em tempo integral, e as puérperas são estimuladas a prestarem, de modo autônomo, todos os cuidados ao bebê durante o período de internação, além dos cuidados com sua própria higiene. A alta hospitalar ocorre com, aproximadamente, 48 horas após o parto.

No mês de dezembro de 2012, os dados estatísticos do AM* $^{*}$ mostraram que houve 464 partos vaginais. Destes, 29,1\% das mulheres mantiveram a integridade perineal. Entre aquelas com trauma perineal, $47,5 \%$ sofreram uma episiotomia mediolateral direita, 43,9\% laceração de primeiro grau e 8,6\% laceração de

\footnotetext{
*Amparo Maternal. Livro de Registros de Partos do Centro de Parto Normal. 2012.
} 
segundo grau. Lacerações de terceiro e quarto graus não foram registradas.

\subsection{POPULAÇÃO E AMOSTRA}

\subsubsection{População}

A população foi composta por todas as mulheres internadas no AC durante o período de coleta dos dados.

\subsubsection{Critérios de Elegibilidade}

Neste estudo, as mulheres que atenderam aos seguintes critérios foram incluídas:

- Ter tido parto normal nas 24 horas prévias à coleta dos dados;

- Gestação a termo com feto único e em apresentação cefálica fletida;

- Não ter recebido anestesia raquidiana ou peridural;

- Estar com o recém-nato em AC e em boas condições clínicas;

- Não apresentar dificuldades de comunicação ou compreensão da língua portuguesa.

\subsubsection{Cálculo Amostral}

O cálculo do tamanho amostral baseou-se na estimativa da prevalência de dor perineal de $36,0 \%$, extraída da dissertação que teve como objetivo caracterizar as lacerações perineais espontâneas ocorridas durante o parto normal atendido na mesma instituição de saúde do atual estudo (LEITE, 2012). Assim, para estimá-la com precisão absoluta de 4,0\%, seria necessária uma amostra mínima de 
554 pacientes (BOLFARINE; BUSSAB; 2005). A amostragem foi realizada de forma consecutiva e estimou-se 500 partos por mês e, destes, 30,0\% não preencheriam os critérios de inclusão.

\subsection{COLETA DE DADOS}

Entre 11 de janeiro e 22 de fevereiro de 2013, diariamente, a pesquisadora consultava o Livro de Registro de Partos do CPN a fim de identificar os nascimentos a termo ocorridos nas últimas 24 horas. Em seguida, o prontuário foi consultado para conferir os critérios de inclusão e a localização da puérpera no AC. O recrutamento ocorreu no AC, quando as puérperas foram convidadas a participar do estudo e questionadas a respeito da dor perineal. Após a leitura, concordância e assinatura do Termo de Consentimento Livre e Esclarecido (Apêndice A), a entrevista e o registro dos dados do prontuário foram realizados. As mulheres que referiram dor perineal de intensidade maior ou igual a 3 eram, posteriormente, convidadas a participarem do ensaio clínico sobre o tempo de duração analgésica da crioterapia, caso atendessem a seus critérios de inclusão.

A mulher foi questionada sobre a ocorrência de dor no períneo, por meio da pergunta "Você está com dor no períneo, agora?". A verbalização das seguintes sensações: "dor", "ardor", "fisgada", "desconforto" e "incômodo" na região perineal foi considerada como dor. Para avaliar a intensidade de dor perineal, a puérpera respondeu de acordo com a escala numérica de avaliação da dor de 0 a 10 (onde zero significa ausência de dor e dez, dor máxima).

O escore de interferência da dor perineal em atividades, como sentar, andar, urinar, evacuar, dormir, amamentar e cuidar do recém-nascido $(\mathrm{RN})$ também foi questionado, utilizando escala semelhante à supracitada, onde 0 equivale a nenhuma interferência 
e 10 a interferência máxima da dor na realização das atividades investigadas. Por fim, a participante informou a presença de acompanhante na internação, o uso de métodos não medicamentosos para alívio da dor utilizados no trabalho de parto e, àquelas que já tinham vivenciado, pelo menos, um parto normal anterior, a condição do períneo após o último parto.

No prontuário, foram recolhidas as seguintes informações: paridade e tipo de parto anterior, dilatação cervical no momento da internação, uso de ocitocina exógena endovenosa (dilatação cervical no início da infusão, duração, dose e volume infundido), condição perineal após o parto, horário da última dose do analgésico e antiinflamatório administrados após o parto, peso, perímetros cefálico e torácico do $\mathrm{RN}$.

\subsubsection{Instrumento de Coleta de Dados}

Para coleta dos dados foi utilizado um formulário estruturado (Apêndice B) dividido em duas partes: entrevista e dados do prontuário. Nele, constam dados de identificação da puérpera, escore de dor perineal, histórico obstétrico, assistência oferecida no trabalho de parto, dados do parto, dados fetais e consumo de analgésico e anti-inflamatório após o parto.

Neste estudo, a Escala Numérica Visual (0 a 10) foi escolhida por ser um instrumento de fácil mensuração da dor e compreensão que não coloca a puérpera em situação de constrangimento ou risco durante o uso (STRONG et al., 2002). Para avaliar a intensidade de dor perineal, foi mostrada a escala à puérpera, que apontou o número correspondente à intensidade (Figura 1) (MCCAFFERY; BEEBE; 1989).

Figura 1. Escala Numérica Visual (0 a 10).

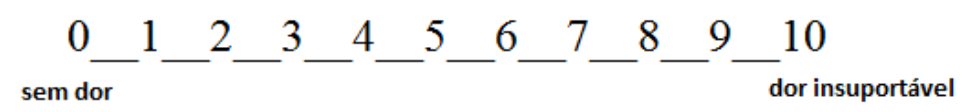

Fonte: Mccaffery; Beebe; 1989. 
Para avaliar o quanto a dor no períneo interferia na realização das atividades, foi utilizada a mesma escala, onde 0 significou ausência de interferência e 10 interferência máxima (Figura 2). Esta escala foi elaborada pelas pesquisadoras para o estudo atual e, também àqueles que estavam em andamento na mesma Instituição no período da coleta de dados, tendo como base as escalas PSEQ e autoeficácia de Gauge (STRONG et al., 2002).

Figura 2. Escala de interferência da dor nas atividades.

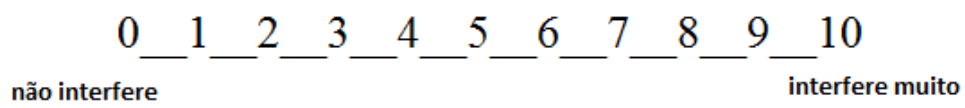

Fonte: a pesquisadora

\subsection{VARIÁVEIS DO ESTUDO}

\subsubsection{Desfecho}

As variáveis de desfecho foram: a ocorrência e a intensidade de dor perineal autorreferida e o escore de interferência da dor na realização das atividades da puérpera: andar, sentar, evacuar, urinar, dormir, amamentar e cuidar do bebê.

\subsubsection{Variáveis Dependentes}

- $\quad$ Dor perineal: presente ou ausente e valor de sua intensidade (de 0 a 10). Quando considerada como variável ordinal, a intensidade de dor foi agrupada em quatro categorias: nenhuma (dor 0), leve (1 a 3), moderada (4 a 6) e intensa (7 a 10) (MCCAFFERY; BEEBE; 1989).

- $\quad$ Escore de interferência da dor nas atividades: valores de 0 a 
10 para cada atividade executada após o parto (sentar, andar, urinar, evacuar, dormir, amamentar e cuidar do bebê).

\subsubsection{Variáveis Independentes}

- $\quad$ Cor da pele: autorreferida e as opções foram oferecidas à mulher de acordo com o designado pelo Instituto Brasileiro de Geografia e Estatística (IBGE, 2012): branca, preta, parda, amarela, indígena;

- Idade: em anos completos no momento da inclusão no estudo. Categorizada por faixas equivalentes a 5 anos cada, com exceção das adolescentes (10 a 19 anos) ${ }^{*}$;

- Escolaridade: em anos completos de estudo formal, classificada em até 8 anos (ensino fundamental), 9 a 11 anos (ensino médio) e acima de 12 anos (graduação e/ou pósgraduação);

- Paridade: número e tipo de partos (normal, fórceps, cesariana), incluindo o atual. Neste estudo, mulheres submetidas à cesariana em gestação(s) anterior(es) foram consideradas como primíparas;

- $\quad$ Condição perineal no parto anterior (apenas para multíparas): autorreferidas, que foi categorizada, conforme a similaridade do trauma: ausência de trauma, laceração espontânea, episiotomia e outras (incluindo: lembra-se apenas que houve sutura ou não se lembra da condição perineal);

- Dilatação cervical na internação: em centímetros. Foi categorizada de acordo com as fases do trabalho de parto, sendo até $3 \mathrm{~cm}$ (fase latente), de 4 a $9 \mathrm{~cm}$ (fase ativa) e expulsivo (aqui classificado como dilatação cervical de $10 \mathrm{~cm}$ ) (FRIEDMAN, 1955).

- Uso de método não medicamentoso de alívio da dor no trabalho de parto: autorreferido, sim ou não;

\footnotetext{
${ }^{*}$ http://www.who.int/topics/adolescent_health/en/
} 
- Uso de ocitocina no trabalho de parto: sim ou não;

- Dilatação cervical no início da infusão de ocitocina, em centímetros. Foi categorizada, de acordo com as fases do trabalho de parto, sendo até $3 \mathrm{~cm}$ (fase latente), de 4 a $9 \mathrm{~cm}$ (fase ativa) e expulsivo (aqui classificado como dilatação cervical de $10 \mathrm{~cm}$ ) (FRIEDMAN, 1955);

- Tempo com infusão de ocitocina: em horas e minutos, de acordo com o registro em prontuário;

- $\quad$ Número de trauma perineal: nenhum, um ou múltiplos;

- $\quad$ Condição do períneo após o parto atual: classificada pela profissional que assistiu o parto e registrada em prontuário. Considerando a possibilidade de ocorrer mais de um trauma perineal no parto, e estes apresentarem graus distintos entre si, o instrumento elaborado pela pesquisadora previu 14 variáveis referentes ao tipo de trauma perineal. Para a análise estatística, estas variáveis foram reagrupadas, de acordo com a maior gravidade do trauma, restando cinco categorias: laceração de 2o grau (inclui também laceração de $1^{\circ}$ e $2^{0}$ graus), episiotomia (agrupada com perineotomia, perineotomia + laceração de $1^{\circ}$ grau e EMLD + laceração de $1^{\circ} \mathrm{grau}$ ), laceração de $1^{\circ} \mathrm{grau}$ (contendo também escoriações periuretrais), laceração de $3^{\circ}$ grau e períneo íntegro;

- $\quad$ Tempo de internação: em horas e minutos, equivalente ao período entre internação na instituição e o parto;

- Peso do recém-nascido: em gramas;

- Perímetros cefálico e torácico do recém-nascido: em centímetros;

- Tempo de pós-parto: em horas e calculado como o intervalo entre a expulsão fetal registrado no prontuário e o momento da inclusão no estudo;

- Tempo após uso de analgésico: em horas, calculado como o intervalo entre o último consumo de analgésico registrado no prontuário e o momento da inclusão no estudo; 
- Tempo após uso de anti-inflamatório: em horas, calculado como o intervalo entre o último consumo de anti-inflamatório registrado no prontuário e o momento da inclusão no estudo.

\subsubsection{Outras}

- Trabalho remunerado: sim ou não;

- Estado marital: com companheiro com coabitação, com companheiro sem coabitação e sem companheiro;

- $\quad$ Tipo de parto anterior: normal, fórceps, cesariana;

- Acompanhante no parto atual: sim ou não e o grau de parentesco;

- Tipo de métodos não medicamentosos para alívio da dor usados no trabalho de parto: massagem, uso da bola de Bobath, uso de cavalinho, banqueta de parto, banho de chuveiro e deambulação.

- Infusão de ocitocina no trabalho de parto: dose prescrita em Unidades Internacionais e volume infundido em $\mathrm{ml}$;

- $\quad$ Sutura perineal: sim ou não;

- Data e hora do parto: dia, mês, ano e horas e minutos;

- Uso de bolsa de gelo no períneo após o parto: sim ou não, motivo e horário;

- Uso de analgésico: sim ou não e horário de administração da última dose;

- Uso de anti-inflamatório: sim ou não e horário da administração da última dose.

\subsection{TRATAMENTO E ANÁLISE DOS DADOS}

Os dados obtidos foram diariamente transcritos para uma planilha eletrônica e analisados pelo programa Statistical Package for Social Sciences (SPSS) versão 17.0 para Windows. 
A análise descritiva dos dados foi realizada para conhecer as características das puérperas do estudo. As variáveis qualitativas foram apresentadas por meio de frequências absolutas e relativas. Para as variáveis quantitativas, foram utilizadas medidas de tendência central e de dispersão (média, mediana, desvio-padrão, valores máximo e mínimo).

Inicialmente, a variável dependente dor perineal foi considerada como dicotômica e foram usados os testes exato de Fisher (variáveis categóricas) e teste $\mathrm{t}$ de Student (variáveis numéricas). A seguir, a variável dependente foi considerada variável categórica ordinal e foram utilizados os testes Qui-quadrado com simulação de Monte Carlo às variáveis categóricas e ANOVA, às variáveis numéricas. Para verificar se a intensidade de dor perineal interferiu na realização das atividades, foi calculada a média do escore (valores 1 a 10) de interferência da dor na realização de cada atividade e utilizada a Análise de Variância (ANOVA) com post hoc de Tukey-HSD. A significância adotada foi de $5,0 \%$ a todos os testes estatísticos.

Para a análise multivariada, foram selecionadas todas as variáveis com valores-p menor que 0,20 nos testes Qui-quadrado e ANOVA. A seguir, o modelo de regressão logística ordinal foi elaborado pelo processo de eliminação regressiva (stepwise backward selection). Nessa etapa, considerou-se como fator associado à dor perineal as variáveis que apresentaram valor$p<0,05$. O risco foi estimado por meio de Odds Ratio (OR) e seu respectivo intervalo de confiança de 95,0\%. O modelo final escolhido foi aquele com menor valor do critério de informação de Akaike (AIC). Para esta análise, foram mantidas as categorias da variável dependente utilizadas nas análises imediatamente anteriores (nenhuma, leve, moderada, intensa) e estimado os fatores de risco e proteção para o aumento em uma categoria de dor. 


\subsection{ASPECTOS ÉTICOS}

A obtenção dos dados, análise e devolução dos resultados seguem os princípios éticos que orientam a pesquisa com seres humanos, de acordo com a Resolução no 196/96, do Conselho Nacional de Saúde (Brasil, 1996), em vigência quando foi aprovado o estudo pelo Comitê de Ética em Pesquisa (abril de 2012). Desta forma, foi garantida a privacidade das mulheres que participaram do estudo e todas as informações obtidas mantidas em sigilo. Cabe destacar que este foi um estudo de risco mínimo às participantes e a todas aquelas que verbalizaram dor perineal acima de 3 foi oferecido receber crioterapia para seu alívio.

As mulheres convidadas para compor a amostra foram esclarecidas, antes da concordância e assinatura do Termo de Consentimento Livre e Esclarecido (Apêndice A), a respeito de sua participação voluntária e sigilosa, além de seu direito de não participar ou deixar de participar do estudo sem que isto the causasse prejuízos.

Este estudo foi aprovado pelo Comitê de Ética da Escola de Enfermagem da Universidade de São Paulo pelo Processo no 1.119/2012 (Anexo 1) e a coleta de dados ocorreu após a autorização da instituição (Anexo 2). 
RESULTADOS 
Diariamente, a coleta de dados era realizada das $7 \mathrm{~h}$ às $15 \mathrm{~h}$, entre 11 de janeiro e 22 de fevereiro de 2013. Na instituição neste período, ocorreram 697 nascimentos por via vaginal, 92 não atenderam os critérios de inclusão e 605 foram de mulheres elegíveis para o estudo. Entre as elegíveis, nove recusaram- se a participar (quatro disseram estar muito cansadas, uma não quis recordar o momento do parto, pois considerou-o um evento traumático e quatro não justificaram o motivo da recusa). Entre as mulheres que não atenderam aos critérios de inclusão, uma teve o parto fora da instituição do estudo, duas tiveram o parto com apresentação pélvica, três apresentaram intercorrências no AC (uma hemorragia pós-parto e duas hipoglicemias) e quatro, intercorrências no parto (uma curagem uterina, uma curetagem e duas hemorragias), quatro usaram anestesia raquidiana no período expulsivo, 14 mulheres estavam com o RN internado no berçário, 18 tinham dificuldade de se comunicar em língua portuguesa, 22 foram localizadas pelas pesquisadoras somente depois de 24 horas de pós-parto e 24 tiveram trabalho de parto pré-termo. Assim, foram incluídas neste estudo 596 mulheres (Figura 3).

Os dados foram coletados conforme descrito no método e os resultados foram apresentados nos seguintes itens: caracterização das mulheres (Tabelas 1 e 2), caracterização do parto e do $\mathrm{RN}$ (Tabelas 3 e 4), caracterização da dor perineal (Figura 4), atividades no pós-parto (Tabelas 5 a 8), métodos de alívio da dor após o parto (Tabelas 9 e 10), análise bivariada (Tabelas 11 a 15) e análise multivariada (Tabela 16).

\subsection{CARACTERIZAÇÃO DAS MULHERES}

Em relação às características sociodemográficas, a maioria $(55,5 \%)$ das participantes era parda, com média de idade e anos de estudo de 24,5 anos $(d p=5,9)$ e 9,5 anos $(d p=2,3)$, respectivamente. Mais da metade $(57,0 \%)$ não exercia atividade remunerada e 
aproximadamente três quartos $(78,4 \%)$ delas vivia com companheiro, conforme os dados da Tabela 1.

Figura 3. Diagrama de recrutamento das participantes do estudo. São Paulo, 2013.

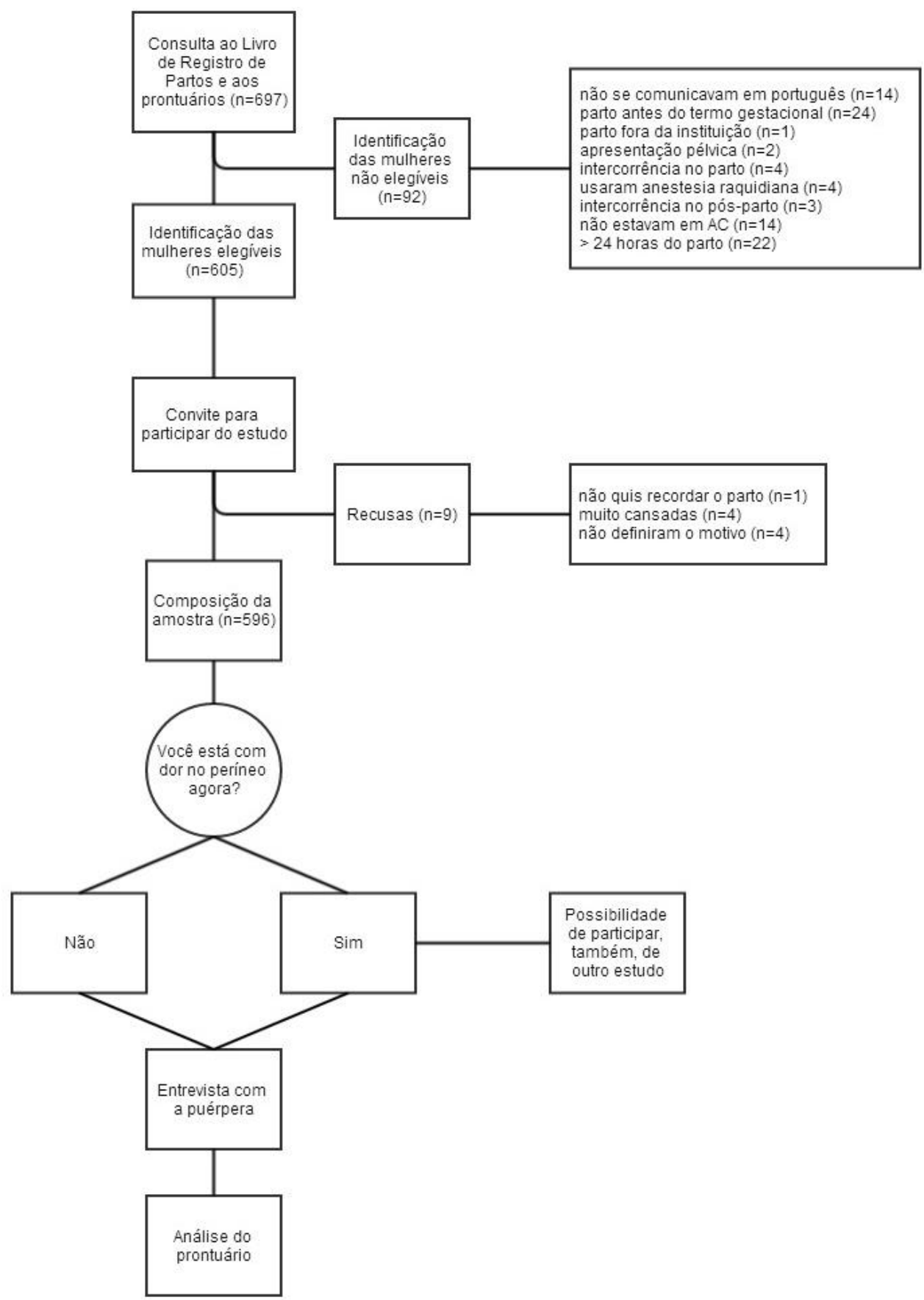

Fonte: a pesquisadora. 
Tabela 1. Distribuição das puérperas, conforme as características sociodemográficas. São Paulo, 2013.

\begin{tabular}{lcc}
\hline \multicolumn{1}{c}{ Variável } & $\mathbf{n}$ & $\%$ \\
\hline Cor da pele & 331 & 55,5 \\
Parda & 168 & 28,3 \\
Branca & 83 & 13,9 \\
Preta & 14 & 2,3 \\
Outras $^{\dagger}$ & & \\
Faixa etária (anos) $_{\text {até 19 }}$ & 143 & 24,0 \\
20 a 24 & 190 & 31,9 \\
25 a 29 & 138 & 23,2 \\
30 a 34 & 92 & 15,4 \\
35 ou mais & 33 & 5,5 \\
Escolaridade (anos) & & \\
até 8 & 219 & 36,7 \\
9 a 11 & 331 & 55,6 \\
12 ou mais & 46 & 7,7 \\
Atividade remunerada & & \\
Não & 340 & 57,0 \\
Sim & 256 & 43,0 \\
Estado marital & & \\
Com companheiro e com coabitação & 467 & 78,4 \\
Com companheiro sem coabitação & 74 & 12,4 \\
Sem companheiro & 55 & 9,2 \\
\hline Total & $\mathbf{5 9 6}$ & $\mathbf{1 0 0}$ \\
\hline
\end{tabular}

${ }^{\top}$ Outras: amarela e indígena

Conforme o histórico obstétrico, quase a metade $(47,7 \%)$ das participantes era primigesta e o número de gestações variou de 1 a 17. Para aquelas que tiveram parto anterior ao atual, o tipo de parto foi predominantemente normal $(90,6 \%)$ com episiotomia $(60,5 \%)$. Merece comentar que 16 mulheres não souberam responder a respeito do tipo de traumatismo ocorrido, apenas lembravam-se de ter tido o períneo suturado, conforme os dados da Tabela 2. 
Tabela 2. Distribuição das puérperas, conforme o histórico obstétrico. São Paulo, 2013.

\begin{tabular}{lcc}
\hline \multicolumn{1}{c}{ Variável } & $\mathbf{n}$ & $\%$ \\
\hline Número de gestações $(\mathrm{n}=596)$ & & \\
1 & 284 & 47,7 \\
2 & 168 & 28,2 \\
3 ou mais & 144 & 24,1 \\
Paridade $(\mathrm{n}=596)$ & 327 & 54,9 \\
Primípara & 269 & 45,1 \\
Multípara & & \\
Tipo de parto anterior $(\mathrm{n}=286)$ & 259 & 90,6 \\
Normal & 22 & 7,7 \\
Cesariana & 5 & 1,7 \\
Fórceps & 164 & 60,5 \\
Condição perineal no parto anterior $(\mathrm{n}=271)$ & 19,6 \\
Episiotomia & 53 & 14,0 \\
Períneo íntegro & 38 & 5,9 \\
Laceração & 16 & \\
Outras &
\end{tabular}

A amostra foi composta por $45,1 \%$ de multíparas (269/596) e $54,9 \%$ de primíparas (327/596). Conforme referido no método, neste estudo, as mulheres submetidas à cesariana em gestação(s) anterior(es) foram consideradas como primíparas. Desta forma, o grupo de primíparas formou-se de 284 primigestas (284/596; 47,7\%) e 43 mulheres que tiveram cesariana(s) e/ou aborto(s) anterior(es) ao parto atual $(43 / 596 ; 7,2 \%)$.

\subsection{CARACTERIZAÇÃO DO PARTO E DO RECÉM-NASCIDO}

Grande parte (86,6\%) das participantes teve um acompanhante de sua escolha durante o trabalho de parto ou parto e a maioria $(60,9 \%)$ optou pela presença do companheiro.

Quanto à assistência obstétrica, notou-se que quase metade $(46,0 \%)$ das mulheres foi internada para o parto quando apresentava menos de 3 centímetros de dilatação cervical e pouco mais da metade $(54,0 \%)$ estava na fase ativa do parto, ou seja, com 
dilatação cervical igual ou maior que 4 centímetros, de acordo com o critério de definição de fase ativa citado no método.

Entre as $380(63,8 \%)$ mulheres que relataram o uso de algum método não medicamentoso para alívio da dor, a massagem foi recebida por 139 (36,6\%) parturientes, 224 (58,9\%) tomaram banho de aspersão e 245 (64,5\%) deambularam durante o trabalho de parto. A banqueta foi utilizada por $35(9,2 \%)$ mulheres, a bola por 26 $(6,8 \%)$ e o cavalinho por $14(3,7 \%)$ delas.

Cerca de três quartos $(73,3 \%)$ das mulheres receberam infusão endovenosa de ocitocina durante o trabalho de parto e/ou no período expulsivo e a infusão foi iniciada, predominantemente $(64,5 \%)$, entre os 4 à 9 centímetros de dilatação cervical. As mulheres receberam, em média, $181 \mathrm{ml}$ de solução glicosada a 5,0\% com ocitocina sintética, permaneceram com a infusão por média de 4h19, variando de 8 minutos a $20 \mathrm{~h} 50$.

Em relação à condição perineal, observou-se que a maioria $(63,8 \%)$ das mulheres teve algum grau de traumatismo perineal, com maior frequência de laceração espontânea de primeiro grau $(32,4 \%)$ e de episiotomia $(25,2 \%)$ e praticamente todas $(99,5 \%)$ foram suturadas, conforme os dados da Tabela 3. O tempo médio de internação até o parto foi de 6 h07 ( $\mathrm{dp}=7 \mathrm{~h} 54)$, mínimo de um minuto e máximo de 34h23, e não havia registro da hora da internação de cinco mulheres. 
Tabela 3. Distribuição das puérperas, conforme as características da assistência obstétrica prestada no CPN. São Paulo, 2013.

\begin{tabular}{|c|c|c|}
\hline Variável & $\mathbf{n}$ & $\%$ \\
\hline \multicolumn{3}{|c|}{ Acompanhante no parto $(n=596)$} \\
\hline Sim & 516 & 86,6 \\
\hline Não & 80 & 13,4 \\
\hline \multicolumn{3}{|c|}{ Tipo de acompanhante $(n=516)$} \\
\hline Companheiro & 314 & 60,9 \\
\hline Mãe & 96 & 18,5 \\
\hline Outra $^{\dagger}$ & 67 & 13,0 \\
\hline Irmã & 36 & 7,0 \\
\hline Sem informação & 3 & 0,6 \\
\hline \multicolumn{3}{|c|}{ Dilatação cervical na internação $(\mathrm{cm})(\mathrm{n}=596)$} \\
\hline até 3 & 274 & 46,0 \\
\hline 4 a 9 & 306 & 51,2 \\
\hline 10 & 12 & 2,0 \\
\hline Sem informação & 4 & 0,7 \\
\hline \multicolumn{3}{|c|}{$\begin{array}{l}\text { Uso de método não medicamentoso para o alívio da dor no } \\
\text { trabalho de parto }(n=596)\end{array}$} \\
\hline Sim & 380 & 63,8 \\
\hline Não & 215 & 36,0 \\
\hline Sem informação & 1 & 0,2 \\
\hline \multicolumn{3}{|c|}{ Uso de ocitocina endovenosa no trabalho de parto $(n=596)$} \\
\hline Sim & 437 & 73,3 \\
\hline Não & 159 & 26,7 \\
\hline \multicolumn{3}{|c|}{ Dilatação cervical no início da infusão de ocitocina $(\mathrm{cm})(\mathrm{n}=437$} \\
\hline até 3 & 153 & 35,0 \\
\hline 4 a 9 & 282 & 64,5 \\
\hline 10 & 2 & 0,5 \\
\hline \multicolumn{3}{|c|}{ Número de trauma perineal no parto atual $(n=596)$} \\
\hline Não & 216 & 36,2 \\
\hline Único & 347 & 58,2 \\
\hline Múltiplo & 33 & 5,6 \\
\hline \multicolumn{3}{|c|}{ Condição perineal no parto atual $(n=596)$} \\
\hline Períneo íntegro & 216 & 36,2 \\
\hline Laceração $1^{\circ}$ grau & 193 & 32,4 \\
\hline Episiotomia & 150 & 25,2 \\
\hline Laceração $2^{\circ}$ grau & 36 & 6,0 \\
\hline Laceração $3^{0}$ grau & 1 & 0,2 \\
\hline \multicolumn{3}{|l|}{ Sutura do trauma $(n=380)$} \\
\hline Sim & 378 & 99,5 \\
\hline Não & 2 & 0,5 \\
\hline
\end{tabular}

${ }^{\dagger}$ Outra: amiga, cunhada, prima, sogra e tia.

Nos dados da Tabela 4 estão apresentadas as características dos neonatos. As médias de peso e perímetros cefálico e torácico 
foram $3.231,7 \mathrm{~g}(\mathrm{dp}=394,5), 34,0 \mathrm{~cm}(\mathrm{dp}=1,4)$ e $33,2 \mathrm{~cm}(\mathrm{dp}=3,2)$, respectivamente.

Tabela 4. Média, desvio-padrão (dp), mediana e valores máximo e mínimo do peso (gramas) e perímetros cefálico e torácico $(\mathrm{cm})$ dos recém-nascidos (RN). São Paulo, 2013.

\begin{tabular}{lccccc}
\hline \multicolumn{1}{c}{ Variável } & n & Mínimo & Máximo & Média (dp) & Mediana \\
\hline Peso & 596 & 2.125 & 4.485 & $3.231,7(394,5)$ & 3.210 \\
Perímetro cefálico & 596 & 29,0 & 39,5 & $34,0(1,4)$ & 34,0 \\
Perímetro torácico & 596 & 27,5 & 41,0 & $33,1(2,1)$ & 33,0 \\
\hline
\end{tabular}

\subsection{CARACTERIZAÇÃO DA DOR PERINEAL}

No momento da inclusão no estudo, as participantes foram questionadas sobre a ocorrência e a intensidade de dor perineal. Verificou-se que $38,3 \%$ (228) delas referiram dor no períneo cuja intensidade média foi 4,6 ( $\mathrm{dp}=1,9)$, mediana de 5 , variando de 1 a 10. A distribuição de frequências de intensidade de dor perineal está apresentada na Figura 4. Ao categorizar, constatou-se que a dor de intensidade leve ( 1 a 3 ) foi referida por $28,9 \%$ (66/228) das mulheres, moderada (4 a 6 ) por $45,2 \%$ (103/228) e intensa (7 a 10) por $25,9 \%$ delas (59/228). Merece destacar que apenas quatro puérperas referiram dor de intensidade 10 .

Além disso, investigou-se a existência de interferência da dor perineal na realização de algumas atividades. As puérperas que relataram dor perineal $(n=228)$, foram questionadas se haviam realizado, entre o parto e a inclusão no estudo, as atividades de interesse do estudo, como amamentar, andar, cuidar do bebê, dormir, evacuar, sentar e urinar, e se a dor no períneo interferiu em sua realização. Com a exceção de evacuar, todas as atividades foram realizadas por mais de $80,0 \%$ das mulheres, conforme os dados das Tabelas 5 e 6. 
Figura 4. Frequências da intensidade de dor perineal. São Paulo, 2013.

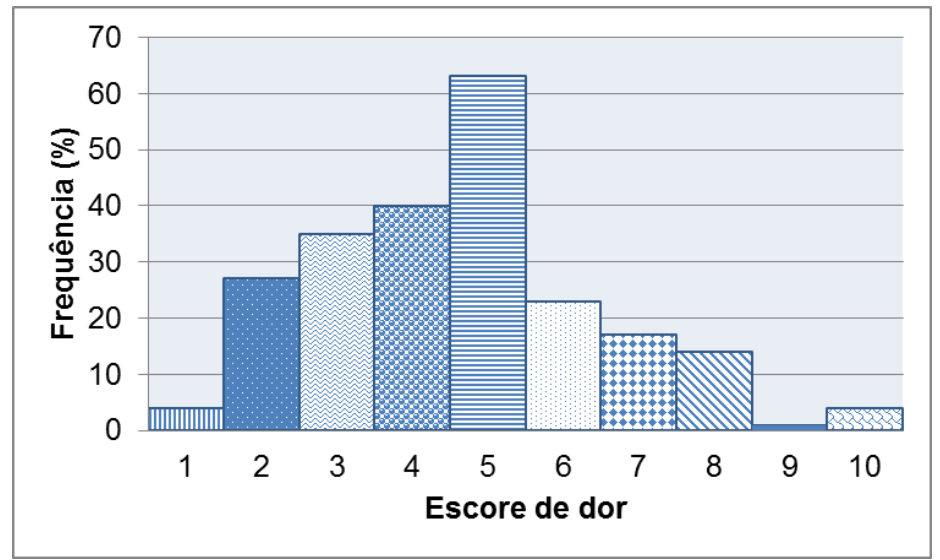

Fonte: Banco de dados do estudo

Tabela 5. Frequências da realização de atividades entre as puérperas com dor perineal no primeiro dia de pós-parto. São Paulo, 2013.

\begin{tabular}{lcccccc}
\hline \multirow{2}{*}{ Variável } & \multicolumn{6}{c}{ Realizou a atividade } \\
\cline { 2 - 7 } & \multicolumn{2}{c}{ Sim } & \multicolumn{2}{c}{ Não } & \multicolumn{2}{c}{ Total } \\
\cline { 2 - 7 } & $\mathbf{n}$ & $\%$ & $\mathbf{n}$ & $\%$ & $\mathbf{n}$ & $\%$ \\
\hline Amamentar & 221 & 96,9 & 7 & 3,1 & 228 & 100 \\
Evacuar & 23 & 10,1 & 205 & 89,9 & 228 & 100 \\
Urinar & 207 & 90,8 & 21 & 9,2 & 228 & 100 \\
Dormir & 203 & 89,0 & 25 & 11,0 & 228 & 100 \\
Sentar & 223 & 97,8 & 5 & 2,2 & 228 & 100 \\
Cuidar do RN & 202 & 88,6 & 26 & 11,4 & 228 & 100 \\
Andar & 209 & 91,7 & 19 & 8,3 & 228 & 100 \\
\hline
\end{tabular}

Tabela 6. Frequências da interferência da dor perineal na realização de atividades no primeiro dia de pós-parto. São Paulo, 2013.

\begin{tabular}{|c|c|c|c|c|c|c|}
\hline \multirow{3}{*}{ Variável } & \multicolumn{6}{|c|}{ Interferência da dor perineal } \\
\hline & \multicolumn{2}{|c|}{ Sim } & \multicolumn{2}{|c|}{ Não } & \multicolumn{2}{|c|}{ Total } \\
\hline & $\mathbf{n}$ & $\%$ & $\mathbf{n}$ & $\%$ & $\mathbf{n}$ & $\%$ \\
\hline Amamentar & 42 & 19,0 & 179 & 81,0 & 221 & 100 \\
\hline Evacuar & 8 & 34,8 & 15 & 65,2 & 23 & 100 \\
\hline Urinar & 114 & 55,1 & 93 & 44,9 & 207 & 100 \\
\hline Dormir & 68 & 33,5 & 135 & 66,5 & 203 & 100 \\
\hline Sentar & 174 & 78,0 & 49 & 22,0 & 223 & 100 \\
\hline Cuidar do RN & 52 & 25,7 & 150 & 74,3 & 202 & 100 \\
\hline Andar & 107 & 51,2 & 102 & 48,8 & 209 & 100 \\
\hline
\end{tabular}


A caracterização dos escores da interferência da dor perineal para realizar cada atividade está apresentada nos dados das Tabelas 7 e 8 . A média do escore da interferência da dor perineal ao executar cada atividade oscilou entre 5,1 e 5,9, e amamentar e evacuar foram as que tiveram maior escore médio (Tabela 7). A dor perineal interferiu, sobretudo, de 4 a 6 pontos em todas as atividades das puérperas (Tabela 8).

Tabela 7. Média, desvio-padrão (dp), mediana e valores máximo e mínimo da interferência da dor perineal ao executar atividades. São Paulo, 2013.

\begin{tabular}{lccccc}
\hline Variável & $\mathbf{n}$ & Mínimo & Máximo & Média (dp) & Mediana \\
\hline Amamentar & 42 & 2 & 10 & $5,9(2,2)$ & 5,0 \\
Evacuar & 8 & 3 & 10 & $5,8(2,8)$ & 4,5 \\
Urinar & 114 & 1 & 10 & $5,5(2,2)$ & 5,0 \\
Dormir & 68 & 1 & 10 & $5,4(2,1)$ & 5,0 \\
Sentar & 174 & 1 & 10 & $5,4(2,0)$ & 5,0 \\
Cuidar do RN & 52 & 2 & 10 & $5,3(2,1)$ & 5,0 \\
Andar & 107 & 1 & 10 & $5,1(2,2)$ & 5,0 \\
\hline
\end{tabular}

Tabela 8. Frequências do escore (1 a 10) de interferência da dor perineal na realização das atividades das puérperas. São Paulo, 2013.

\begin{tabular}{lcccccccc}
\hline \multirow{2}{*}{ Variável } & \multicolumn{1}{c}{$\mathbf{1} \mathbf{a} \mathbf{3}$} & \multicolumn{2}{c}{$\mathbf{4} \mathbf{~ a ~}$} & \multicolumn{2}{c}{$\mathbf{7} \mathbf{~ 1 0}$} & \multicolumn{2}{c}{ Total } \\
\cline { 2 - 9 } & $\mathbf{n}$ & $\mathbf{\%}$ & $\mathbf{n}$ & $\mathbf{\%}$ & $\mathbf{n}$ & $\%$ & $\mathbf{n}$ & $\%$ \\
\hline Amamentar & 12 & 28,6 & 20 & 47,6 & 10 & 23,8 & 42 & 100 \\
Evacuar & 3 & 37,5 & 5 & 62,5 & - & - & 8 & 100 \\
Urinar & 33 & 28,9 & 59 & 51,8 & 22 & 19,3 & 114 & 100 \\
Dormir & 12 & 17,6 & 39 & 57,4 & 17 & 25,0 & 68 & 100 \\
Sentar & 44 & 25,3 & 97 & 55,7 & 33 & 19,0 & 174 & 100 \\
Cuidar do RN & 10 & 19,2 & 28 & 53,8 & 14 & 26,9 & 52 & 100 \\
Andar & 28 & 26,2 & 57 & 53,3 & 22 & 20,6 & 107 & 100 \\
\hline
\end{tabular}

Após o parto e até o momento da inclusão das participantes no estudo, identificou-se que um grande número $(97,5 \%)$ delas havia consumido analgésicos. Verificou-se também que pouco mais de um décimo $(11,2 \%)$ das mulheres utilizou a crioterapia. Conforme 
descrito no método, em razão do acordo com a maternidade para a suspensão do anti-inflamatório poucas $(7,9 \%)$ puérperas receberam este medicamento (Tabela 9).

Tabela 9. Distribuição das puérperas, conforme os métodos de alívio da dor utilizados durante a internação pós-parto. São Paulo, 2013.

\begin{tabular}{lcc}
\hline Variável & $\mathbf{n}$ & $\%$ \\
\hline Uso de bolsa de gelo no períneo & & \\
Sim & 67 & 11,2 \\
Não & 529 & 88,8 \\
Uso de analgésico & & \\
Sim & 581 & 97,5 \\
Não & 15 & 2,5 \\
Uso de anti-inflamatório & & \\
Sim & 47 & 7,9 \\
Não & 549 & 92,1 \\
\hline Total & $\mathbf{5 9 6}$ & $\mathbf{1 0 0}$ \\
\hline
\end{tabular}

Em média, as mulheres foram incluídas no estudo com $12 \mathrm{~h} 23$ $(\mathrm{dp}=5 \mathrm{~h} 40)$ de pós-parto e os intervalos de tempo entre o consumo de analgésico e de anti-inflamatório e sua inclusão no estudo foram 4 h29 e 4h59, respectivamente (Tabela 10).

Tabela 10. Média, desvio-padrão (dp), mediana e valores máximo e mínimo do intervalo de tempo entre o consumo de fármacos e pósparto e inclusão no estudo. São Paulo, 2013.

\begin{tabular}{lcccc}
\hline Variável & Média (dp) & Mediana & Mínimo & Máximo \\
\hline $\begin{array}{l}\text { Consumo de } \\
\text { analgésico }\end{array}$ & $4 \mathrm{~h} 29(2 \mathrm{~h} 03)$ & $4 \mathrm{~h} 50$ & $00 \mathrm{~h} 01$ & $18 \mathrm{~h} 50$ \\
$\begin{array}{l}\text { Consumo de anti- } \\
\text { inflamatório }\end{array}$ & $4 \mathrm{~h} 59(4 \mathrm{~h} 05)$ & $3 \mathrm{~h} 30$ & $00 \mathrm{~h} 05$ & $20 \mathrm{~h} 15$ \\
$\begin{array}{l}\text { Tempo de pós- } \\
\text { parto }\end{array}$ & $12 \mathrm{~h} 23(5 \mathrm{~h} 40)$ & $11 \mathrm{~h} 31$ & $1 \mathrm{~h} 32$ & $23 \mathrm{~h} 59$ \\
\hline
\end{tabular}

\subsection{ANÁLISE BIVARIADA}

Inicialmente foram analisadas as associações entre todas as variáveis e a presença ou não de dor perineal, e os resultados estão apresentados nos dados das Tabelas 11 e 12. Houve associação 
significativa entre a ocorrência de dor perineal e escolaridade, paridade, número de traumas e condição perineal no parto atual (Tabela 11).

Mulheres com 12 ou mais anos de estudo apresentaram frequência de dor perineal maior $(63,0 \%)$ do que as que estudaram até 8 anos $(29,2 \%)$.

As primíparas tiveram maior frequência $(43,7 \%)$ de dor comparadas às multíparas $(31,6 \%)$.

Conforme citado no método, quando ocorreu mais de um tipo de trauma no períneo em uma mesma mulher, eles foram agrupados, de acordo com sua complexidade. Convém mencionar que houve apenas um caso de laceração de $3^{\circ}$ grau, que foi excluído da análise estatística.

O número e o tipo de trauma perineal associaram-se significativamente à ocorrência de dor perineal. Puérperas sem trauma perineal tiveram menor ocorrência de dor $(23,1 \%)$ e as com um único trauma apresentaram maior frequência de dor $(47,4 \%)$, assim como mulheres com episiotomia apresentaram maior frequência de dor $(52,7 \%)$ comparadas com aquelas de períneo íntegro $(23,1 \%)$.

Não houve associação entre faixa etária, cor de pele, condição perineal no parto anterior, dilatação cervical na admissão, uso de método não medicamentoso no trabalho de parto, uso de ocitocina no trabalho de parto e dilatação cervical no início da infusão de ocitocina. 
Tabela 11. Análise estatística bivariada das variáveis categóricas em relação à ocorrência de dor perineal. São Paulo, 2013.

\begin{tabular}{|c|c|c|c|c|c|c|c|}
\hline \multirow{3}{*}{ Variável } & \multicolumn{4}{|c|}{ Dor Perineal } & \multirow{2}{*}{\multicolumn{2}{|c|}{ Total }} & \multirow{3}{*}{$\begin{array}{c}\text { Valor- } \\
\mathbf{p}^{\star}\end{array}$} \\
\hline & \multicolumn{2}{|c|}{ Sim } & \multicolumn{2}{|c|}{ Não } & & & \\
\hline & $\mathrm{n}$ & $\%$ & $\mathbf{n}$ & $\%$ & $\mathbf{n}$ & $\%$ & \\
\hline \multicolumn{8}{|c|}{ Cor da pele $(n=596)$} \\
\hline Parda & 118 & 35,6 & 213 & 64,4 & 331 & 55,6 & \multirow{4}{*}{0,057} \\
\hline Branca & 78 & 46,4 & 90 & 53,6 & 168 & 28,2 & \\
\hline Preta & 26 & 31,3 & 57 & 68,7 & 83 & 13,9 & \\
\hline Outra $^{\dagger}$ & 6 & 42,9 & 8 & 57,1 & 14 & 2,3 & \\
\hline \multicolumn{8}{|c|}{ Faixa etária (anos) $(\mathrm{n}=596)$} \\
\hline 14 a 19 & 50 & 35,0 & 93 & 65,0 & 143 & 24,0 & \multirow{5}{*}{0,588} \\
\hline 20 a 24 & 76 & 40,0 & 114 & 60,0 & 190 & 31,9 & \\
\hline 25 a 29 & 138 & 42,8 & 79 & 57,2 & 138 & 23,2 & \\
\hline 30 a 34 & 32 & 34,8 & 60 & 65,2 & 92 & 15,4 & \\
\hline 35 ou mais & 11 & 33,3 & 22 & 66,7 & 33 & 5,5 & \\
\hline \multicolumn{8}{|c|}{ Escolaridade (anos) $(n=596)$} \\
\hline até 8 & 64 & 29,2 & 155 & 70,8 & 219 & 36,7 & \multirow{3}{*}{$<0,001$} \\
\hline 9 a 11 & 135 & 40,8 & 196 & 59,2 & 331 & 55,6 & \\
\hline 12 ou mais & 29 & 63,0 & 17 & 37,0 & 46 & 7,7 & \\
\hline \multicolumn{8}{|c|}{ Número de gestações $(n=596)$} \\
\hline 1 & 124 & 43,7 & 160 & 56,3 & 284 & 47,7 & \multirow{3}{*}{0,060} \\
\hline 2 & 64 & 38,1 & 104 & 61,9 & 168 & 28,2 & \\
\hline 3 ou mais & 40 & 27,8 & 104 & $72 ., 2$ & 144 & 24,2 & \\
\hline \multicolumn{8}{|c|}{ Paridade $(n=596)$} \\
\hline Primípara & 143 & 43,7 & 184 & 56,3 & 327 & 54,9 & \multirow{2}{*}{0,002} \\
\hline Multípara & 85 & 31,6 & 184 & 68,4 & 269 & 45,1 & \\
\hline \multicolumn{8}{|c|}{ Condição perineal no parto anterior $(n=271)$} \\
\hline Episiotomia & 61 & 37,2 & 103 & 62,8 & 164 & 60,5 & \multirow{4}{*}{0,170} \\
\hline Períneo íntegro & 14 & 26,4 & 39 & 73,6 & 53 & 19,6 & \\
\hline Outras $^{\dagger \dagger}$ & 3 & 18,8 & 13 & 81,2 & 16 & 5,9 & \\
\hline Laceração & 9 & 23,7 & 29 & 76,3 & 38 & 14,0 & \\
\hline \multicolumn{8}{|c|}{ Dilatação cervical na admissão $(\mathrm{cm})(\mathrm{n}=592)$} \\
\hline Até 3 & 108 & 39,4 & 166 & 60,6 & 274 & 46,3 & \multirow{3}{*}{0,324} \\
\hline 4 a 9 & 117 & 38,2 & 189 & 61,8 & 306 & 51,7 & \\
\hline 10 & 2 & 16,7 & 10 & 83,3 & 12 & 2,0 & \\
\hline \multicolumn{8}{|c|}{ Uso de método não medicamentoso no trabalho de parto $(n=595)$} \\
\hline Sim & 149 & 39,2 & 231 & 60,8 & 380 & 63,9 & \\
\hline Não & 79 & 36,7 & 136 & 63,3 & 215 & 36,1 & 0,599 \\
\hline Uso de ocitocir & traba & o de p & $0(n=$ & & & & \\
\hline Sim & 172 & 39,4 & 264 & 60,6 & 436 & 73,2 & \\
\hline Não & 56 & 35,0 & 104 & 65,0 & 160 & 26,8 & 0,343 \\
\hline Dilatação cervi & iníci & da inf & io de & itocin & $(\mathrm{cm})($ & $=437)$ & \\
\hline Até 3 & 65 & 42,2 & 89 & 57,8 & 154 & 35,2 & \\
\hline 4 a 9 & 107 & 37,9 & 175 & 62,1 & 282 & 64,4 & 0,770 \\
\hline 10 & 1 & 50,0 & 1 & 50,0 & 2 & 0,4 & \\
\hline Trauma perinea & parto & ual $(n=$ & & & & & \\
\hline Não & 50 & 23,1 & 166 & 76,9 & 216 & 36,2 & \\
\hline Único & 164 & 47,4 & 182 & 52,6 & 346 & 58,1 & $<0,001$ \\
\hline Múltiplo & 14 & 41,2 & 20 & 58,8 & 34 & 5,7 & \\
\hline
\end{tabular}


(Continuação)

Condição perineal no parto atual $(n=596)$

Períneo íntegro $\quad 50 \quad 23,1 \quad 166$

Laceração $1^{\circ} \mathrm{grau} \quad 80 \quad 41,5 \quad 113$

$\begin{array}{llll}\text { Episiotomia } & 79 & 52,7 & 71\end{array}$

$76,9 \quad 216 \quad 36,2$

Laceração $2^{\circ}$ grau

*Teste exato de Fisher

Para testar a associação entre as variáveis contínuas e a presença ou não da dor perineal, foi utilizado o teste t de Student. Nenhuma variável apresentou associação com a frequência de dor perineal, conforme os dados da Tabela 12.

Tabela 12. Análise estatística bivariada das médias das variáveis numéricas em relação à presença de dor perineal. São Paulo, 2013.

\begin{tabular}{lccc}
\hline \multirow{2}{*}{\multicolumn{1}{c}{ Variável }} & \multicolumn{2}{c}{ Dor Perineal } & \multirow{2}{*}{ Valor-p } \\
\cline { 2 - 3 } & Sim & Não & \\
\hline Tempo entre internação e o parto $(\mathrm{h})$ & $6 \mathrm{~h} 34$ & $5 \mathrm{~h} 40$ & 0,129 \\
Tempo com infusão de ocitocina $(\mathrm{h})$ & $4 \mathrm{~h} 20$ & $3 \mathrm{~h} 53$ & 0,141 \\
Peso do RN $(\mathrm{g})$ & $3.255,7$ & $3.216,8$ & 0,242 \\
Perímetro cefálico do RN $(\mathrm{cm})$ & 34,1 & 33,9 & 0,083 \\
Perímetro torácico do RN $(\mathrm{cm})$ & 33,1 & 33,3 & 0,522 \\
Tempo de pós-parto $(\mathrm{h})$ & $12 \mathrm{~h} 17$ & $12 \mathrm{~h} 27$ & 0,739 \\
Tempo após uso de analgésico $(\mathrm{h})$ & 4,59 & 4,41 & 0,310 \\
Tempo após uso de anti-inflamatório $(\mathrm{h})$ & 4,91 & 5,05 & 0,912 \\
\hline
\end{tabular}

Teste t de Student

A seguir, foram testadas a existência de associações entre as variáveis independentes e a intensidade de dor perineal. Da análise estatística, foi excluída a dilatação cervical na internação hospitalar de quatro mulheres cujos prontuários não constavam a anotação desse dado. Os resultados estão apresentados nos dados das Tabelas 13 e 14 .

Não houve associação significativa entre a intensidade de dor perineal e faixa etária, cor da pele, número de gestações, condição perineal no parto anterior, dilatação cervical na internação, uso de método não medicamentoso no trabalho de parto, uso de ocitocina no trabalho de parto e dilatação cervical no início da infusão de ocitocina, assim como na análise bivariada que considerou a dor perineal como variável dicotômica. As variáveis que se associaram significativamente com a intensidade de dor perineal foram as 
mesmas encontradas na análise da dor como variável dicotômica, ou seja, escolaridade, paridade, número de trauma e condição perineal no parto atual, conforme os dados da Tabela 13.

Mulheres que estudaram 12 anos ou mais foram as que mais apresentaram dor leve $(23,9 \%)$ e moderada $(34,8 \%)$, sendo essa diferença significativa $(p=0,001)$. Aquelas que estudaram até 8 anos relataram menor frequência $(5,9 \%)$ de dor leve que o esperado e não houve diferença estatística entre as intensidades de dor das mulheres que estudaram de 9 a 11 anos. As frequências de dor intensa foram estatisticamente iguais para as três categorias.

Quanto à paridade, as diferenças ocorreram somente para nenhuma dor e dor leve, e as intensidades moderada e intensa não se associaram à paridade. As primíparas tiveram maior frequência de dor leve $(14,1 \%)$ e menor frequência de nenhuma dor $(56,3 \%)$ que o esperado, ocorrendo o inverso para às multíparas $(p=0,012)$.

O número de trauma perineal também apresentou diferença estatística entre as intensidades de dor no períneo $(p<0,001)$. As mulheres sem trauma perineal apresentaram maior ausência de dor (76,9\%). A intensidade de dor leve não esteve associada ao número de traumas. Puérperas com um trauma apresentaram maior frequência de dor moderada (26,9\%) e aquelas com múltiplos traumas, maior frequência de dor intensa (17,6\%). Em relação à condição perineal no parto atual, as médias do escore de dor, de acordo com o tipo de trauma, foram de 4,6 $(\mathrm{dp}=1,9)$ em mulheres com laceração de $1^{\circ}$ grau, $5,1(\mathrm{dp}=1,6)$ na ocorrência de laceração de $2^{\circ}$ grau, 4,7 $(\mathrm{dp}=1,9)$ na presença de episiotomia e, àquelas com o períneo íntegro, a média de dor foi 4,3 $(\mathrm{dp}=1,8)$ (dados não apresentados em tabela). As intensidades de dor estiveram associadas à condição do períneo $(\mathrm{p}<0,001)$. Mulheres com períneo íntegro relataram maior frequência de nenhuma dor $(76,9 \%)$ e menores frequências de dor moderada $(13,4 \%)$ e intensa $(1,8 \%)$. As frequências de intensidades de dor perineal foram semelhantes para 
puérperas com laceração de $1^{\circ}$ e de $2^{\circ}$ graus, entretanto, aquelas com episiotomia relataram maiores frequências de dor leve $(16,0 \%)$ e intensa $(10,0 \%)$.

Tabela 13. Análise estatística bivariada das variáveis categóricas em relação à intensidade de dor perineal. São Paulo, 2013.

\begin{tabular}{|c|c|c|c|c|c|c|c|c|c|c|c|}
\hline \multirow{3}{*}{ Variável } & \multicolumn{8}{|c|}{ Dor Perineal } & \multirow{2}{*}{\multicolumn{2}{|c|}{ Total }} & \multirow{3}{*}{$\begin{array}{c}\text { Valor- } \\
\mathbf{p}^{\star}\end{array}$} \\
\hline & \multicolumn{2}{|c|}{ Nenhuma } & \multicolumn{2}{|c|}{ Leve } & \multicolumn{2}{|c|}{ Moderada } & \multicolumn{2}{|c|}{ Intensa } & & & \\
\hline & $\mathbf{n}$ & $\%$ & $\mathbf{n}$ & $\%$ & $\mathbf{n}$ & $\%$ & $\mathbf{n}$ & $\%$ & $\mathbf{n}$ & $\%$ & \\
\hline \multicolumn{12}{|c|}{ Cor da pele $(n=596)$} \\
\hline Parda & 213 & 64,4 & 30 & 9,1 & 67 & 20,2 & 21 & 6,3 & 331 & 55,5 & \multirow{4}{*}{0,379} \\
\hline Branca & 90 & 53,6 & 26 & 15,5 & 41 & 24,4 & 11 & 6,5 & 168 & 28,2 & \\
\hline Preta & 57 & 68,7 & 8 & 9,6 & 15 & 18,1 & 3 & 3,6 & 83 & 13,9 & \\
\hline Outra $^{\dagger}$ & 8 & 57,1 & 2 & 14,3 & 3 & 21,5 & 1 & 7,1 & 14 & 2,5 & \\
\hline \multicolumn{12}{|c|}{ Faixa etária (anos) $(n=596)$} \\
\hline 14 a 19 & 93 & 65,0 & 18 & 12,6 & 23 & 16,1 & 9 & 6,3 & 143 & 24,0 & \multirow{5}{*}{0,385} \\
\hline 20 a 24 & 114 & 60,0 & 20 & 10,5 & 46 & 24,2 & 10 & 5,3 & 190 & 31,9 & \\
\hline 25 a 29 & 79 & 57,2 & 19 & 13,8 & 28 & 20,3 & 12 & 8,7 & 138 & 23,2 & \\
\hline 30 a 34 & 60 & 65,2 & 9 & 9,8 & 19 & 20,7 & 4 & 4,3 & 92 & 15,4 & \\
\hline 35 ou mais & 22 & 66,7 & - & - & 10 & 30,3 & 1 & 3,0 & 33 & 5,5 & \\
\hline \multicolumn{12}{|c|}{ Escolaridade (anos) $(n=596)$} \\
\hline até 8 & 155 & 70,8 & 13 & 5,9 & 40 & 18,3 & 11 & 5,0 & 219 & 36,7 & \multirow{3}{*}{0,001} \\
\hline 9 a 11 & 196 & 59,2 & 42 & 12,7 & 70 & 21,2 & 23 & 6,9 & 331 & 55,6 & \\
\hline 12 ou mais & 17 & 37,0 & 11 & 23,9 & 16 & 34,8 & 2 & 4,3 & 46 & 7,7 & \\
\hline \multicolumn{12}{|c|}{ Número de gestações $(n=596)$} \\
\hline 1 & 160 & 56,3 & 39 & 13,7 & 66 & 23,2 & 19 & . & 284 & 47,7 & \multirow{3}{*}{0,068} \\
\hline 2 & 104 & 61,9 & 18 & 10,7 & 37 & 22,0 & 9 & 4 & 168 & 28,2 & \\
\hline 3 ou mais & 104 & 72,2 & 9 & 6,3 & 23 & 16,0 & 8 & 5,6 & 144 & 24,2 & \\
\hline \multicolumn{12}{|c|}{ Paridade $(n=596)$} \\
\hline Primípara & 184 & 56,3 & 46 & 14,1 & 75 & 22,9 & 22 & 6,7 & 327 & 54,9 & \multirow{2}{*}{0,012} \\
\hline Multípara & 184 & 68,4 & 20 & 7,4 & 51 & 19,0 & 14 & 5,2 & 269 & 45,1 & \\
\hline \multicolumn{12}{|c|}{ Condição perineal no parto anterior $(n=271)$} \\
\hline Episiotomia & 103 & 62,8 & 12 & 7,3 & 37 & 22,6 & 12 & 7,3 & 164 & 60,5 & \multirow{4}{*}{0,199} \\
\hline $\begin{array}{l}\text { Períneo } \\
\text { íntegro }\end{array}$ & 39 & 73,6 & 7 & 13,2 & 7 & 13,2 & - & - & 53 & 19,6 & \\
\hline Laceração & 29 & 76,3 & 2 & 5,3 & 6 & 15,8 & 1 & 2,6 & 38 & 14,0 & \\
\hline Outras $^{\dagger \dagger}$ & 13 & 81,3 & - & - & 2 & 12,5 & 1 & 6,3 & 16 & 5,1 & \\
\hline \multicolumn{12}{|c|}{ Dilatação cervical na internação $(\mathrm{cm})(\mathrm{n}=592)$} \\
\hline até 3 & 166 & 60,6 & 36 & 13,1 & 59 & 21,5 & 13 & 4,7 & 274 & 46,3 & \multirow{3}{*}{0,623} \\
\hline 4 a 9 & 189 & 61,8 & 30 & 9,8 & 65 & 21,2 & 22 & 7,2 & 306 & 51,7 & \\
\hline 10 & 10 & 83,4 & - & - & 1 & 8,3 & 1 & 8,3 & 12 & 2,0 & \\
\hline \multicolumn{12}{|c|}{ Uso de método não medicamentoso no trabalho de parto $(n=595)$} \\
\hline Sim & 231 & 60,8 & 51 & 13,4 & 79 & 20,8 & 19 & 5,0 & 380 & 63,9 & \\
\hline Não & 136 & 63,3 & 15 & 7,0 & 47 & 21,9 & 17 & 7,9 & 215 & 36,1 & 0,060 \\
\hline Uso d & Sina $n$ & o trab & alho & de pa & to $(r$ & $=596)$ & & & & & \\
\hline Sim & 264 & 60,5 & 54 & 12,4 & 89 & 20,4 & 29 & 6,7 & 436 & 73,0 & \\
\hline Não & 104 & 65,0 & 12 & 7,5 & 37 & 23,1 & 7 & 4,4 & 160 & 27,0 & \\
\hline
\end{tabular}


(Continuação)

Dilatação cervical no início da infusão de ocitocina $(\mathrm{cm})(\mathrm{n}=437)$

$\begin{array}{lccccccccccc}\text { Até } 3 & 89 & 57,8 & 26 & 16,9 & 31 & 20,1 & 8 & 5,2 & 154 & 35,2 & \\ 4 \text { a } 9 & 175 & 62,1 & 27 & 9,6 & 59 & 20,9 & 21 & 7,4 & 282 & 64,4 & 0,430 \\ 10 & 1 & 50,0 & 1 & 50,0 & - & - & - & - & - & 0,4 & \end{array}$

Número de trauma perineal no parto atual $(n=596)$

$\begin{array}{lllllllllll}\text { Nenhum } & 166 & 76,9 & 17 & 7,9 & 29 & 13,4 & 4 & 1,9 & 216 & 36,3\end{array}$

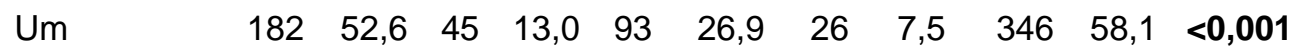

$\begin{array}{lllllllllll}\text { Múltiplos } & 20 & 58,8 & 4 & 11,8 & 4 & 11,8 & 6 & 17,6 & 34 & 5,7\end{array}$

Condição perineal no parto atual $(n=595)$

$\begin{array}{lccccccccccc}\begin{array}{l}\text { Períneo } \\ \text { íntegro }\end{array} & 166 & 76,9 & 17 & 7,9 & 29 & 13,4 & 4 & 1,8 & 216 & 36,3 & \\ \begin{array}{l}\text { Laceração } \\ \text { 1o grau }\end{array} & 113 & 58,5 & 21 & 10,9 & 46 & 23,9 & 13 & 6,7 & 193 & 32,4 & \\ \text { Episiotomia } & 71 & 47,3 & 24 & 16,0 & 40 & 26,7 & 15 & 10,0 & 150 & 25,2 & <001 \\ \begin{array}{l}\text { Laceração } \\ \text { 2o grau }\end{array} & 18 & 50,0 & 3 & 8,3 & 11 & 30,6 & 4 & 11,1 & 36 & 6,0 & \\ \end{array}$

${ }^{*}$ Qui-quadrado com simulação de Monte Carlo

†amarela e indígena

${ }^{+t}$ refere ter tido trauma ou sutura

Nenhuma variável quantitativa numérica apresentou associação estatística com a intensidade de dor perineal, conforme os dados da Tabela 14.

Tabela 14. Análise estatística bivariada das médias das variáveis numéricas em relação à intensidade de dor perineal. São Paulo, 2013.

\begin{tabular}{|c|c|c|c|c|c|}
\hline \multirow{2}{*}{ Variável } & \multicolumn{4}{|c|}{ Intensidade de dor } & \multirow{2}{*}{$\begin{array}{c}\text { Valor- } \\
\text { p }^{*}\end{array}$} \\
\hline & Nenhuma & Leve & Moderada & Intensa & \\
\hline $\begin{array}{l}\text { Tempo entre } \\
\text { internação e parto }(\mathrm{h})\end{array}$ & $5 \mathrm{~h} 40$ & $6 h 55$ & $6 h 57$ & $5 h 35$ & 0,129 \\
\hline $\begin{array}{l}\text { Tempo com infusão } \\
\text { de ocitocina (h) }\end{array}$ & $3 h 53$ & $4 \mathrm{~h} 35$ & $4 \mathrm{~h} 26$ & $3 h 38$ & 0,262 \\
\hline Peso do RN (g) & $3.216,82$ & $3.245,68$ & $3.264,83$ & $3.242,22$ & 0,679 \\
\hline $\begin{array}{l}\text { Perímetro cefálico do } \\
\text { RN (cm) }\end{array}$ & 33,9 & 34,0 & 34,2 & 34,3 & 0,203 \\
\hline $\begin{array}{l}\text { Perímetro torácico do } \\
\mathrm{RN}(\mathrm{cm})\end{array}$ & 33,3 & 33,1 & 33,1 & 33,3 & 0,923 \\
\hline Tempo pós-parto (h) & $12 \mathrm{~h} 27$ & $12 \mathrm{~h} 20$ & $11 \mathrm{~h} 56$ & $13 \mathrm{~h} 27$ & 0,535 \\
\hline $\begin{array}{l}\text { Tempo após uso de } \\
\text { analgésico }(\mathrm{h})\end{array}$ & $4 \mathrm{~h} 24$ & $4 \mathrm{~h} 43$ & $4 h 38$ & $4 \mathrm{~h} 13$ & 0,484 \\
\hline $\begin{array}{l}\text { Tempo após uso de } \\
\text { anti-inflamatório (h) }\end{array}$ & $5 \mathrm{~h} 03$ & 5 h33 & $4 \mathrm{~h} 34$ & $5 \mathrm{~h} 17$ & 0,979 \\
\hline
\end{tabular}

${ }^{*}$ ANOVA

Todas as atividades investigadas sofreram interferência estatisticamente significativa da dor perineal em sua realização, exceto evacuar, conforme os dados da Tabela 15. Foi, então, 
realizado o teste de Tukey-HSD, em que as médias da interferência da dor perineal na realização de cada atividade foram analisadas par a par, e observou-se que as médias do escore de interferência de dor no períneo ao sentar e ao andar foram significativamente diferentes entre as três intensidades de dor perineal. Ao urinar e ao amamentar, a interferência de dor só foi significativa nas mulheres com dor perineal leve. Já ao dormir e cuidar do bebê, a diferença das médias de interferência de dor ocorreu entre mulheres com dor perineal leve e intensa.

Tabela 15. Análise estatística bivariada das médias da interferência da dor perineal na realização das atividades em relação à intensidade de dor perineal. São Paulo, 2013.

\begin{tabular}{lcccc}
\hline \multirow{2}{*}{ Variável } & \multicolumn{3}{c}{ Intensidade de dor } & \multirow{2}{*}{ Valor-p* } \\
\cline { 2 - 4 } & Leve & Moderada & Intensa & \\
\hline $\begin{array}{l}\text { Interferência da dor ao } \\
\text { amamentar }\end{array}$ & $4,2(1,4)$ & $6,1(2,3)$ & $7,5(1,7)$ & $\mathbf{0 , 0 0 1}$ \\
$\begin{array}{l}\text { Interferência da dor ao } \\
\text { evacuar }\end{array}$ & $7,3(2,1)$ & $4,8(2,9)$ & - & 0,245 \\
$\begin{array}{l}\text { Interferência da dor ao } \\
\text { urinar }\end{array}$ & $4,2(2,2)$ & $5,8(2,1)$ & $6,5(1,7)$ & $<\mathbf{0 , 0 0 1}$ \\
$\begin{array}{l}\text { Interferência da dor ao } \\
\text { dormir }\end{array}$ & $4,5(2,6)$ & $5,2(2,0)$ & $6,6(1,7)$ & $\mathbf{0 , 0 1 9}$ \\
$\begin{array}{l}\text { Interferência da dor ao } \\
\text { sentar }\end{array}$ & $4,1(2,1)$ & $5,3(1,6)$ & $7,1(2,0)$ & $<\mathbf{0 , 0 0 1}$ \\
$\begin{array}{l}\text { Interferência da dor ao } \\
\text { cuidar do bebê }\end{array}$ & $4,4(1,9)$ & $4,9(1,9)$ & $6,5(2,3)$ & $\mathbf{0 , 0 2 7}$ \\
$\begin{array}{l}\text { Interferência da dor ao } \\
\text { andar }\end{array}$ & $3,6(1,5)$ & $5,1(2,1)$ & $6,9(1,7)$ & $<\mathbf{0 , 0 0 1}$ \\
\hline
\end{tabular}

${ }^{*}$ ANOVA

\subsection{ANÁLISE MULTIVARIADA}

As variáveis que ficaram no modelo estão apresentadas nos dados da Tabela 16. No modelo, foram incluídas: escolaridade, número de gestações, paridade, condição perineal no parto anterior, uso de método não medicamentoso para alívio de dor no trabalho de parto, tempo de internação, condição perineal no parto atual e número de trauma perineal no parto atual. As variáveis foram excluídas individualmente de acordo com o maior valor-p e o teste 
era, então, repetido até que o maior valor-p entre as variáveis restantes fosse significativo. No modelo, permaneceram: escolaridade $(p=0,046)$ e condição perineal no parto atual $(p<0,001)$.

Ter estudado até 8 anos apresentou efeito protetor contra a dor, com 50,0\% menos chances de aumentar uma categoria na intensidade de dor perineal. As mulheres que tiveram laceração perineal de primeiro grau apresentaram 2,3 vezes mais chances de aumentar uma categoria da dor, já aquelas com episiotomia e laceração de segundo grau apresentaram, respectivamente, 3,4 e 3,2 vezes mais chances de aumentar uma categoria da dor do que aquelas com períneo íntegro.

Tabela 16. Análise estatística multivariada em relação à intensidade de dor perineal. São Paulo, 2013.

\begin{tabular}{lcc}
\hline \multirow{2}{*}{ Variável } & \multicolumn{2}{c}{ Análise multivariada } \\
\cline { 2 - 3 } & OR & IC (95\%) \\
\hline Escolaridade (anos) & & \\
até 8 & 0,5 & $0,3-0,9$ \\
9 a 11 & 0,7 & $0,4-1,2$ \\
12 ou mais & 1,0 & \\
Condição perineal no parto atual & & \\
Períneo íntegro & 1,0 & \\
Laceração 1ํgrau & 2,3 & $1,5-3,5$ \\
Laceração 2o grau & 3,4 & $1,7-6,9$ \\
Episiotomia & 3,2 & $2,0-5,0$ \\
\hline AIC=261,3 & &
\end{tabular}




\section{DISCUSSÃO}


A discussão está apresentada considerando as características das puérperas e os objetivos do estudo: prevalência e intensidade de dor perineal no primeiro dia após o parto normal, fatores relacionados (variáveis que apresentaram diferença estatística) e interferência da dor perineal na realização das atividades da puérpera. A seguir, estão citadas as variáveis que permaneceram no modelo de regressão; por último, as variáveis sem significância estatística, mas, que estiveram associadas à dor em outras pesquisas.

As características sociodemográficas, obstétricas e de assistência ao parto mostraram que as mulheres deste estudo eram, sobretudo, pardas, entre 20 e 29 anos, com até 11 anos de estudos, tinham companheiro e eram primíparas. Foram admitidas entre 4 e 9 cm de dilatação cervical, receberam ocitocina no trabalho de parto e cerca de um terço delas manteve a integridade perineal. Entre aquelas com traumatismo perineal, mais de um terço foi de laceração espontânea e um quarto de episiotomia. Praticamente, todos os traumas perineais foram suturados e quase a totalidade das puérperas recebeu analgésico após o parto.

Inicialmente, são apresentados os principais resultados encontrados neste estudo. A escolaridade, a paridade, a condição perineal após 0 parto e 0 número de traumas perineais apresentaram associação estatística com a dor no períneo. Todas as atividades investigadas sofreram interferência significativa da dor perineal em sua realização, exceto evacuar. A média de interferência da dor no períneo na execução de atividades pelas puérperas foi em torno de 5 para todas elas. Na análise multivariada, a escolaridade e a condição perineal no parto foram fatores associados às categorias de intensidade de dor.

Embora haja muitos estudos que apresentam a frequência da dor perineal, não são todos que avaliaram sua intensidade e há uma lacuna na literatura sobre quais fatores associam-se à intensidade de dor no períneo após o parto. 
É importante ressaltar que os estudos utilizaram escalas de dor diferentes entre si, sendo a VAS, o questionário McGill e a escala numérica as mais empregadas. Também a forma de apresentação dos resultados divergiu: alguns estudos mostraram apenas a frequência; outros, o escore e/ou a intensidade de dor e, ainda, alguns apontaram a razão de chances (OR) ou risco relativo (RR). Desta forma, nem sempre foi possível estabelecer um parâmetro para comparação com os resultados deste estudo.

Como citado no Método, o local de coleta dos dados foi um CPN intra-hospitalar e, neste contexto, a dor perineal esteve presente em $38,3 \%$ das puérperas. A implantação de CPNs no Brasil é mais recente que a dos Centros Obstétricos e, desta forma, a literatura sobre o cuidado perineal neste modelo, em especial, a dor, ainda é reduzida. As frequências de dor perineal apresentadas nos estudos brasileiros são divergentes em ambos os modelos de assistência ao parto. Entre dois estudos realizados no mesmo local da atual pesquisa, um deles identificou maior frequência de dor perineal nos primeiro e segundo dias de pós-parto, respectivamente $82,7 \%$ e $86,5 \%$ em primíparas submetidas à episiotomia (FRANCISCO et al., 2012) e outro, menor ocorrência (36,0\% e $13,0 \%)$ em mulheres que tiveram laceração perineal espontânea (LEITE, 2012).

Estudo transversal realizado no CO do Hospital Universitário da USP, que incluiu 303 mulheres de diferentes paridades e tipos de trauma perineal, verificou menor frequência de dor $(18,5 \%)$, entre $2 h$ e 98h (FRANCISCO et al., 2011a). Por outro lado, uma pesquisa descritiva conduzida no interior do Estado constatou maiores frequências de dor perineal (em repouso - 52,0\% e ao movimento $100 \%$ ), em uma amostra composta por 50 primíparas submetidas à episiotomia, entre $6 \mathrm{~h}$ e $24 \mathrm{~h}$ de pós-parto vaginal e sem uso de analgésico ou anti-inflamatório (BELEZA et al., 2012).

A literatura internacional aponta frequências maiores que as nacionais em estudos cuja coleta de dados ocorreu apenas no 
hospital. O estudo que apresenta menor frequência de dor no períneo foi conduzido na Turquia por Sayiner et al. (2010), incluiu 1.500 primíparas no primeiro dia de pós-parto vaginal e encontrou que a dor foi referida por $56,8 \%$. Já no survey norte-americano, as multíparas relataram $52,0 \%$ de dor e as primíparas $77,0 \%$, com até 6 meses de pós-parto (DECLERCQ et al., 2014). No estudo transversal realizado na Austrália, a dor esteve presente em 90,0\% das puérperas de diversas paridades em até $72 \mathrm{~h}$ de pós-parto (EAST et al., 2012). Frequência ainda maior $(96,7 \%)$ foi verificada entre as primíparas recrutadas na coorte de Macleod et al. (2013), nas primeiras $24 \mathrm{~h}$.

O conhecimento da intensidade de dor no períneo, bem como seus fatores de risco, possibilitam que a equipe de saúde providencie estratégias eficazes para seu alívio durante o pós-parto. Neste estudo, grande número das mulheres referiu intensidade entre 4 e 6, valor considerado como moderado. Assim como a frequência, a intensidade citada na literatura também tem valores conflitantes. Entre os primeiro e terceiro dias de pós-parto, outros estudos também indicaram que a dor foi, sobretudo, moderada, sendo $51,8 \%$ e 43,0\% das puérperas nos estudos de Francisco et al. (2011b) e de Fodstad et al. (2013), respectivamente; e em ocorrência quatro vezes menor $(11,0 \%)$ foi observada em puérperas com lacerações espontâneas (LEITE, 2012).

A intensidade de dor maior foi apontada em um levantamento entre 18 mulheres com trauma perineal no parto; para $77,0 \%$ delas, foi de moderada a insuportável nas primeiras 24 horas de pós-parto (SWAIN; DAHLEN; 2013).

Outros estudos encontraram menor intensidade de dor perineal. A dor foi majoritariamente leve nos primeiro e segundo dias de pós-parto $(64,4 \%$ e $72,1 \%$, respectivamente) em estudo anteriormente citado (FRANCISCO et al., 2012). Entre as 215 puérperas de um estudo transversal australiano, a intensidade de dor foi leve para $53,0 \%$ delas, contudo o período de pós-parto 
avaliado foi maior (até 3 dias) do que o da atual pesquisa (EAST et al., 2012). Nos Estados Unidos da América, uma coorte composta por 565 puérperas de um hospital universitário comparou a dor perineal, utilizando o questionário de McGill e a escala VAS, e constatou maior ocorrência $(40,4 \%)$ de dor leve na alta hospitalar (LEEMAN et al., 2009).

Em relação à intensidade média de dor no períneo, este estudo verificou 4,6 pontos da escala numérica. Média semelhante $(4,8)$ também foi apontada no estudo brasileiro de Francisco et al. (2011a). Valores diferentes foram constatados, entre as primíparas com episiotomia $(5,0)$ e $(4,2)$, respectivamente, nos estudos de Pitangui et al. (2009) e Beleza et al. (2012), considerando o mesmo período de pós-parto (até 24h).

Neste estudo, a escolaridade apresentou associação com a intensidade de dor. As mulheres que estudaram até 8 anos mostraram maior ausência de dor, e as que estudaram por 12 anos ou mais foram as que mais se queixaram de dor nas intensidades leve e moderada.

Leeman et al. (2009) encontraram associação significativa entre a dor perineal e maior nível de escolaridade, embora não tenha especificado em qual intensidade ocorreu a associação e tão pouco referiu quantos anos de estudo correspondiam ao maior nível de escolaridade.

Em contraponto, uma coorte sueca composta por 11.464 pacientes que realizaram artroplastia de quadril, teve como objetivo avaliar se o nível de escolaridade interfere na redução da dor e na satisfação com o tratamento, após 1 ano da cirurgia. Os autores observaram associação entre alto nível de escolaridade e menor escore de dor, já os níveis baixo e médio de ensino não tiveram associação significativa com a redução da dor após a cirurgia. Concluem que generalizar seus resultados às populações não sueca pode ser inadequado em razão das particularidades do ensino de cada país (GREENE et al., 2014). 
Classificar a escolaridade como uma variável contínua não é adequado quando se comparam estudos entre países distintos, uma vez que há variação entre número de anos de estudo obrigatório em todo o mundo. Na pesquisa de Greene et al. (2014), não havia definição do que foi considerado alto nível de educação, desta forma, não foi possível comparar com nossos achados. Faltam estudos brasileiros que investiguem a associação entre escolaridade, condição socioeconômica e dor perineal.

Conforme citado no Método e nos Resultados, vale mencionar que, neste estudo, se adotou como primíparas as mulheres com cesariana ou abortamento prévios e multíparas, aquelas com, pelo menos, um parto vaginal anterior. Desta forma, a dor perineal leve esteve associada à primiparidade, e as multíparas tiveram, significativamente, menor frequência de dor. Dois estudos apresentam resultados que concordaram com os nossos achados. $\mathrm{Na}$ coorte conduzida por Macarthur e Macarthur (2004), as primíparas tiveram maior ocorrência e intensidade de dor nos três momentos do pós-parto no qual a dor no períneo foi investigada (primeiro e sétimo dias e sexta semana; $p<0,05$ ). No entanto, esses autores não mostraram as frequências e intensidades de dor entre os grupos. No estudo de Leeman et al. (2009), as nulíparas também apresentaram associação estatística com a dor perineal no momento da alta hospitalar, todavia, os autores não especificaram a intensidade de dor nem quanto tempo de pós-parto ocorreu a alta hospitalar.

Por outro lado, não houve associação entre a dor no períneo e a paridade em estudos citados anteriormente (EAST et al., 2012; FRANCISCO et al., 2011a).

No presente estudo, embora houvesse mulheres com períneo íntegro que relataram dor, a ausência de trauma esteve associada à ausência de dor perineal. Pesquisas já referidas anteriormente apontam que mulheres sem lesão perineal citaram dor, entretanto, 
com menores frequências e intensidades (EAST et al., 2012; MACARTHUR; MACARTHUR; 2004).

Mulheres com múltiplos traumas estiveram associadas à dor intensa e aquelas com um único trauma, à dor de intensidade moderada. Em oposição a nossos resultados, em um ensaio clínico composto por 300 mulheres com episiotomia mediana ou mediolateral não foi encontrada associação entre a intensidade de dor e a presença de somente um trauma (episiotomia) ou múltiplos traumas (episiotomia com laceração e episiotomia com lesão de esfíncter anal) (FODSTAD; LAINE; STAFF; 2013).

Neste estudo, a intensidade de dor esteve associada à condição perineal. Assim, mulheres com períneo íntegro tiveram significativamente menores frequências de dor moderada e intensa $e$ aquelas com episiotomia foram as que tiveram mais dor leve e intensa. Não foi observada diferença estatística entre as intensidades de dor no períneo das puérperas com laceração de $1^{\circ}$ ou de $2^{\circ}$ grau.

No que se refere à intensidade de dor, os resultados de uma coorte taiwanesa composta por 243 puérperas de diversas paridades concordam com nossos achados. Os dados apontaram maior intensidade de dor em mulheres com episiotomia do que naquelas com laceração, na primeira e na segunda semana de pós-parto, utilizando a escala VAS e, na sexta semana com o questionário de McGill. Não foi observada diferença de dor entre os grupos (episiotomia vs laceração) nos primeiro e terceiro dias e no terceiro mês após o parto, em ambas as escalas (CHANG et al., 2011).

Neste estudo, analisando a intensidade média de dor perineal, de acordo com o trauma ocorrido no parto, notou-se que mulheres com laceração de $2^{0}$ grau tiveram a maior média $(5,1)$. Entretanto, uma coorte composta por primíparas apresentou associação da episiotomia com maior média de dor comparada às mulheres sem episiotomia $(1,95$ vs 1,$36 ; p<0,001)$ (KARAÇAM et al., 2013). As mulheres com episiotomia também tiveram maior média de dor em 
outro estudo supracitado ( 1,15 pontos maior do que aquelas com períneo íntegro) avaliadas pela escala VAS (EAST et al., 2012).

Por outro lado, a coorte que investigou a dor nos primeiro e sétimo dias e na sexta semana de pós-parto mostrou que, utilizando a escala numérica, as medianas de intensidade de dor aumentam de acordo com o grau da lesão perineal, nos primeiro e sétimo dias depois do parto. Entretanto, as medianas foram semelhantes entre mulheres com laceração de $1^{\circ}$ ou $2^{\circ}$ grau no primeiro dia do puerpério. Os autores não investigaram se houve diferença estatística entre a dor e os tipos de traumas, conforme o tempo de pós-parto (MACARTHUR; MACARTHUR; 2004).

Ressalta-se que, na instituição onde se deu a coleta de dados, não há protocolo para classificação do trauma perineal. $\mathrm{Na}$ literatura científica, há evidência de viés de classificação da lesão perineal, tanto ao subestimar como ao hiperestimar o grau do trauma, em especial, nas lacerações de $2^{\circ}$ grau por apresentarem diversos tamanhos, profundidades e complexidades distintas (COLACIOPPO et al., 2011; METCALFE et al., 2002). Houve registro de apenas uma lesão de $3^{\circ}$ grau entre as mulheres da amostra e especula-se que poderia haver outras mulheres com esta gravidade de trauma que tenham sido classificados como de $2^{\circ}$ grau, fato que ajudaria a compreender a maior média de dor entre mulheres com laceração de $2^{\circ}$ grau.

Quando se analisaram as atividades realizadas pelas puérperas, com exceção de evacuar, verificou-se que todas apresentaram interferência estatística significante de acordo com a categoria de intensidade de dor no períneo. A dor perineal leve interferiu em todas as atividades investigadas, a dor moderada apenas ao sentar e ao andar e a dor intensa, ao dormir, sentar, andar e cuidar do RN (Tabela 15). É importante lembrar que poucas mulheres $(n=23)$ evacuaram no intervalo de tempo entre o parto e o ingresso neste estudo. 
No atual estudo, quanto ao escore de interferência, as mulheres pontuaram a interferência da dor perineal entre 4 e 6 pontos da escala ( 0 a 10) na realização de todas as atividades. Não foi possível discutir este resultado, pois ainda não foram conduzidos trabalhos na área obstétrica com escala semelhante à utilizada neste estudo.

Neste estudo, as frequências de interferência da dor perineal nas atividades variaram-se de $19,0 \%$ e $78,0 \%$ A maioria das mulheres com queixa dolorosa relatou interferência da dor ao sentar $(78,0 \%)$, urinar $(55,1 \%)$ e andar $(51,2 \%)$ e menos da metade delas ao evacuar $(34,8 \%)$, dormir $(33,5 \%)$, cuidar do bebê $(25,7 \%)$ e amamentar (19,0\%).

Estudo que investigou a frequência de interferência da dor no períneo ao sentar, andar, urinar e dormir, de acordo com o tipo de trauma perineal (períneo íntegro, laceração de $1^{0}$ ou $2^{\circ}$ grau, episiotomia e laceração de $3^{\circ}$ ou $4^{\circ}$ grau), obteve menores frequências de interferência da dor entre todas as variáveis no primeiro dia de pós-parto. Em mulheres com períneo íntegro, a maior interferência de dor ocorreu ao sentar (14,3\%). Embora não tenha sido investigada associação entre a intensidade de dor perineal e interferência, esse estudo foi importante por ter sido um dos primeiros a apresentar dados referentes a interferência da dor (MACARTHUR; MACARTHUR; 2004).

Em estudo supracitado, as mulheres referiram menor frequência de dor e de intensidade ao realizar atividades. A dor leve foi informada por $28,4 \%$ das puérperas ao cuidar do bebê e por $22,4 \%$ ao amamentar, enquanto a moderada por $38,1 \%$ ao deitar, 29,4\% ao sentar e 28,4\% ao andar (EAST et al., 2012).

Por outro lado, dois estudos encontraram frequências maiores de interferência da dor perineal em algumas atividades e menores em outras. O estudo de Francisco et al. (2012), de modo geral, apontou elevada interferência da dor nas atividades no primeiro dia $(92,3 \%)$ e no segundo dia pós-parto $(86,5 \%)$. Nas primeiras 24 
horas, as puérperas queixaram-se de dor, sobretudo, ao sentar $(90,4 \%)$, ao caminhar $(48,1 \%)$ e ao dormir $(38,5 \%)$. Já no trabalho de Beleza et al. (2012), as mulheres relataram frequências ainda maiores de interferência ao sentar $(98,0 \%)$, ao caminhar $(82,0 \%)$ e durante o sono $(36,0 \%)$ e menores ao urinar $(40,0 \%)$ e ao evacuar $(4,0 \%)$. Estes estudos não avaliaram o escore de interferência da dor nas atividades e seus valores demonstraram o quanto a dor no períneo prejudica a vivência da mulher no pós-parto.

Entre 241 puérperas inglesas de uma coorte, as medianas de dor perineal durante o repouso, ao se movimentar e ao sentar-se estiveram associadas à condição perineal utilizando a Escala Numérica Visual ( 0 a 10). No primeiro dia de pós-parto, as mulheres com períneo íntegro ou laceração de $1^{\circ}$ grau relataram estatisticamente menor mediana da dor durante as três atividades do que aquelas com episiotomia e laceração de $2^{\circ}$ grau ou laceração grave. Ao comparar a dor durante as atividades apenas entre as mulheres com episiotomia e laceração de $2^{\circ}$ grau, houve diferença estatística apenas ao sentar-se $(4,9$ vs 3,7) (ANDREWS et al., 2008). $\mathrm{Na}$ atual pesquisa, não foi comparada a interferência da dor perineal na realização de atividades, conforme condição perineal.

Além disso, os trabalhos mostram que a interferência da dor no períneo persiste para além do período puerperal. Após 2 e 6 meses do parto de mulheres com episiotomia, $69,6 \%$ e $29,2 \%$, respectivamente, ainda citaram dor no períneo (SOUZA e SILVA et al., 2013) No survey realizado nos Estados Unidos da América com 2.400 mulheres com 6 meses depois do parto, foi identificada persistência da queixa dolorosa em $41,0 \%$ daquelas cujo parto foi vaginal. Para $11,0 \%$ dessas mulheres, a dor representou um grande problema no pós-parto (DECLERCQ et al., 2014).

A dor perineal é um fator debilitante e tem interferência de leve à extrema no cotidiano das mulheres nos primeiros 6 meses pós-parto, com impacto negativo na experiência da maternidade (DECLERCQ et al., 2014), além de comprometer o relacionamento 
conjugal. Entre mulheres com episiotomia, há evidências de dispareunia em $69,7 \%$ delas aos 2 meses e 29,2\% aos 6 de pósparto (SOUZA e SILVA et al., 2013) e em $21,0 \%$ das mulheres que sofreram episiotomia de modo rotineiro e de $18,0 \%$ seletivo, 4 anos depois do parto (FRITEL et al., 2008).

De acordo com os resultados já referidos, entre os fatores associados à intensidade de dor no períneo após o parto normal, foram encontrados: escolaridade, paridade, número e tipo de trauma perineal. Estas variáveis interagiram entre si, restando apenas a condição perineal, como fator de risco independente para a intensidade de dor perineal. Considerando os resultados da análise de regressão logística ordinal, foi possível observar que as mulheres que estudaram até 8 anos $(\mathrm{OR}=0,5)$ tiveram proteção contra o aumento em uma categoria de dor no períneo. Com relação ao tipo de trauma perineal, o risco de aumentar uma categoria de dor foi maior para mulheres com episiotomia $(\mathrm{OR}=3,2)$ e laceração de $2^{\circ}$ grau $(\mathrm{OR}=3,4)$.

Convém destacar que não foram localizados estudos científicos que abordem a escolaridade no contexto da dor perineal no pós-parto. Assim, uma hipótese explicativa é que a escolaridade oferece ao indivíduo condições de se posicionar no mundo e analisálo criticamente, além de facilitar que conheça e reivindique seus direitos. Desta forma, espera-se que mulheres com maior escolaridade tenham maior consciência de seus direitos e verbalizem com maior frequência a dor.

Quanto ao tipo de trauma, valor semelhante ao deste estudo foi encontrado por Francisco et al. (2011a), que verificaram que mulheres com episiotomia tiveram 3,8 vezes mais chances de ter períneo doloroso.

Em contrapartida, outros estudos apontaram maior chance de dor em mulheres com episiotomia. O estudo turco com primíparas mostrou que este procedimento aumentou a probabilidade de ocorrência de dor perineal em, aproximadamente, cinco vezes (OR 
5,07 ) e duas vezes de dor severa (OR 2,26) no primeiro dia de pósparto. A probabilidade de ter dor intensa também apresentou aumento de duas vezes na presença de episiotomia, tanto no primeiro dia como na terceira semana (KARAÇAM et al., 2013). Quanto ao protocolo para realizar a episiotomia, entre primíparas com episiotomia restritiva, foi relatada maior frequência de dor perineal no pós-parto imediato do que naquelas com a episiotomia de rotina $(98,9 \%$ contra $87,8 \%$, RR 1,10$)$, entretanto, esta diferença não se manteve com 6 semanas ou 1 ano após o parto (MACLEOD et al., 2013).

Neste estudo, as variáveis que não apresentaram associação com a intensidade de dor perineal, mas, que foram investigadas em outros estudos, serão discutidas a seguir.

A média de idade materna das mulheres de nossa amostra foi de 24,5 anos. As mulheres entre 20 e 29 anos apresentaram maiores prevalências de dor em todas as intensidades, contudo, esta variável não esteve associada à intensidade de dor. A literatura mostra estudos com resultados controversos. No ensaio clínico anteriormente citado, a idade também não esteve associada à dor perineal $(p=0,800)$ (FODSTAD; LAINE; STAFF; 2013). Mas, na pesquisa com mulheres de diversas paridades, foi identificada maior média de idade materna associada estatisticamente à presença de dor (25,8 anos versus 23,9 anos) (FRANCISCO et al., 2011b). Por fim, Howard et al. (2000) encontraram correlação positiva entre o aumento de 1 ano da idade materna e a elevação de 6,0\% na propensão da mulher ter trauma perineal e, conforme demonstraram os estudos anteriormente citados (KARAÇAM et al., 2013; SAYINER et al., 2010; SHAHRAKI et al., 2011), a presença do trauma perineal está associada à dor.

Quanto à cor da pele, mais da metade da amostra foi constituiu-se de mulheres que se autodeclararam pardas e, apesar da dor moderada ter sido mais frequente entre as mulheres brancas $(24,4 \%)$ e a dor intensa entre as mulheres amarelas ou indígenas 
(7,1\%), a cor da pele não esteve associada à intensidade de dor, concordando com um estudo brasileiro em que não houve diferença estatisticamente significativa entre estas variáveis (FRANCISCO et al., 2011a).

Há estudos que apontam a associação da etnia / cor da pele com a presença de dor no períneo. Na pesquisa já citada de Leeman et al. (2009), mulheres brancas de etnia não hispânica estiveram associadas à dor no períneo na alta hospitalar. Da mesma forma, outros dois estudos apontaram associação entre maior dor e etnia asiática. Dahlen e Homer (2008) identificaram que, no primeiro dia após o parto, primíparas de origem asiática submetidas ao parto vaginal estiveram significativamente mais propensas à dor perineal de moderada à intensa, comparadas àquelas de origem não asiática ( $54,0 \%$ versus $41,0 \%)$, entretanto, não foi observada diferença no escore de dor entre os grupos no segundo dia pós-parto. No estudo de Williams, Herron-Marx e Knibb (2007), também as mulheres asiáticas tiveram significativamente maior ocorrência de dor no períneo do que as brancas, depois de 1 ano do parto $(62,1 \%$ vs $28,0 \%)$.

Convém comentar que, na maternidade deste estudo, há atendimento ao parto de mulheres asiáticas com a presença de tradutoras voluntárias. No entanto, as puérperas asiáticas atendidas no período de coleta de dados não falavam a língua portuguesa, assim, não compuseram a amostra.

Apesar da hipótese que maiores medidas (peso, PC e PT) do neonato provocassem maior distensão do assoalho pélvico e que poderiam culminar em dor no pós-parto, estas variáveis não estiveram associadas à queixa de dor perineal neste estudo, assim como no de Francisco et al (2011a). O peso do RN também não foi associado à dor perineal, tanto no primeiro quanto no segundo dia de pós-parto na coorte tailandesa conduzida por Watanatitan, Armarttasn e Manusirivithaya (2009), que buscou identificar os fatores associados à dor perineal em primíparas. 
As variáveis relativas à assistência obstétrica não apresentaram associação com a intensidade de dor no atual estudo. No entanto, permitiram- nos caracterizar a assistência oferecida no CPN. A finalidade foi verificar se os cuidados comumente oferecidos à parturiente estão associados à dor perineal no puerpério, uma vez que não há estudos com estes dados na literatura.

Quase metade das mulheres foi internada na fase latente do trabalho de parto, ou seja, foi admitida precocemente, tomando como base o modelo de evolução do trabalho de parto proposto por Friedman (1955). As evidências atuais indicam que o diagnóstico de fase ativa deve ser mais tardio, ao atingir $6 \mathrm{~cm}$ de dilatação cervical (ZHANG et al., 2010). Esta recomendação é reforçada pelo The American College of Obstetricians and Gynecologists (ACOG) em sua diretriz mais recente, pois possibilita a evolução fisiológica do trabalho de parto e reduz a necessidade de intervenções desnecessárias (ACOG, 2014).

Merece citar que a instituição deste estudo assiste parturientes de todas as regiões da cidade de São Paulo. Assim, mulheres que moram em bairros mais distantes, em geral, poderiam ser admitidas mais precocemente para o parto.

Neste estudo, mais da metade das mulheres relatou ter usado, pelo menos, um método não medicamentoso para alívio da dor no trabalho de parto, entre eles, massagem, banho de aspersão, deambulação, banqueta, bola e cavalinho. A frequência deste estudo foi quase três vezes maior do que o apontado no inquérito nacional brasileiro (LEAL et al., 2014).

Quanto ao alívio da dor no pós-parto, consta do protocolo desta maternidade a administração rotineira de analgésico e antiinflamatórios. A primeira dose destes medicamentos é administrada nas primeiras $2 \mathrm{~h}$ depois do parto, e a presença ou a intensidade de dor não e rotineiramente investigada pela equipe profissional no puerpério. Poucas mulheres usaram o anti-inflamatório em razão do acordo realizado com a instituição, que previa suspender este 
fármaco, pois ao mesmo tempo, um ensaio clínico estava sendo conduzido. Observou-se que as mulheres haviam consumido o analgésico, em média, 4h29 e anti-inflamatório, 4h59, antes da entrada neste estudo, o que corresponde ao período de ação dos fármacos (FONSECA; GUEDES; 2012). Tal fato poderia justificar a menor frequência de dor do que o encontrado na literatura.

Apesar da frequência menor de dor, constatou-se que cerca de um quarto das mulheres referiu dor intensa ( 7 a 10). Este dado indica que os medicamentos prescritos e administrados não foram adequados no alívio à dor perineal. Existem propostas de associação de terapias distintas até que se elimine a dor (LOESER, 2009). Há terapias de ação local para reduzir a dor que podem estar associadas ao medicamento via oral, como a crioterapia, e podem ser oferecidas às mulheres, por possuírem ação anti-inflamatória e serem eficazes em seu alívio (EAST et al., 2011).

Quanto à administração rotineira de medicamentos para alívio da dor, vem sendo discutida a recomendação referente à adoção da prevenção quaternária em todos os níveis de complexidade das instituições de saúde. A prevenção quaternária, assim denominada por Marc Jamoulle na década de 1980, consiste, entre outras coisas, na prevenção do "excessivo intervencionismo diagnóstico e terapêutico e medicalização desnecessária" (NORMAM; TESSER; 2009, p. 2013).

Esta recomendação poderia ser aplicada no CPN e, embora demandasse revisão dos protocolos institucionais evitaria que mulheres sem dor consumissem drogas desnecessariamente $e$ proporcionaria uma redução dos gastos. Além disso, a prescrição de qualquer medicamento para uma lactente deve ser cautelosa, uma vez que os fármacos ficam presentes no leite materno e nem todas as drogas são seguras para o RN. Estudos apontam maior alívio da dor perineal ao associar analgésico, anti-inflamatório e medidas não medicamentosas, além de permitir que a puérpera escolha quando e qual o método utilizar ou não empregar nenhuma opção de alívio da 
dor (SWAIN; DAHLEN; 2013; WATANATITAN; ARMARTTASN; MANUSIRIVITHAYA; 2009).

Como uma das limitações deste estudo, apontou-se a fonte secundária dos dados, ou seja, por se tratar de registros de prontuário médico, não foi possível assegurar a confiabilidade da classificação da condição perineal realizada pela profissional que assistiu o parto. Como afirma Leite (2012), existem dificuldades na classificação das lesões perineais em razão da falta de padronização detalhada ou mesmo de consenso dos profissionais quanto ao grau do trauma perante a grande variabilidade de tipos, formas, tamanhos e localizações das lacerações.

Outra limitação da fonte secundária de dados foi a ausência de informações referentes à assistência ao parto, uma vez que não havia registros do número de toques vaginais realizados no trabalho de parto, da duração do período expulsivo, das manobras de proteção do períneo e do tipo de desprendimento da apresentação fetal, da justificativa para realizar a episiotomia, do fio e da técnica empregados no reparo do trauma. Não foram localizadas, no Livro de Registro de Partos, anotações das mulheres que tiveram indução do parto e qual foi o método adotado. Em alguns prontuários, faltaram informações do parto, como o horário e a dilatação cervical na internação hospitalar.

Por fim, o desenho de estudo transversal, no qual as pesquisadoras coletaram os dados em um único contato com as puérperas, pode ser visto como um fator limitante para estabelecer inferência de causalidade, uma vez que a exposição e o desfecho são avaliados simultaneamente. 
CONCLUSÃO

Neste estudo, foi possível concluir que:

- A dor perineal esteve presente em $38,3 \%$ das puérperas; 
- A intensidade média foi de 4,6 pontos $(d p=1,9)$, classificada como moderada.

Foram fatores associados à intensidade de dor perineal:

- Ter estudado por 12 anos ou mais esteve associado à dor leve e moderada $(p=0,001)$;

- A primiparidade esteve associada à dor leve $(p=0,012)$;

- Puérperas com um trauma perineal tiveram mais dor moderada e aquelas com múltiplos traumas relataram mais dor intensa $(p<0,001)$;

- Mulheres com períneo íntegro tiveram menor frequência de dor perineal e aquelas com episiotomia relataram dor leve e intensa com maiores frequências $(p<0,001)$.

Houve associação entre a intensidade de dor perineal e o escore de interferência nas atividades das puérperas:

- As puérperas relataram interferência significativa em todas as intensidades de dor ao andar $(p<0,001)$ e ao sentar $(p<0,001)$, entre as intensidades leve e intensa ao dormir $(p=0,019)$ e ao cuidar do $R N(p=0,027)$ e da dor leve na amamentação $(p=0,001)$ e na micção $(p<0,001)$.

A análise de regressão logística ordinal mostrou que foi fator de proteção para o aumento em uma categoria da intensidade de dor perineal:

- $\quad$ Mulheres que estudaram até 8 anos tiveram proteção contra aumento em um escore de dor (OR 0,5; IC 95\% 0,3-0,9).

Foram fatores de risco para o aumento em uma categoria da intensidade de dor perineal:

- $\quad$ Presença de laceração de $2^{\circ}$ grau (OR 3,4; IC 95\% 1,7 - 6,9),

- Presença de episiotomia (OR 3,2; IC 95\% 2,0 - 5,0). 


\section{CONSIDERAÇÕES FINAIS}

Neste estudo, a ocorrência de dor perineal foi menor que a apontada na literatura científica, entretanto, quase todas as 
mulheres haviam consumido medicamentos para seu alívio, antes de entrar no estudo e estavam, portanto, sob efeito analgésico.

Por outro lado, a intensidade média de dor não foi menor do que a encontrada em outros estudos, o que poderia sugerir que 0 analgésico ingerido não foi eficaz na resolução da dor. Não foi objetivo deste estudo investigar os métodos de alívio da dor, e os achados sugerem a necessidade de estudos que apontem outras alternativas, além da farmacológica, para alívio da dor no períneo de mulheres que pariram em CPN.

Há uma lacuna entre os estudos no que diz respeito à associação entre intensidade de dor no períneo, a escolaridade materna, a assistência obstétrica e o escore de interferência da dor na realização de atividades pela mulher no puerpério. Ademais, a maior parte dos estudos que investigou a dor perineal não foi de base populacional e ainda existem fatores cuja associação com a intensidade de dor não está completamente esclarecida.

Entre os nossos achados, foi possível observar que, embora o CPN seja um local de menor intervenção na assistência ao parto, quase metade das mulheres foi internada precocemente e grande parte delas recebeu infusão endovenosa de ocitocina no trabalho de parto. Houve elevada ocorrência de traumatismo perineal, contudo, sem gravidade e praticamente todas as lesões foram suturadas. No pós-parto, a administração de analgésico foi de quase totalidade das mulheres e, mesmo assim, constatou-se dor perineal intensa.

Embora não tenha sido objetivo desta pesquisa, convém mencionar que não há protocolo que avalie a ocorrência e a intensidade de dor como parte dos cuidados de rotina no local do estudo. Conforme evidenciado, é possível reduzir a dor e a prescrição de medicamentos e melhorar a satisfação das mulheres ao adotar práticas que associem métodos não medicamentosos para alívio da dor.

A presença de trauma perineal é um fator associado à dor nesta região em todos os estudos. Desta forma, as mulheres se 
beneficiariam com menos dor no períneo quando fossem adotados, na assistência ao parto, os cuidados relativos à prevenção do trauma perineal, em especial, a prática reduzida da episiotomia.

Conforme indicado na Discussão, encontra-se muita divergência na estimativa do trauma perineal em razão da não existência de uma padronização detalhada, como a encontrada na diretriz inglesa que especifica os tecidos afetados em cada grau do trauma e a técnica de reparo da lesão. Os profissionais que estão devidamente treinados são mais propensos a fornecer um cuidado perineal de alto padrão (NICE, 2007). 
ALMEIDA, S. F. S.; RIESCO, M. L. G. Ensaio clínico controlado aleatório sobre duas técnicas de sutura do trauma perineal no parto 
normal. Revista Latino-Americana de Enfermagem, v. 16, n. 2, 2008.

AMERICAN COLLEGE OF OBSTETRICIANS AND GYNECOLOGISTS (ACOG). Safe prevention of the primary caesarean delivery. Obstetric Care Consensus $n^{\circ} 1$. Obstetrics and Gynecology, n. 123, p. 693-711, 2014.

ANDREWS, V. et al. Evaluation of postpartum perineal pain and dyspareunia-a prospective study. European Journal of Obstetrics, Gynecology, and Reproductive Biology, v. 137, n. 2, p. 152-6, 2008.

BELEZA, A. C. S. et al. Mensuração e caracterização da dor após episiotomia e sua relação com a limitação de atividades. Revista Brasileira de Enfermagem, v. 65, n. 2, p. 264-268, 2012.

BOLFARINE H, BUSSAB WO. Elementos de Amostragem. São Paulo: ABE - Projeto Fisher, 2005. p 61-90.

BRASIL. Ministério da Saúde. Departamento de Informática do Sus (DATASUS). Nascidos Vivos - Dados Preliminares - Brasil. Brasília, s.d. Disponível em: http://tabnet.datasus.gov.br/cgi/deftohtm.exe?sinasc/cnv/nvuf.def. Acesso em: 9 nov. 2012.

BRASIL. Ministério da Saúde. Gabinete do Ministro. Portaria GM/MS no 985, de 5 de agosto de 1999. Cria o Centro de Parto Normal-CPN, no âmbito do Sistema Único de Saúde, para o atendimento à mulher no período gravídico-puerperal. 1999.

Portaria GM/MS no 1.459, de 24 de junho de 2011. Institui, no âmbito do Sistema Único de Saúde - SUS - a Rede Cegonha. In: Brasília, 2011.p.109-111. Diário Oficial da União.

Portaria GM/MS no 904 de 29 de maio de 2013. Estabelece diretrizes para implantação e habilitação de Centro de Parto Normal (CPN), no âmbito do Sistema Único de Saúde (SUS), para o atendimento à mulher e ao recém-nascido no momento do parto e do nascimento, Brasília, 2013.

CARROLI, G.; MIGNINI, L. Episiotomy for vaginal birth. Cochrane Database of Systematic Reviews In: The Cochrane Library, Issue 2, Oxford: 2009. Update Software (1): CD000081. DOI: $10.1002 / 14651858$.

CHANG, S.-R. et al. Comparison of the effects of episiotomy and no episiotomy on pain, urinary incontinence, and sexual function 3 months postpartum: a prospective follow-up study. International Journal of Nursing Studies, v. 48, n. 4, p. 409-18, abr. 2011. 
COLACIOPPO, P. M. et al. Avaliação do viés de classificação da laceração perineal no parto normal. Acta Paulista de Enfermagem, v. 24, n. 1, p. 61-66, 2011.

DAHLEN, H.; HOMER, C. Perineal trauma and postpartum perineal morbidity in Asian and non-Asian primiparous women giving birth in Australia. Journal of Obstetric, Gynecologic, and Neonatal Nursing, v. 37, n. 4, p. 455-63, 2008.

DECLERCQ, E. et al. Major Survey Findings of Listening to Mothers(SM) III: New Mothers Speak Out. Report of National Surveys of Women's Childbearing Experiences. Nova lorque: Childbirth Connection, p. 17-24, 2014.

EAST, C. E. et al. Local cooling for relieving pain from perineal trauma sustained during childbirth. Cochrane Database of Systematic Reviews In: The Cochrane Library, v 2, n3, Oxford: 2011. Update Software (1): CD003604. DOI: 10.1002/14651858.

Perineal pain following childbirth: prevalence, effects on postnatal recovery and analgesia usage. Midwifery, v. 28, n. 1, p. 93-7, fev. 2012.

FAUCONNIER, A. et al. Measurement of acute pelvic pain intensity in gynecology: a comparison of five methods. Obstetrics and Gynecology, v. 113, n. 2, p. 260-9, fev. 2009.

FODSTAD, K.; LAINE, K.; STAFF, A. C. Different episiotomy techniques, postpartum perineal pain, and blood loss: an observational study. International Urogynecology Journal, v. 24, n. 5, p. 865-72, 2013.

FONSECA, A. L. DA; GUEDES, S. Dicionário de Especialidades Farmacêuticas: DEF 2011/2012. 40. ed. Rio de janeiro: Publicações Científicas, 2012. p. 826-829

FRANCISCO, A. A. et al. Women's experiences of perineal pain during the immediate postnatal period: a cross-sectional study in Brazil. Midwifery, v. 27, n. 6, p. e254-9, 2011a.

.Avaliação e tratamento da dor perineal no pósparto vaginal. Acta Paulista de Enfermagem, v. 24, n. 1, p. 94-100, $2011 b$.

v. 21, n. 3, p. $150-154,2012$.

Efecto del dolor perineal. Index de Enfermeria,

FRIEDMAN, E. Primigravid labor: a graphicostatistical analysis. Obstetrics and Gynecology, v. 6, n. 6, p. 567-589, 1955. 
FRITEL, X. et al. Pelvic floor disorders 4 years after first delivery: a comparative study of restrictive versus systematic episiotomy. British Journal of Obstetrics and Gynaecology, v. 115, n.2, p 247-252, 2008.

GREENE, M. E. et al. Education attainment is associated with patient-reported outcomes: findings from the Swedish Hip Arthroplasty Register. Clinical Orthopaedics and Related Research, v. 472, n. 6, p. 1868-76, 2014.

HOWARD, D. et al. Differences in perineal lacerations in black and white primiparas. Obstetrics and Gynecology, v. 96, n. 4, p. 622-4, 2000.

INSTITUTO BRASILEIRO DE GEOGRAFIA E ESTATÍSTICA (IBGE). Conceitos. Disponível em: http://www.ibge.gov.br/home/estatistica/populacao/condicaodevida/in dicadoresminimos/conceitos.shtm. Acesso em: 12 nov. 2012.

INTERNATIONAL ASSOCIATION FOR THE STUDY OF PAIN (IASP). Classification of Chronic Pain. p. 3-54, 2011.

KARAÇAM,Z; EKMEN, H; ÇALIZIR, H. The use of perineal massage in the second stage of labor and follow-up of postpartum perineal outcomes. Health Care for Women International, v. 33, n.8, p. 697718, 2012.

KARAÇAM, Z. et al. Prevalence of episiotomy in primiparas, related conditions, and effects of episiotomy on suture materials used, perineal pain, wound healing 3 weeks postpartum, in Turkey: A prospective follow-up study. Iranian Journal of Nursing and Midwifery Research, v. 18, n. 3, p. 237-245, 2013.

KETTLE, C.; DOWSWELL, T.; ISMAIL, K. M. Absorbable suture materials for primary repair of episiotomy and second degree tears. Cochrane Database of Systematic Reviews In: The Cochrane Library. Oxford: 2009. CD000947. DOI: 10.1002/14651858.CD000947.pub1.

Continuous and interrupted suturing techniques for repair of episiotomy or second-degree tears. Cochrane Database of Systematic Reviews In: The Cochrane Library, Issue 2, Oxford: 2012. Update Software. CD000947. DOI:10.1002/14651858

LAGO, T. D.; LIMA, L. Assistência à gestação, ao parto e ao puerpério: diferenciais regionais e desigualdades socioeconômicas. In: BRASIL. MINISTÉRIO DA SAÚDE; CENTRO BRASILEIRO DE ANÁLISE E PLANEJAMENTO. PNDS 2006: Pesquisa Nacional de Demografia e Saúde da Criança e da Mulher: Dimensões do 
processo reprodutivo e da saúde da criança. Série G. Estatística e Informaçao em Saúde. Brasília: 2009. p. 151 - 170.

LAINE, K. et al. Prevalence and risk factors for anal incontinence after obstetric anal sphincter rupture. Acta Obstetricia et Gynecologica Scandinavica, v. 90, n. 4, p. 319-24, 2011.

LEAL, M. DO C. et al. Intervenções obstétricas durante o trabalho de parto e parto em mulheres brasileiras de risco habitual. Cadernos de Saúde Pública, v. 30, p. S17-S32, 2014.

LEEMAN, L. et al. Postpartum perineal pain in a low episiotomy setting: association with severity of genital trauma, labor care, and birth variables. Birth, v. 36, n. 4, p. 283-8, 2009.

LEITE, J. S. Caracterização das lacerações perineais espontâneas no parto normal. 2012. Dissertação (Mestrado em Enfermagem) - Escola de Enfermagem, Universidade de São Paulo, São Paulo. p. 1-111

LOESER, J. D. Aspectos atuais do controle da dor. In: ROENN, J. H. VON; PAICE, J. A.; PREODOR, M. E. (Ed.). Current Medicina Diagnóstica e Tratamento da Dor. 3. ed. Rio de janeiro: Mc Graw Hill, 2009. p. 1-9.

MACARTHUR, A. J.; MACARTHUR, C. Incidence, severity, and determinants of perineal pain after vaginal delivery: a prospective cohort study. American Journal of Obstetrics and Gynecology, v. 191, n. 4, p. 1199-204, 2004.

MACLEOD, M. et al. Morbidity experienced by women before and after operative vaginal delivery: prospective cohort study nested within a two-centre randomised controlled trial of restrictive versus routine use of episiotomy. British Journal of Obstetrics and Gynaecology, v. 120, n. 8, p. 1020-1027, 2013.

MCCAFFERY, M.; BEEBE, A. Pain: Clinical manual for nursing practice. Mosby: 1989.

MELZACK, R.; KATZ, J. Pain. Wiley Interdisciplinary Reviews: Cognitive Science, v. 4, n. 1, p. 1-15, 2013.

METCALFE, A. et al. A pragmatic tool for the measurement of perineal tears. British Journal of Midwifery, v. 10, n. 7, p. 412-417, 2002.

NATIONAL COLLABORATING CENTRE FOR WOMEN'S AND CHILDREN'S HEALTH (NICE). Intrapartum Care. Care of health women and their babies during childbirth. Clinical Guideline. Londres: Royal College of Obstetricians and Gynaecologists, 2007. 
NORMAN, A. H.; TESSER, C. D. Prevenção quaternária na atenção primária à saúde: uma necessidade do Sistema único de Saúde. Caderno de Saúde Pública v.25, n.9, p. 2012-2020, 2009.

PITANGUI, A. C. R. et al. Mensuração e características da dor perineal em primíparas submetidas à episiotomia. Acta Paulista de Enfermagem, v. 22, n. 1, p. 77-82, 2009.

SAYINER, F. et al. The effect of postpartum perineal trauma on the frequencies perineal pain, urinary incontinence and dyspareunia. International Journal of Epidemiology, v. 8, n. 1, 2010.

SCHNECK, C. A. et al. Resultados maternos e neonatais em centro de parto normal peri-hospitalar e hospital. Revista de Saúde Pública, v. 46, n. 1, p. 77-86, 2012.

SHAHRAKI, A. D. et al. A comparison between early maternal and neonatal complications of restrictive episiotomy and routine episiotomy in primiparous vaginal delivery. Journal of Research in Medical Sciences, v. 16, n. 2, p. 1583-1589, 2011.

SOUZA E SILVA, N. L. et al. Dispareuia, dor perineal e cicatrizaçao após episiotomia. Revista de Enfermagem da UERJ, v. 21, n. 2, p. 216-220, 2013.

STEEN, M. "I can't sit down": easing genital tract trauma. British Journal of Midwifery, v. 13, n. 5, p. 311-314, 2005.

Care and consequences of perineal trauma. British Journal of Midwifery, v. 18, n. 11, p. 710-715, 2010.

STRONG, J. et al. Pain assessment and measurement. In: (Ed.) Pain: A Textbook for Therapists. Edinburgh: Churchill Livingstone, 2002. p. 123-147.

SWAIN, J.; DAHLEN, H. G. Putting evidence into practice: a quality activity of proactive pain relief for postpartum perineal pain. Women and Birth : Journal of the Australian College of Midwives, v. 26, n. 1 , p. $65-70,2013$.

TWADDLE, M.; COOKE, K. J. Avaliação da dor e síndromes dolorosas comuns. In: ROENN, J. H VON; PAICE, J. A.; PREODOR, M. E. (Ed). Current Medicina Diagnóstica e Tratamento da dor. 3. ed. Rio de janeiro: Mc Graw Hill, 2009. p. 10-20.

WATANATITAN, J.; ARMARTTASN, S.; MANUSIRIVITHAYA, S. Incidence and Factors Associated with Postpartum Perineal Pain in Primipara. Thai Journal of Obstetric and Gynaecology, v. 17, p. 139-144, 2009. 
WILLIAMS, A.; HERRON-MARX, S.; KNIBB, R.. The prevalence of enduring postnatal perineal morbidity and its relationship to type of birht and birth risk factors. Journal of Clinical Nursing, v. 16, 549561, 2007.

YENIEL, A O.; PETRI, E. Pregnancy, childbirth, and sexual function: perceptions and facts. International Urogynecology Journal, v. 25, n. 1, p. 5-14, 2014.

ZHANG, J. et al. Contemporary patterns of spontaneous labor with normal neonatal outcomes. Obstetrics and Gynecology, v. 116, n. 6, p. 1281-1287, 2010. 
Prezada Senhora,

Meu nome é Renata Luana da Silva, sou estudante de pósgraduação da Escola de Enfermagem da USP, sob orientação da $\operatorname{Prof}^{\mathrm{a}} \operatorname{Dr}^{\mathrm{a}}$ Sonia Maria Junqueira Vasconcellos de Oliveira e estou pesquisando sobre a dor no períneo após o parto normal. O objetivo desta pesquisa é identificar se a dor na região de onde sai o bebê está associada à assistência recebida durante o parto e com o peso do bebê.

Nesta pesquisa, as mulheres que tiveram o parto normal nas últimas 24 horas serão questionadas sobre a ocorrência de dor na região de onde saiu o bebê e terão os prontuários consultados para identificar informações sobre o parto.

Os resultados deste estudo serão apresentados em eventos científicos e encaminhados para publicação em revistas científicas da área e, em nenhum momento seu nome aparecerá como colaboradora ou participante da pesquisa.

Como participante do estudo você tem garantido o direito de receber orientações sobre as dúvidas que tiver em relação à pesquisa e a liberdade de deixar de participar da pesquisa em qualquer momento, sem que isso prejudique a assistência recebida neste hospital ou em outras instituições de saúde.

Em caso de dúvidas, meu telefone para contato é 3061-7603 ou 3061-7602. O contato do Comitê de Ética em Pesquisa da EEUSP é edipesq@usp.br.

$\mathrm{Eu}$,

RG número , abaixo-assinada, recebi

e entendi as informações acima e concordo em participar voluntariamente da pesquisa.

Este documento tem duas vias, uma ficará em seu poder e outra com a pesquisadora, garantindo as condições referidas.

São Paulo, de de 


\section{APÊNDICE B}

INSTRUMENTO DE COLETA

$\mathrm{N}^{\circ}$ Identificação:

Iniciais

Data

Você está com dor na região do períneo agora?

Hora:
Grupo: $\square$ primípara (p) $\square$ multípara(m)

Como você classificaria sua dor? $\quad \begin{gathered}0,1-2-3 \\ \text { sem dor }\end{gathered}-4-5-6-7-8-9-10$
$\mathrm{RH}$

$\square$ não (0)
Leito

$\square \operatorname{sim}(1)$

\begin{tabular}{|c|c|c|}
\hline Atividade & Interferência da dor & Escore de interferência \\
\hline Sentar & $\square$ não (0) $\square$ sim (1) $\square$ não fiz (88) & 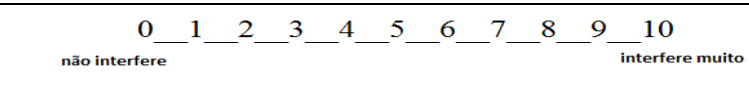 \\
\hline Andar & $\square$ não (0) $\square \operatorname{sim}(1) \square$ não fiz (88) & 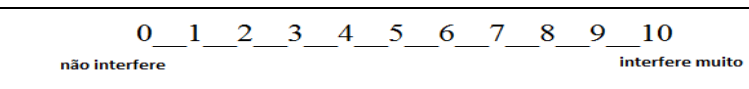 \\
\hline Urinar & $\square$ não (0) $\square \operatorname{sim}(1) \square$ não fiz (88) & $\underset{\text { não interfere }}{0}-^{1}-^{2}-{ }^{3}-{ }^{4}-5-6-^{7}-8-9{ }^{9} \underbrace{10}_{\text {Interfere muito }}$ \\
\hline Evacuar & $\square$ não (0) $\square$ sim (1) $\square$ não fiz (88) & 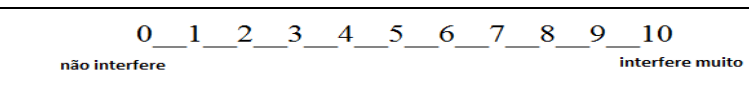 \\
\hline Dormir & $\square$ não (0) $\square \operatorname{sim}(1) \square$ não fiz (88) & $\underset{\text { näo interfere }}{0-1}-^{2}-{ }^{3}-4-5-6-^{7}-8-9{ }^{9}{ }_{\text {interfere muito }}^{10}$ \\
\hline Amamentar & $\square$ não (0) $\square$ sim (1) $\square$ não fiz (88) & 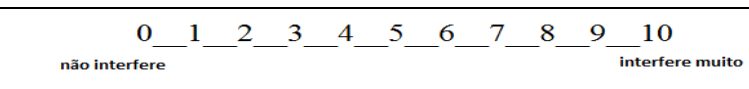 \\
\hline $\begin{array}{l}\text { Cuidar do } \\
\text { bebê }\end{array}$ & $\square$ não (0) $\square$ sim (1) $\square$ não fiz (88) & 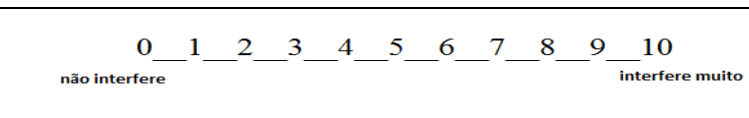 \\
\hline
\end{tabular}

\section{A) ENTREVISTA}

Cor da pele:

$$
\begin{aligned}
& \square \text { branca (1) } \\
& \square \text { preta (2) } \\
& \square \text { parda (3) }
\end{aligned}
$$

Escolaridade: anos de estudos concluídos

Trabalho remunerado

$$
\square \text { não (0) }
$$

Estado marital

$$
\begin{aligned}
& \square \text { com companheiro com coabitação (1) } \\
& \square \text { com companheiro sem coabitação (2) } \\
& \square \text { sem companheiro (3) }
\end{aligned}
$$

Acompanhante no parto atual? $\square$ não (0)

$\square \operatorname{sim}(1):$

Você usou método não farmacológico para alívio da dor no trabalho de parto? $\square$ não (0)

Usou bolsa de gelo no períneo após o parto?
$\square$ massagem
$\square$ bola de Bobath
$\square$ banqueta de parto
$\square$ banho de chuveiro
$\square$ cavalinho
$\square$ deambulação

$\square \operatorname{sim}(1)$

$\square$ não (0)Motivo:

Horário:

Apenas para multípara:

Você teve trauma perineal no parto anterior?

$\square$ sim, não sei qual trauma (1)

$\square$ EMLD + sutura (4)

$\square$ não (0)

$\square$ lacer sem sutura (2)

$\square$ apenas sutura (5)

$\square$ lacer + sutura (3)

$\square$ outra (6): 


\section{B) DADOS DO PRONTUÁRIO}

Dados Obstétricos:

Paridade: G $\mathrm{PN}$ PF A (inclui parto atual)

Tipo de parto anterior $\square$ primípara (88) $\square$ normal (1)

$\square$ fórceps (2) cesariana (3)

Parto atual Data: Hora:

Tempo de pós-parto:

Colo uterino no momento da internação: $\quad$ Dimpérvio (0) पpérvio para: $\mathrm{cm}$

Uso de ocitocina no trabalho de parto $\square$ não (0) $\square \operatorname{sim}(1)$ Início: cm Tempo de uso: horas

Dose: /SG 5\%

Volume total: $\mathrm{mL}$

№ de trauma perineal

$\square$ não (0) $\quad \square$ único (1)

$\square$ múltiplos (2)

Condição perineal:

$\square$ laceração $1^{\circ}$ grau (1)

$\square$ laceração $2^{\circ}$ grau (2)

$\square$ laceração 3ำ grau (3)

$\square$ laceração 4ำ grau (4)

$\square$ EMLD (5)

$\square$ perineotomia (6)

$\square$ lacer $1^{\circ}$ grau+ perineotomia (7)

$\square$ laceração $1^{\circ}$ grau+EMLD (8)

$\square$ laceração $1^{\circ}+2^{\circ}$ grau (9)

$\square$ laceração $3^{\circ}$ grau+ EMLD (10)

$\square$ lacer $3^{\circ}$ grau+ perineotomia (11)

$\square$ laceração $4^{\circ}$ grau+ EMLD

$\square$ lacer 4음 grau+ perineotomia (13)

$\square$ outra (14):

Sutura:

$\square$ não (0) $\quad \square \operatorname{sim}(1)$

Fez uso de analgésico após o parto?

$\square$ não (0)

$\square \operatorname{sim}(1)$ Horário da última dose:

Fez uso de anti-infamatório após o

$\square$ não (0)

parto?

$\square \operatorname{sim}(1)$ Horário da última dose:

Dados do Recém-Nascido:

Peso do recém-nascido g

Perímetro cefálico $\mathrm{cm}$ $\mathrm{cm}$ 


\title{
ANEXO 1
}

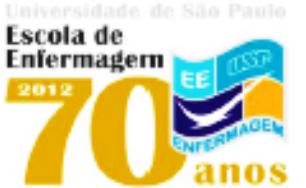

\author{
UNIVERSIDADE DE SÄO PAULO \\ ESCOLA DE ENFERMAGEM \\ Av. Dr. Enéas de Carvalho Aguiar, 419 - CEP 05403-000 \\ Tel: (11) 3061-7548/8858 - Fax: (11) 3061-7548 \\ Săo Paulo - SP - Brasil \\ E-mail: edipesq@usp.br
}

São Paulo, 12 de abril de 2012

$\mathrm{Ilm} .{ }^{\mathrm{a}} \mathrm{Sr} .{ }^{\mathrm{a}}$

Sonia Maria Junqueira Vasconcellos de Oliveira

Ref.: Processo nº 1119/2012/CEP-EEUSP - SISNEP CAAE: 0147.0.196.000-11

Prezada Senhora,

Em atenção à solicitação referente à análise do projeto "Tempo de duraçào do efeito analgésico da crioterapia na dor perineal no pós-parto: ensaio clinico", informamos que o mesmo foi considerado aprovado pelo Comitê de Ética em Pesquisa da Escola de Enfermagem da Universidade de São Paulo (CEP/EEUSP).

Analisado sob o aspecto ético-legal, atende às exigências da Resolução $\mathrm{n}^{\circ}$ 196/96 do Conselho Nacional de Saúde.

Esclarecemos que após o término da pesquisa, os resultados obtidos deverão ser encaminhados ao CEP/EEUSP, para serem anexados ao processo.

Atenciosamente,

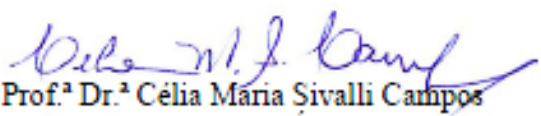

Prof. ${ }^{2} \mathrm{Dr}^{2}$ Célia Maria Sivalli Canpos

Escola de Enfermagem da Universidade de São Paulo 


\section{ANEXO 2}

\section{TERMO DE AUTORIZAÇÃO PARA PESQUISA}

IImo Senhor Eder de Souza Viana

DD. Coordenador Científico do Amparo Maternal - São Paulo

Prezado Senhor,

Eu, Renata Luana da Silva, aluna do Programa de Pós-Graduação em Enfermagem da Escola de Enfermagem da Universidade de São Paulo, venho por meio desta solicitar a autorização para a coleta de dados da pesquisa entitulada "Prevalência e fatores associados a intensidade da dor perineal após o parto normal".

Trata-se de um projeto de mestrado, realizado sob orientação da Profa $\mathrm{Dr}^{\mathrm{a}}$. Sonia M. J. V. de Oliveira, que tem como objetivo geral identificar a prevalência e a intensidade da dor perineal no primeiro dia de pós-parto normal.

Os dados serão coletados mediante autorização das mulheres que atenderem aos critérios de inclusão na pesquisa e concordarem em participar após a leitura e assinatura do Termo de Consentimento Livre e Esclarecido.

Informo que o projeto deste estudo foi aprovado pelo Comitê de Ética da Escola de Enfermagem da Universidade de São Paulo (Processo $n^{\circ}$ 1119/2012/CEP-EEUSP) e que os resultados obtidos serão apresentados em eventos científicos e enviados para publicação em periódicos da área.

Agradeço sua colaboração e coloco-me à disposição para os esclarecimentos que se fizerem necessários. Meu telefone para contato é: (11) 961532356

São Paulo, 10 de janeiro de 2013.

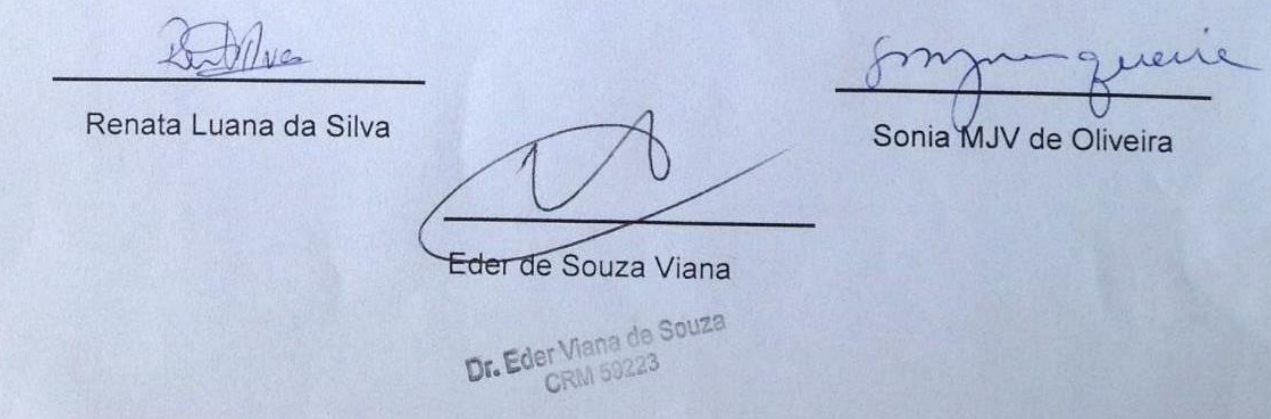

